University of Rhode Island

DigitalCommons@URI

Open Access Master's Theses

1999

\title{
Elucidation of Hot Melt Wax Coating Systems
}

Anand S. Achanta

University of Rhode Island

Follow this and additional works at: https://digitalcommons.uri.edu/theses

\section{Recommended Citation}

Achanta, Anand S., "Elucidation of Hot Melt Wax Coating Systems" (1999). Open Access Master's Theses. Paper 816.

https://digitalcommons.uri.edu/theses/816

This Thesis is brought to you for free and open access by DigitalCommons@URI. It has been accepted for inclusion in Open Access Master's Theses by an authorized administrator of DigitalCommons@URI. For more information, please contact digitalcommons-group@uri.edu. 
ELUCIDATION OF HOT MELT WAX COATING SYSTEMS

BY

ANAND S. ACHANTA

A THESIS SUBMITTED IN PARTIAL FULFILLMENT OF THE REQUIREMENTS FOR DEGREE OF MASTER OF SCIENCE IN

PHARMACEUTICAL SCIENCES

UNIVERSITY OF RHODE ISLAND 


\section{MASTER OF SCIENCE THESIS}

OF

ANAND S. ACHANTA.

Approved:

Thesis Committee

Major Professor

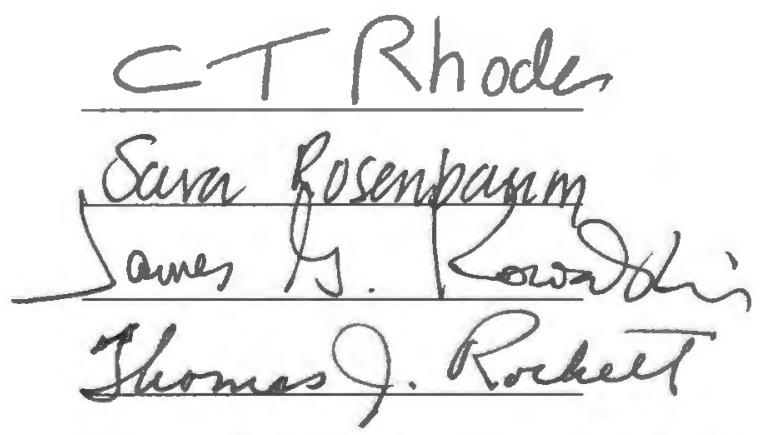

DEAN OF THE GRADUATE SCHOOL

UNIVERSITY OF RHODE ISLAND 


\section{ABSTRACT}

Hot melt coating methods are an interesting alternative to commonly used aqueous polymeric film coating methods. A critical evaluation of development of hot melt coating methods for sustained drug release and protection of moisture labile active ingredient applications has been performed. A detailed examination of the interaction of water with excipient films of pharmaceutical significance is reported. As water is an important detrimental variable in performance of pharmaceutical dosage forms, the description of a convenient method to characterize the interaction of water with excipient films is very useful. The widespread use of coated pharmaceutical products for a variety of applications accentuates the need to obtain a fundamental understanding of waterexcipient film systems during development.

A simple and rapid method employing the powerful new technique of dynamic vapor sorption was developed to understand the interaction of water with two excipient films (glyceryl behenate/lipidic and a formulation of polyvinyl alcohol/polymeric) of pharmaceutical significance. This method allows estimation of adsorption $\left(k_{1}\right)$ and desorption $\left(\mathrm{k}_{2}\right)$ microrate constants. It was found that $\mathrm{k}_{1}$ varied exponentially with water activity for the polymeric film showing predictive utility of such a relationship. The dramatic influence that film thickness and temperature may have on water sorption of films has been demonstrated. Results from application of theoretical models and thermodynamic analysis were not always consistent. Established models are useful for quantitative analysis, whereas thermodynamic analysis allows qualitative insights into water-excipient film interaction. 
Young \& Nelson model was successful in accurately modeling the hysteresis phenomena but did not offer any information on the mechanistic details. Computation of isoteric heats of adsorption confirmed hydrogen bonding as the reason for hysteresis and allowed determination of number of hydrogen bonds per water molecule. Comparison of weighted relative partial molal free energies of excipient film and water showed that assumption of adsorbent to be an inert participant in the sorption process as being incorrect for both excipients at all temperatures. In conclusion, (a) hot melt coating methods are an interesting alternative to aqueous coating techniques (b) dynamic vapor sorption is very useful in investigation of water-excipient film interactions, and (c) it is necessary to apply both theoretical models and thermodynamic concepts for complete characterization of water interaction with excipient films. 


\section{ACKNOWLEDGEMENTS}

I would like to thank my major professor Dr. Christopher Rhodes for his support and guidance during my association with him. I am grateful to Dr. Sara Rosenbaum and Dr. James Kowalski for serving on my thesis committee. I thank Dr. Raymond Panzica for acting as the chairman of the thesis examining committee.

I am grateful to Mr. Kenneth W. James, Head of Product DevelopmentWorldwide, Dr. Prasad S. Adusumilli, Associate Director and Mr. Stanley J. Lech, Associate Director at SmithKline Beecham Consumer Healthcare, Parsippany, NJ. Their generous financial support, access to laboratory, library and computing facilities of SmithKline Beecham are most gratefully appreciated. It would have been very difficult to complete this work without their support.

It is not possible to list here all my friends to whom I am very grateful. I thank Swami Iyer, Bina \& Bali Gangadharan, Ganesh Deshpande, Brendan Walsh, Phil Oths and Sandip Shah who have been very helpful to me in numerous ways. Finally, I want to thank my parents, family members and my wife for their support and love. 
This document has been prepared in the format of the manuscript plan in accordance to section 11-3 of the Graduate Manual at the University of Rhode Island. This thesis has been divided into three sections.

Section I contains the statement of the problem and a brief introduction to the objectives of this research. Section II forms the central part of this thesis and is composed of three manuscripts written in the format prescribed by the scientific journal to which they have been or will be submitted for publication. Section III contains appendices that include the list of publications and experimental details useful for clearer understanding of the results described in the preceding manuscripts. A general summary of conclusions and bibliography for the entire thesis follows this section. 
\begin{tabular}{lr} 
ABSTRACT & ii \\
ACKNOWLEDGEMENTS & iv \\
PREFACE & $\mathrm{v}$ \\
LIST OF TABLES & vii \\
LIST OF FIGURES & vii \\
SECTION I & 1 \\
\multicolumn{1}{c}{ INTRODUCTION } & 2 \\
OBJECTIVES & 5
\end{tabular}

$\begin{array}{ll}\text { SECTION II } & 6\end{array}$

$\begin{array}{ll}\text { MANUSCRIPT I } & 7\end{array}$

$\begin{array}{ll}\text { MANUSCRIPT II } & 31\end{array}$

$\begin{array}{ll}\text { MANUSCRIPT III } & 60\end{array}$

$\begin{array}{lr}\text { SECTION III } & 90\end{array}$

$\begin{array}{ll}\text { APPENDIX A } & 91\end{array}$

$\begin{array}{ll}\text { APPENDIX B } & 92\end{array}$

$\begin{array}{ll}\text { APPENDIX C } & 94\end{array}$

$\begin{array}{lr}\text { SUMMARY OF CONCLUSIONS } & 98\end{array}$

$\begin{array}{ll}\text { BIBLIOGRAPHY } & 101\end{array}$ 


\section{LIST OF TABLES}

\section{MANUSCRIPT I}

Table 1. Suitable commercial lipidic excipients for hot melt coating (pp. 28)

\section{MANUSCRIPT II}

Table 1. Estimates of microrate constants for sorption $\left(\mathrm{k}_{1}\right)$ and desorption $\left(\mathrm{k}_{2}\right)$ processes assuming Langmuir behavior for glyceryl behenate film at $\mathrm{T}=293,303$ and $313 \mathrm{~K}$ (pp. 48)

Table 2. Estimates of microrate constants for sorption $\left(\mathrm{k}_{1}\right)$ and desorption $\left(\mathrm{k}_{2}\right)$ processes assuming Langmuir behavior for polyvinyl alcohol film at $\mathrm{T}=293,303$ and $313 \mathrm{~K}$ (pp. 49)

Table 3. Results of BET and GAB model fits for glyceryl behenate and polyvinyl alcohol films at varying temperatures. (th) indicates films of greater thickness and BET results are valid for $0.17 \leq \mathrm{a}_{\mathrm{w}} \leq 0.51$ (pp. 50)

Table 4. Estimates of Young and Nelson model parameters A, B and E used to describe hysteresis in sorption data at various temperatures for glyceryl behenate and polyvinyl alcohol films (pp. 51)

\section{MANUSCRIPT III}

Table 1. An illustrative example of smoothed adsorption data shown for water-GB thin film system at $\mathrm{T}=293 \mathrm{~K}$ (pp. 74) 


\section{LIST OF FIGURES}

\section{MANUSCRIPT I}

Figure 1. Formation of a triglyceride where $R_{1}, R_{2}$ and $R_{3}$ denote any alkyl group (pp. 29)

Figure 2. Modifications to a conventional fluid bed coater to suit hot melt coating and cross section of insulated spray nozzle wand (pp. 30)

\section{MANUSCRIPT II}

Figure 1. Schematic representation of the dynamic vapor sorption technique apparatus (pp. 51)

Figure 2. Sorption isotherms for glyceryl behenate film at various temperatures. Values of equilibrium moisture content (V) are mean of $n=3$ (pp. 52)

Figure 3. Sorption isotherms for polyvinyl alcohol film at various temperatures. Values of equilibrium moisture content (V) are mean of $n=3$ (pp. 53)

Figure 4. Arrhenius plots of mean equilibrium moisture content $(\mathrm{V}$ and $\mathrm{n}=3)$ at constant water activity for glyceryl behenate film (solid lines are best fit lines) (pp. 54)

Figure 5. Variation in energy of sorption $\left(E_{\text {sorp }}\right)$ for glyceryl behenate and polyvinyl alcohol films (solid lines are best fit lines) (pp. 55)

Figure 6. Fit of sorption data using GAB model for polyvinyl alcohol film at $\mathrm{T}=293 \mathrm{~K}$, • indicates actual data and - represents the fitted data obtained by nonlinear regression. $1 / \mathrm{V}$ is the reciprocal of mean equilibrium moisture content $(\mathrm{n}=3)$. ( $\mathrm{pp} .56)$

Figure 7. Comparative sorption isotherms of actual and predicted data obtained using Young and Nelson model for polyvinyl alcohol film at $\mathrm{T}=303 \mathrm{~K}$. V is mean equilibrium moisture content ( $\mathrm{n}=3)$. (pp. 57)

Figure 8. Comparative sorption isotherms for glyceryl behenate films of varying thickness at $\mathrm{T}=303 \mathrm{~K}$. V is mean equilibrium moisture content $(n=3)$. (pp. 58)

Figure 9. Comparative sorption isotherms for polyvinyl alcohol films of varying thickness at $T=303 \mathrm{~K}$. V is mean equilibrium moisture content $(n=3)$. (pp. 59)

\section{MANUSCRIPT III}

Figure 1. Sorption isotherms for glyceryl behenate thin film at various temperatures. Values of equilibrium moisture are mean of $n=3$ (pp. 75) 
Figure 2. Sorption isotherms for polyvinyl alcohol thin film at various temperatures. Values of equilibrium moisture are mean of $n=3$ (pp. 76)

Figure 3. Relative partial molal free energy of adsorbed water on GB thin film at various temperatures (pp. 77)

Figure 4. Relative partial molal free energy of adsorbed water on PVA thin film at various temperatures (pp. 78)

Figure 5. Integral free energy of adsorption $(\Delta \mathrm{G})$ and weighted relative partial molal free energies of excipient film $\left(n_{1} \Delta G_{1}\right)$ and water $\left(n_{2} \Delta G_{2}\right)$ for water-GB thin film system at $\mathrm{T}=303 \mathrm{~K}$ (pp. 79)

Figure 6. Integral free energy of adsorption $(\Delta \mathrm{G})$ and weighted relative partial molal free energies of excipient film $\left(n_{1} \Delta G_{1}\right)$ and water $\left(n_{2} \Delta G_{2}\right)$ for water-PVA thin film system at $\mathrm{T}=303 \mathrm{~K}$ (pp. 80)

Figure 7. Relative partial molal free energy of hysteresis for adsorbed water on GB thin film at various temperatures (pp. 81)

Figure 8. Relative partial molal free energy of hysteresis for adsorbed water on PVA thin film at various temperatures (pp. 82)

Figure 9. Relative partial molal enthalpy of adsorbed water on GB thin film at various temperatures (pp. 83)

Figure 10. Relative partial molal enthalpy of adsorbed water on PVA thin film at various temperatures (pp. 84)

Figure 11. Integral enthalpy of adsorption $(\Delta \mathrm{H})$ and weighted relative partial molal enthalpies of excipient film $\left(\mathrm{n}_{1} \Delta \mathrm{H}_{1}\right)$ and water $\left(\mathrm{n}_{2} \Delta \mathrm{H}_{2}\right)$ for water-GB thin film system at $\mathrm{T}=303 \mathrm{~K}$ (pp. 85)

Figure 12. Integral enthalpy of adsorption $(\Delta \mathrm{H})$ and weighted relative partial molal enthalpies of excipient film $\left(\mathrm{n}_{1} \Delta \mathrm{H}_{1}\right)$ and water $\left(\mathrm{n}_{2} \Delta \mathrm{H}_{2}\right)$ for water-PVA thin film system at $\mathrm{T}=303 \mathrm{~K}($ pp. 86)

Figure 13. Relative partial molal entropy of adsorbed water on GB thin film at various temperatures (pp. 87)

Figure 14. Relative partial molal entropy of adsorbed water on PVA thin film at various temperatures (pp. 88)

Figure 15. Variation of sorption microrate constants $\left(\mathrm{k}_{1}\right)$ with water activity for waterPVA thin film system at different temperature (solid lines are best fit lines) (pp. 89) 
SECTION I 


\section{INTRODUCTION}

A vast majority of pharmaceutical coating occurs using an application medium that must be evaporated. Available materials are applied as solutions or dispersions and typically contain only $30 \%$ solids or less (1). An alternative is to select a coating material that can be applied in molten state leading to considerably short processing times. Additionally, many common goals (such as sustained release, improved stability and taste masking) of pharmaceutical coating may be achieved by the selection of appropriate coating excipients with low melting points $(2,3)$. Hot melt coating technology does not require the use of a solvent (aqueous or organic) deeming it a unique solvent-free and environment friendly technology. The potential for application of hot melt coating in pharmaceutical formulation is enormous. The applications of hot melt coating may be broadly categorized as: a) improvement of palatability of dosage forms b) prevention of environmental degradation of dosage forms and, c) retardation of drug release from dosage forms. Prevention of environmental degradation comprises protection from physical degradation (light, humidity), protection from drug incompatibilities and protection from physiological degradation (enzymatic breakdown in stomach, $\mathrm{pH}$ sensitivity). The tedious and expensive routine of compliance with regulatory directives is completely eliminated. One irresolvable difficulty encountered with aqueous polymeric coatings is the validation of coating dispersions for absence of microbial presence. In fact, it is impossible to completely control microbial presence without any compromise. Hot melt coating methods do not suffer from any such shortcomings. However, development of hot melt coating methods also presents the following challenges: 
1. Investigation of the batch variability of lipidic coating excipients and development of methods for evaluation of raw material.

2. Physicochemical characterization of coating excipients and evaluation of their functionality.

3. Investigation of thermal behavior of lipidic coating excipient and its interaction with the drug in the formulation.

4. Characterization of coating equipment for hot melt coating.

5. Investigation of drug release characteristics from the coated substrates.

Hot melt coating offers a simple, quick, inexpensive and efficient alternative to common aqueous polymeric coating techniques. Hence, it is necessary to perform a detailed evaluation of the process of developing hot melt coating methods.

Apart from achieving sustained drug release, hot melt coating can also be used to form moisture protective coatings for labile active ingredients. It has been well documented that moisture in pharmaceutical dosage forms (either from formulation excipients or active ingredients) can seriously affect their properties and performance. But, often a fundamental characterization of the underlying water-solid interaction is either nebulous or unavailable. A complete characterization of the amount and state of moisture present in a pharmaceutical excipient is of great importance (4). This importance only increases when the excipient function is to form a film that acts as a barrier to moisture ingress. In this context, the following questions are of keen interest: (a) How much water is present and what is the corresponding water activity (b) What are the kinetics of moisture uptake/loss, and is the rate constant, and (c) Where is the water located in the material. It is the objective of this thesis to develop an experimental 
methodology and evaluate data analysis techniques to answer the above questions for films of pharmaceutical excipients that can form moisture protective coatings. It is interesting to note that despite the extensive use of film coatings in pharmaceuticals, a detailed examination of the interaction of water with excipient films has not been reported.

\section{REFERENCES}

1. M. R. Harris and I. Ghebre-Sellassie, in Aqueous Polymeric Coatings for Pharmaceutical Dosage Forms (J. W. McGinity, ed.), Marcel Dekker, New York, 1997, pp. 81-100.

2. D. M. Jones and P. J. Percel, in Multiparticulate Oral Drug Delivery (I. GhebreSellassie, ed.), Marcel Dekker, New York, 1994, pp. 113-142.

3. A. S. Achanta, P. S. Adusumilli, K.W. James and C. T. Rhodes, Drug Dev. \& Ind. Pharm., 23(5), 441-449 (1997).

4. M. J. Kontny and G. Zografi, in Physical Characterization of Pharmaceutical Solids (H. G. Brittain, ed.), Marcel Dekker, New York, 1995, pp. 387-418. 


\section{OBJECTIVES}

The salient objectives of this study have been listed below:

1) Perform a systematic evaluation of development of hot melt coating methods for sustained drug release and protection of moisture labile active ingredient applications.

2) Develop a method to construct sorption/desorption isotherms for excipient films using dynamic vapor sorption technique (DVST). This includes optimization of sample preparation and handling, sample size, defining threshold value for reaching equilibrium and exposure time at each water activity condition.

3) Complete analysis of isotherms using Langmuir, BET and GAB models. Evaluate hysteresis and distribution of moisture using Young and Nelson model.

4) Study influence of temperature and film thickness on sorption/desorption behavior of excipient films. Estimate microrate constants for sorption and desorption and examine their variation with temperature.

5) Generate smoothed adsorption data from isotherms and use the data for completion of thermodynamic analysis of water-excipient film systems. Perform a comparative evaluation of the results obtained from application of established models and thermodynamic analysis. 
SECTION II 
MANUSCRIPT I

Development of Hot Melt Coating Methods 


\section{mintion of pharmaceutical coating technology}

Modern pharmaceutical coating as practiced today, is a mature and routine pharmaceutical unit operation which facilitates efficient modification of biopharmaceutical properties, organoleptic properties and/or stability of various dosage forms. The evolutionary course of coating technology to its current status in pharmaceuticals spans over this century and deserves mention at the outset of this review.

Van Savage and Rhodes recently published an excellent historical review of developments in sustained release coating technology of tablets (1). Similar reviews offering comprehensive description of tablet coating have also been published by Seitz et. al. and Porter $(2,3)$.

The origins of modern pharmaceutical coating can probably be traced back to the confectionery kitchens of early nineteenth century (4). Pharmacists of that period adopted the "art" of pan coating from confectioners and used it primarily to increase the palatability of bitter medicaments. Also, coating was done as part of extemporaneous compounding in small batches and no specialized equipment was available. By the end of first half of this century, the art of sugar coating had been perfected and became the standard of that period. Yet, there were only few developments of great significance in coating technology during that period.

The introduction of film coating in 1953 probably marks the onset of "the era of contemporary pharmaceutical coating". This introduction along with innovations in the area of polymeric coatings and development of precise and efficient coating equipment facilitated the rapid transformation of coating technology from a skilled art into a science-based versatile unit operation in pharmaceutical formulation. The inception of 
perforated pans and fluid bed coaters are arguably, the most significant milestones in the design of newer coating equipment and allow for precise, efficient and elegant coating of a variety of dosage forms irrespective of batch size. Alternatively, many different polymers have also been evaluated in the past four decades, but the three most popular categories, which remain even to this day are: cellulose acetate, ethylcellulose and methacrylic acid copolymer.

Apart from the quest for superior performance, an important determinant in the evolution of contemporary coating technology has been the dynamic regulatory environment in the pharmaceutical community. Compliance requirements with regulatory agencies such as FDA, EPA and OSHA have strongly influenced progress in this area. The clear shift to aqueous polymeric coatings in recent years can be substantially attributed to regulatory compliance, amongst other factors.

But even aqueous polymeric coating methods suffer from some shortcomings and certainly, are not the "end". In the present environment of global competition and cost containment in the pharmaceutical industry, it is necessary to develop novel coating processes which are simple, efficient, precise, cost effective and allow easy compliance with regulatory requirements. Under such demanding circumstances, the promise of hot melt coating methods is attractive and their development forms the central theme of this article.

\section{0. melt coating methods}

\subsection{Introduction}


Traditionally, almost all coating methods require the use of solvents in which the coating material is either dissolved or dispersed. Initially, organic solvents were in vogue, but, stringent regulatory constraints have been responsible in changing the preference to aqueous based coating systems. In hot melt coating methods, the coating material is applied in its molten state over the substrate. Hence, the necessity for the use of any solvent is fully eliminated. Lipids, waxes and fatty bases are the most suitable coating materials in hot melt coating and will be discussed later. This strategy of applying coating material in molten form offers several benefits and potential for a wide variety of applications in pharmaceutical formulation.

\section{Advantages and disadvantages}

Hot melt coating methods offer many advantages over current and conventional coating techniques. Firstly, hot melt methods do not require the use of a solvent (aqueous or organic) deeming it as a unique solvent-free coating technique. As there is no solvent to be evaporated, the processing times are much shorter than the same for current practices. Consequently, the tedious and expensive processes of solvent disposal/treatment associated with organic solvents are eliminated. Also, the routine of compliance with regulatory directives for the use of organic solvents is fully precluded making hot melt coating environment-friendly.

Although, aqueous based coating systems are currently in vogue, they are not completely flawless. The irresolvable difficulty encountered with aqueous coating systems is the validation of coating dispersions for control of microbial presence. In fact, it is almost impossible to control microbial presence or growth in coating dispersions without any compromise. Hot melt coating methods do not suffer from any such 
shortcomings. Further, the required weight gains with lipid materials are lesser than those commonly employed with polymers to achieve the same effect. Existing coating equipment such as a fluid bed coater can be easily modified to suit the requirements of hot melt coating. As lipid based coating materials are relatively inexpensive and processing times are short, hot melt coating is also cost effective.

A difficulty in hot melt coating methods is maintaining adequate operator safety, as high temperatures close to $200^{\circ} \mathrm{C}$ are employed. Hence, adherence to safety and protective measures is important during coating. Also, the in vivo fate of lipidic coating material should be investigated.

\subsection{Potential for application}

The potential for application of hot melt coating in pharmaceutical formulation is enormous. The applications of hot melt coating may be broadly categorized as:

a) improvement of palatability of dosage forms

b) prevention of environmental degradation of dosage forms, and

c) retardation of drug release from dosage forms

Prevention of environmental degradation comprises protection from physical degradation (light, humidity), protection from drug incompatibilities and protection from physiological degradation (enzymatic breakdown in stomach, $\mathrm{pH}$ sensitivity). Controlled release of drug is probably the most popular objective of hot melt coating and is, hence, the main theme of this review.

4. Challenges in development

Development of hot melt coating methods offers the following challenges: 
1. Investigation of the batch variability of lipidic coating excipients and development of methods for evaluation of raw material.

2. Physicochemical characterization of coating excipients and evaluation of their functionality.

3. Investigation of thermal behavior of lipidic coating excipient and its interaction with the drug in the formulation.

4. Characterization of coating equipment for hot melt coating.

5. Investigation of drug release characteristics from the coated substrates.

\section{Development strategy}

This section attempts to describe the multitude of factors which require critical investigation in the development of hot melt coating methods. The physicochemical behavior of coating excipients and efficiency of coating process are probably, the two most important considerations in hot melt coating. Hence, these topics will form the focal point of the discussion below.

\subsection{Coating excipients}

The hydrophobic coating material (lipidic excipients) which are suitable for application in hot melt coating comprise waxes, fatty bases and hydrogenated vegetable oils. The choice of the coating excipient depends primarily on its 'function' (such as retardation of drug release rate, prevention of environmental degradation and masking of unpalatable taste) in the dosage form. This discussion primarily focuses on hot melt coating aimed at retardation of drug release rate from the formulation.

\subsection{Chemical nature}


The coating excipients most suitable for application in hot melt coating fall under the category of fats and waxes. Chemically, fats and waxes are hydrophobic substances consisting predominantly of glyceryl esters of fatty acids, also known as triglycerides. A triglyceride is the reaction product of one molecule of glycerol and three molecules of fatty acids to yield three molecules of water and one molecule of a triglyceride, if the three fatty acids are identical, the product is a simple triglyceride; when they are dissimilar, it is a mixed triglyceride. The chemical reaction in figure 1 shows the formation of a triglyceride. Structural isomers of the same triglyceride can be observed depending on the site of ester linkage and nature of the fatty acid. Monoglycerides and diglycerides can also be obtained if all the three hydroxyl groups of glycerol have not been esterified by the fatty acid.

\subsubsection{Ideal characteristics}

The excipient characteristics ideally desired for application in hot melt coating are listed below :

1. It should not undergo physical or chemical degradation at temperatures below $200^{\circ} \mathrm{C}$.

2. It should have a melting point in the $75^{\circ} \mathrm{C}-80^{\circ} \mathrm{C}$ range.

3. Its melt transition should occur over a narrow temperature range and it should not soften before melting.

4. Its thermal behavior in the range $30^{\circ} \mathrm{C}-200^{\circ} \mathrm{C}$ should be independent of the preparation, storage conditions and thermal history.

5. It should not undergo any crystal modifications when subject to temperatures as high as $200^{\circ} \mathrm{C}$.

6. It should be stable when subject to repeated heating-cooling cycles. 
7. It should be available in varying HLB values.

8. Its melt viscosity should facilitate easy flow and spray.

It is difficult to find an excipient which has all the above properties and hence, the pharmaceutical scientist should exercise careful discretion in choosing the right excipient. Additionally, the coating excipient should have the necessary regulatory approval for use in pharmaceuticals.

\section{Suitable commercial excipients}

For sustained release applications, coating excipients of special interest can be divided broadly into:

1. Natural and synthetic waxes

2. Hydrogenated vegetable oils

\section{Polyglycolyzed glycerides}

Table 1 lists a few coating excipients along with their commercial sources found favorable for hot melt coating from experience. Gelucires are a class of polyglycolyzed glycerides supplied by Gattefossè. Gelucires are specified by their melting point and HLB value (Gelucire 50/13 melts at $50^{\circ} \mathrm{C}$ and has an HLB value of 13) and various combinations of melting point and HLB value are available. Stearines are a family of partially hydrogenated vegetable oils and are used for 'structuring' in the food industry.

\section{ysicochemical characterization and Excipient functionality}

......pharmaceutical scientists have become increasingly aware of the fundamental effects that excipients can exert on the bioavailability, bioequivalence, and stability of formulations; excipients can no longer be regarded simply as 'inert' or 'inactive' substances. (From Handbook of Pharmaceutical Excipients, Second Edition, 1994) 
The above statement demonstrates the importance of, and need for a thorough investigation of the functional effects of the excipient in dosage form development. Also, it is desirable to identify and examine excipient properties to which its 'functionality' is sensitive. Such information would be a useful tool to engineer the performance of the dosage form. In this regard, the following excipient properties deserve special attention in the development of hot melt coating methods.

9.1. Molecular weight and hydrophobicity

Waxes are complex mixtures of high molecular weight organic compounds. But, molecular weight of the glyceryl portion $\left(\mathrm{C}_{3} \mathrm{H}_{5}\right)$ of a triglyceride is only 41 . Hence, the remaining portion of the triglyceride (fatty acid residue) contributes largely to the overall molecular weight. Molecular weight is a key physicochemical parameter and can provide information about the strength, flexibility and rheological behavior of the material. It can also be correlated to the ability of the excipient to retard drug release.

Hussain and coworkers reported a simple method for the determination of molecular weight averages of fats and oils using size exclusion chromatography (SEC) (5). They used SEC to determine the weight average $\left(M_{w}\right)$, number average $\left(M_{n}\right)$ and the Z-average $\left(M_{z}\right)$ of various fats. Size exclusion chromatography is a well-accepted technique to characterize synthetic polymers and has been extensively reviewed by Barth and coworkers (6). Size exclusion chromatography studies were also employed by Arroyo et. al. and Sánchez-Muniz et. al. in the evaluation of sunflower oil $(7,8)$.

Because of their preponderant weight in the glyceride molecules, fatty acids greatly influence the physical and chemical nature of glycerides. Any contributions that a fatty acid makes to hydrophobic character of triglycerides are limited to the amount of 
hydrophobic character in the fatty acid itself (9). Acid number and saponification number of waxes have been used as measures of inter-batch variability. Acid number is defined as the number of milligrams of potassium hydroxide required to neutralize the free acids in one gram of the substance and saponification number is defined as the number of milligrams of potassium hydroxide required to neutralize the free acids and saponify the esters contained in one gram of the substance (10). Hence, knowledge of acid and saponification numbers is useful in understanding the fatty acid moiety of the wax.

\subsubsection{Thermal behavior}

Hot melt coating requires melting of the coating excipient and exposure to high temperature ( about $200^{\circ} \mathrm{C}$ ). Hence, complete investigation of the excipient's thermal behavior is important. Such an investigation should aim at elucidating the effects of thermal treatment of the excipient on:

a. physicochemical drug-excipient interactions

b. excipient's ability to retard drug release rate

c. stability of the dosage form

From this perspective, thermal and polymorphic behavior of the excipient, which are closely interrelated deserve special attention (11). Literature describing analytical techniques and methods to study the thermal behavior of fatty waxes and glycerides has been widely published $(11-17,19-21)$. However, such reports have focused on thermal behavior and its significance in the formulation of suppositories, creams and matrices for controlled release. But, such methods can be appropriately modified to serve as investigative tools in the thermal characterization of excipients in hot melt coating. 
Flaherty reported the application of differential scanning calorimetry in the characterization of hydrocarbon and natural waxes in 1971 (12). Craig has recently reviewed thermal techniques to characterize materials in solid or molten state (13). This review focused on the utility of differential scanning calorimetry in studying the structure and properties of polyethylene glycols. He reported that differential scanning calorimetry is a highly versatile thermoanalytical technique. Simon and Süverkrüp performed a comparative evaluation of current techniques to characterize fatty bases (14). Busfield and Proschogo investigated the thermal properties of palm stearine using differential scanning calorimetry $(15,16)$. They demonstrated that thermal treatment controls the physical state of palm stearine. They also found that heating rate influences nature of the transition, the material can undergo and its observation during a differential scanning calorimetry scan. Craig and Newton reported the suitability of differential scanning calorimetry to detect solid state changes in materials and thus facilitate their standardization (17). Lètoffè et. al. described the application of differential scanning calorimetry in conjunction with thermomicroscopy to study waxes in the crude oil industry (18). They reported that thermomicroscopy is useful in correlating morphological or structural changes with thermal effects observed by differential scanning calorimetry.

The report of Ginès et. al. elaborating the interactions between cinnarizine and gelucire $53 / 10$ further justifies the value of differential scanning calorimetry in investigating drug-excipient binary systems (19). This report employed differential scanning calorimetry and hot stage microscopy to demonstrate the ability of molten gelucire $53 / 10$ to dissolve cinnarizine crystals. Sutananta and coworkers described the 
effects of aging on the thermal behavior of gelucire family of excipients $(20,21)$. This report investigated the long term stability of gelucires and heat treatment methods which accelerate the transformation to equilibrium form and structure of these glycerides.

Thus, differential scanning calorimetry can be employed to investigate the thermal behavior of excipients in hot melt coating. But, investigations should be modified to reflect the appropriate temperature range of operation. Also, the behavior of excipients upon repeated heat-cool cycles should be investigated as such thermal treatment is likely to be employed during hot melt coating. Kotsiomiti and McCabe studied the stability of dental waxes upon repeated heating (22). Thus, effects of thermal treatment on the excipient and subsequent drug-excipient interactions require complete examination in the development of hot melt coating methods.

\subsubsection{Polymorphic behavior}

Most organic molecules can crystallize in several different ways, and these different lattice configurations of the same molecule are called polymorphs (23). Each of the structural isomers resulting from the esterification of glycerols by fatty acids can exist in alpha $(\alpha)$, beta prime $\left(\beta^{\prime}\right)$ or beta $(\beta)$ polymorphic forms (11). The variability encountered in the observation of transition temperatures and melting point of triglycerides and fatty bases has been partially attributed to such complex polymorphism. In general, the morphology of glycerides is strongly dependent on thermal history of the samples. To a certain extent the morphology can be controlled by tempering or annealing (heating the material at a temperature higher than the melting point for a specified time duration) and the rate of cooling from the molten state (15). Also, it is well known that polymorphic changes can influence the intrinsic dissolution rate and other solid state 
properties of materials (24). Hence, it is worthwhile to investigate the polymorphic behavior of excipients in hot melt coating.

deMan and others studied the polymorphic behavior of hydrogenated oils using differential scanning calorimetry and x-ray crystallography (25). They investigated the crystallization temperatures of various oils. Busfield et. al. also described the crystalline modifications in palm stearine and correlated these changes to thermal conditions (15). Hagemann and Tallent examined the polymorphism of thirteen single acid triglycerides as a function of the acyl group chain length and unsaturation using differential scanning calorimetry (26). Coben and Lordi employed x-ray diffraction and differential scanning calorimetry studies to characterize amorphous to crystalline transitions in several semisynthetic suppository bases (27).

Yap and coauthors reported a study comprehensively describing the polymorphic behavior of palm oil and related compounds (28). Simon and Süverkrüp also reported an isothermal variant of differential scanning calorimetry to study the crystallization of fatty suppository bases (14). They concluded the crystallization behavior of fatty bases to be a biphasic process, where the content of partial glycerides and the extent of supercooling determine the formation of crystal nuclei while final solidification level depends on the crystallization temperature.

\subsubsection{Rheology in molten state}

As the lipidic coating excipient is spray coated on the substrate in its molten state, an investigation of the rheological behavior of the coating material and its temperature dependence is required. Primarily, the melt viscosity of the coating excipient should facilitate convenient flow for uninterrupted delivery by a peristaltic pump and spray in 
the coating chamber. Hence, it may be necessary to spray the coating material at temperatures of about $60-75^{\circ} \mathrm{C}$ above its melting point.

Bourret and coworkers studied the rheological behavior and its variation with temperature of gelucire family of excipients (29). They reported that the apparent viscosity of these glycerides decreases exponentially with temperature and follows an Arrhenius type relationship. It was found from experience that an optimal combination of flow pattern and temperature of the coating material needs to be achieved for efficient coating.

\subsection{Coating process}

\subsection{Modification of coating equipment}

Typically, any fluidized bed coating equipment can be modified to suit the needs of hot melt coating. Detailed evaluation of coating equipment and related processing conditions, including fluid bed equipment has been reported by Mehta (30). In our laboratory it was found that top-spray fluidized bed coater is most suitable for hot melt coating, due to its ability to operate with product temperature closest to the congealing temperature of the molten excipient. However, the use of a Wurster column in the fluidbed coater can also be employed.

The changes employed to existing equipment to facilitate hot melt coating, should allow delivery of the molten material on the substrate in the fluidized bed without any discontinuity due to solidification or hardening of the melt. This can be achieved by the passage of hot air to envelope the delivery tube in the spray nozzle through which the molten coating material passes before being atomized and sprayed on the substrate. An electric heating tower was used to obtain the hot air supply. Also, the tube delivering 
coating material from the reservoir to the spraying gun should be maintained at high temperature to prevent hardening of the molten coating material. A heating device to control the temperature of the coating material in the reservoir is also necessary. The spray gun inside the expansion chamber should be well insulated. This is required to prevent the remelting of coating material on the substrates, when they come in contact with the spray gun while falling back into the bed. A schematic sketch of the modified coating equipment used by these authors is shown in figure 2 .

Excellent reviews of the processing conditions and the characterization of coating equipment for hot melt coating have been published by Jones et. al. and Jozwiakowski et. al. $(31,32)$. Jozwiakowski and coworkers recommended that increasing the length of the expansion chamber, making it conical in shape and providing alternate filter shaking facility to avoid interrupting fluidization in a conventional fluid bed coater is required for hot melt coating.

2. Statistical experimental design and optimization

The application of optimization techniques to pharmaceutical systems has been thoroughly discussed by Schwartz et. al. (33). Mathematical optimization techniques allow control of variability in desired responses and facilitate precision in product quality. Generally, optimization protocols in pharmaceuticals follow the completion of data collection based on a predetermined set of experiments. The generation of data for use in optimization protocols through rational experimentation forms the subject of statistical experimental design. Although, a variety of experimental designs have been employed, the factorial design or some variation of it (full or fractional factorial), is probably the most popular design. Factorial designs allow the identification of both, the 
main and interaction effects, of factors. Statistical experimentation and multiple regression techniques allow correlation between the effect of a causative factor over a certain range and the responses of interest. However, causative factors and their ranges of operation should be empirically chosen.

Several reports of application of optimization techniques to pharmaceutical systems have been reported in recent literature (34-38). Renoux and coworkers employed a full factorial experimental design to improve the industrial production of tablets by direct compression (34). Khan et. al. reported the application of second order BoxBehnken design to optimize the levels of polymer, diluent and the compression force in the formulation of controlled release tablets (35). The use of experimental design in the study of ruggedness and robustness of analytical methods in validation of assays has been reported by Torbeck (36). Bouckaert and coauthors have published the optimization of a wet granulation procedure using central composite and full factorial designs (37). Our laboratory has recently employed response surface methodology and multiple regression to control and counteract the inherent variability in the determination of wet granulation endpoint and the effect of such variability on tablet properties such as friability, hardness and disintegration time (38). Röscheisen and Schmidt investigated the effects of compression force and lubricant concentration on the lubricant effectiveness, disintegration time and hardness of effervescent tablets using simplex optimization and two factor full factorial design (39). Thus, experimental design and optimization protocols are valuable tools to rationally, efficiently and scientifically refine formulations and processes. Their utility and value in hot melt coating is indisputable and will be discussed in the next section. 
Jones and Percel state the product bed temperature and droplet size of the molten material being sprayed, as key process variables in hot melt coating using a top-spray fluid bed coater (31). The temperature in the coating zone determines the adhesion to, and spreading of the coating material over the substrate. If the temperature is very high the coating material may not adhere to the substrate, whereas, if it is too low, it may not spread on the substrate. This, in turn affects the surface properties of the coated substrates and hence, the nature of drug release from them.

Droplet size and its uniformity is very important. Droplet size is influenced by the atomization air pressure, viscosity of the molten coating material and the spray rate. Typically, droplet size should be smaller relative to the substrate size for effective coating. Higher atomization pressure leads to smaller droplet size. As has been discussed earlier, the melt viscosity should facilitate satisfactory atomization. Spray rate affects the coating quality and the degree of agglomeration. Other important process variables are temperature of the molten material and atomization air, batch size and substrate size. Hence, an optimization protocol for hot melt coating should include all these process variables in the experimental design, so that their effects can be systematically studied. Jozwiakowski and coworkers employed a modified central composite design to optimize the release rate from a hot melt coated formulation (32). They coated drug loaded sugar beads with Stearine 07. The independent factors in their design were temperature of atomization air and molten wax, spray rate and atomization air pressure and the measured responses included bulk density, flow and percentage drug dissolution. They used 
multiple regression, response surface methodology and contour plots for optimizing the measured responses.

\section{Conclusion}

The stringent regulatory environment and the ever-changing requirements of the pharmaceutical industry have, once again, determined the evolutionary course of modern pharmaceutical coating technology. The unique feature of hot melt coating methods which does not warrant the use of any solvent, probably marks the advent of "the era of solvent-free coating techniques'. The promise and potential of hot melt coating methods is very attractive. It is believed that the efforts of researchers will help circumvent challenges in the development of these coating techniques and lead to further beneficial innovation.

\section{$\underline{\text { 5. Acknowledgments }}$}

The generous financial support and access to library and laboratory resources of SmithKline Beecham Consumer Healthcare to ASA is gratefully acknowledged.

\section{References}

1. G. Van Savage and C.T. Rhodes, Drug Dev. \& Ind. Pharm., 21(1), 93 (1995).

2. J.A. Seitz, S.P. Mehta and J.L. Yeager, in "The Theory and Practice of Industrial Pharmacy," 3rd. ed., L. Lachman, H.A. Lieberman and J.L. Kanig, eds., Lea \& Febiger, Philadelphia, 1986, pp. 346-373. 
3. S.C. Porter, in "Remington's Pharmaceutical Sciences," 18th ed., A.R. Gennaro, eds., Mack Publishing, Easton, Pennsylvania, 1990, pp. 1666-1675.

4. T.S. Weigand, “Parrish's Treatise on Pharmacy,” Henry C. Lea, Philadelphia, 1874.

5. S. Hussain, G.S.R. Sastry and N.P. Raju, J. Amer. Oil Chem. Soc., 68(11), 822 (1991).

6. H.G. Barth, B.E. Boyes and C. Jackson, Anal. Chem., 66, 595R (1994).

7. R. Arroyo, C. Cuesta, C. Garrido-Polonio, S. López-Varela and F.J. Sánchez-Muniz, J. Amer. Oil Chem. Soc., 69(6), 557 (1992).

8. F.J. Sánchez-Muniz, C. Cuesta and C. Garrido-Polonio, J. Amer. Oil Chem. Soc., 70(3), 235 (1993).

9. N.O.V. Sonntag, in "Bailey's Industrial and Fat Products," D. Swern, ed., John Wiley \& Sons, New York, 1979, pp. 2.

10. The United States Pharmacopeia, 23rd ed., United States Pharmacopeial Convention, Inc., Rockville, 1995.

11. G.G. Liversidge, D.J.W. Grant and J.M. Padfield, in "Analytical Proceedings," Royal Society of Chemistry, London, 1982, pp. 549.

12. B. Flaherty, J. Appl. Chem. Biotechnol., 21, 144 (1971).

13. D.Q.M. Craig, Thermochim. Acta, 248, 189 (1995).

14. K. Simon and R. Süverkrüp, Thermochim. Acta, 248, 271 (1995).

15. W.K. Busfield and P.N. Proschogo, J. Amer. Oil Chem. Soc., 67(3), 171 (1990).

16. W.K. Busfield and P.N. Proschogo, J. Amer. Oil Chem. Soc., 67(3), 176 (1990).

17. D.Q.M. Craig and J.M. Newton, Intl. J. Pharm., 74, 33 (1991).

18. J.M. Létoffé, P. Claudy, M.V. Kok, M. Garcin and J.L. Volle, Fuel, 74(6), 810 (1995). 
19. J.M. Ginés, M.D. Veiga, M.J. Arias and A.M. Rabasco, Intl. J. Pharm., 126, 287 (1995).

20. W. Sutananta, D.Q.M. Craig and J.M. Newton, Intl. J. Pharm., 111, 51 (1994).

21. W. Sutananta, D.Q.M. Craig and J.M. Newton, J. Pharm. Pharmacol., 45(S2), 1099 (1993).

22. E. Kotsiomiti and J.F. McCabe, J. Oral Rehab., 22, 135 (1995).

23. J.T. Carstensen, "Solid Pharmaceutics : Mechanical Properties and Rate Phenomena," Academic Press, New York, 1980.

24. S.P. Duddu and D.J.W. Grant, Thermochim. Acta, 248, 131 (1995).

25. L. deMan, J.M. deMan and B. Blackman, J. Amer. Oil Chem. Soc., 66(12), 1777 (1989).

26. J.W. Hagemann, W.H. Tallent and K.E. Kolb, J. Amer. Oil Chem. Soc., 49, 118 (1972).

27. L.J. Coben and N.J. Lordi, J. Pharm. Sci., 69(8), 955 (1980).

28. P.H. Yap, J.M. deMan and L. deMan, J. Amer. Oil Chem. Soc., 66(5), 693 (1989).

29. E. Bourret, V. Ratsimbazafy, L. Maury and C. Brossard, J. Pharm. Pharmacol., 46, 538 (1994).

30. A.M. Mehta in "Aqueous Polymeric Coatings for Pharmaceutical Dosage forms," J.W. McGinity, ed., Marcel Dekker, Inc., New York, 1989, pp. 267-302.

31. D.M. Jones and P.J. Percel in "Multiparticulate Oral Drug Delivery," I. GhebreSellasie, ed., Marcel Dekker, Inc., New York, 1994, pp. 113-142.

32. M.J. Jozwiakowski, D.M. Jones and R.M. Franz, Pharm. Res., 7(11), 1119 (1990). 
33. J.B. Schwartz and R.E. O'Connor in "Modern Pharmaceutics," 3rd ed., G.S. Banker and C. T. Rhodes, eds., Marcel Dekker, Inc., New York, 1996, pp. 727-752.

34. R. Renoux, J.A. Demazieres, J.M. Cardot and J.M. Aiache, Drug Dev. \& Ind. Pharm., 22(2), 103 (1996).

35. M.A. Khan, J. Dib and I.K. Reddy, Drug Dev. \& Ind. Pharm., 22(2), 135 (1996).

36. L.D. Torbeck, Pharm. Technol., 20(3), 168 (1996).

37. S. Bouckaert, D.L. Massart, B. Massart and J.P. Remon, Drug Dev. \& Ind. Pharm., 22(4), 321 (1996).

38. A.S. Achanta, P.S. Adusumilli and K.W. James, Drug Dev. \& Ind. Pharm., 23(6), 539 (1997).

39. G. Röscheisen and P.C. Schmidt, Eur. J. Pharm. Biopharm., 41(5), 302 (1995). 
Table 1: Suitable commercial lipidic excipients for hot melt coating

\begin{tabular}{|c|c|c|}
\hline Coating excipient & Category & Commercial source \\
\hline Gelucires & Polyglycolyzed glycerides & Gattefosse \\
\hline Stearines & Hydrogenated vegetable oils & Quest \\
\hline Myvaplex 600 & Glyceride & Eastman \\
\hline PEG family & Ethylene glycol polymers & Union Carbide \\
\hline Carnuaba wax & Natural wax & Frank B. Ross \\
\hline Ross wax \#100 & Synthetic wax & Frank B. Ross \\
\hline
\end{tabular}


Figure 1: Formation of a triglyceride where $R_{1}, R_{2}$ and $R_{3}$ denote any alkyl group

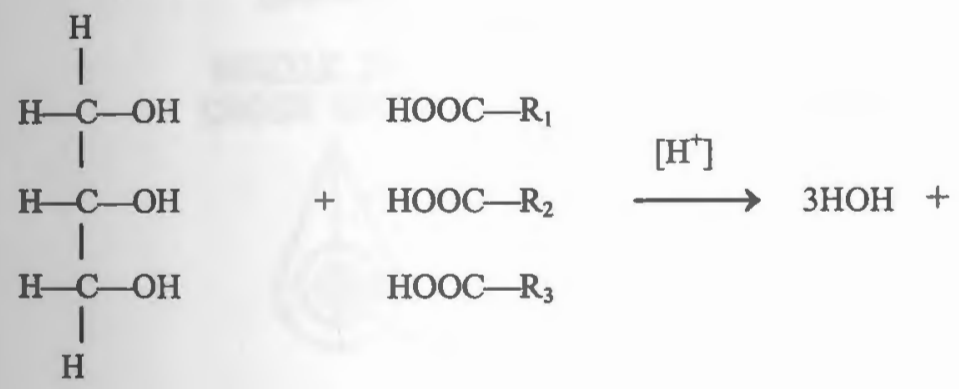

Glycerol
Fatty Acids<smiles>COC(C)OCC(C)OC(C)=O</smiles>

Water
Triglyceride 
Figure 2: Modifications to a conventional fluid bed coater to suit hot melt coating and cross section of insulated spray nozzle wand

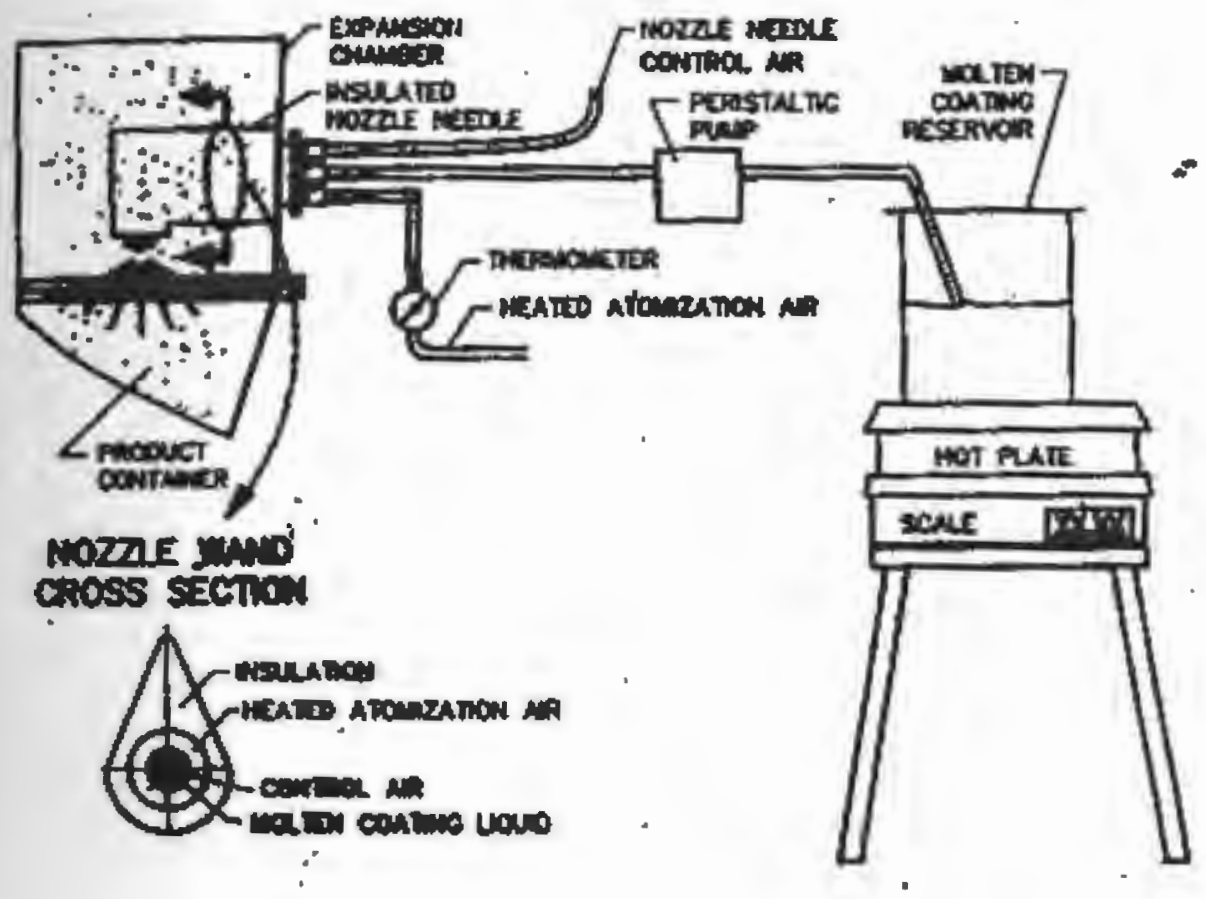




\section{MANUSCRIPT II}

Hot melt coating: Water sorption behavior of excipient films 
Abstract

Hot melt coating allows encapsulation of water labile drug laden substrates to form a barrier that resists moisture ingress. To understand the interaction of water with excipients that can form moisture protective coatings, sorption behavior of films of lipidic (glyceryl behenate) and polymeric (polyvinyl alcohol) coating excipients was investigated. A simple and rapid method employing a new, fully automated instrumental technique to investigate the sorption/desorption behavior of excipient films is reported. Further, the influence of temperature and film thickness on the sorption behavior of films was examined. Both excipient films displayed sorption isotherms that were classified as type III and demonstrated hysteresis during desorption. The sorption data for both films did not follow the Langmuir model and the BET model could only be used restrictively. The GAB model fitted the sorption data at all conditions and over the entire range of water activity studied. The ability of Young and Nelson model to explain the hysteresis behavior, from analytical and mechanistic perspectives, was evaluated. Temperature and film thickness were found to profoundly influence the nature of moisture-interaction and distribution of moisture in the excipient films. An Arrhenius type relationship was observed between equilibrium moisture content of excipient films and temperature at constant water activity. 
Development of hot melt coating methods for retardation of drug release applications has been recently reviewed (1). Typically, lipidic/waxy excipients with low melting points $(<373 \mathrm{~K})$ are sprayed in their molten state to form a uniformly continuous film that acts as the rate controlling membrane for drug release. This coating approach may also be employed to achieve protection for substrates of moisture labile active ingredients by appropriately modifying the film thickness. The hydrophobic wax coating presents a barrier for moisture ingress into the drug-laden substrate. Hence, a clear understanding of the water sorption/desorption behavior of such excipient films is necessary $(2,3,4,5,6)$. From experience, glyceryl behenate (GB) was found to be a suitable excipient for hot melt applications and was included in this study. For comparison, a novel formulation of polyvinyl alcohol (PVA) being commercially promoted as a moisture protective aqueous film coating excipient was used. GB is a low molecular weight waxy excipient whereas PVA is a high molecular weight polymeric excipient.

Dynamic vapor sorption technique (DVST) is a fully automated gravimetric sorption system used to rapidly measure uptake and loss of moisture. This is done by flowing a carrier gas (nitrogen) at a specified relative humidity (RH) over the material specimen suspended from an ultrasensitive microbalance capable of measuring changes in mass lower than 1 part in 10 million. A schematic of the DVST apparatus is shown in figure 1. Compared to traditional experimental approaches utilizing saturated salt solutions, DVST offers fast equilibration times, high precision/sensitivity in mass determination and temperature control, small sample size requirement and full 
automation to facilitate convenient and accurate moisture sorption/desorption investigations.

The purpose of this investigation was to study the sorption/desorption behavior of the excipient films and the nature of their interaction with water. It is intended to investigate the moisture distribution and how it is influenced by temperature and film thickness. Evaluation of the utility of DVST in studying the sorption/desorption phenomenon of excipient films was also of great interest.

\section{Materials and methods}

Glyceryl behenate (Compritol 888 ATO, Lot \# A17008) and polyvinyl alcohol (Opadry AMB OY-B-28920, Lot \# 5066503) were obtained from Gattefossé, Saint Priest, France and Colorcon, West Point, USA respectively. Films of GB were cast by melting five grams of material (melting point $\approx 342 \mathrm{~K}$ ) in a flat, circular aluminum pan (diameter $=9.53 \times 10^{-2} \mathrm{~m}$ and height $=9.53 \times 10^{-3} \mathrm{~m}$ ) normally used for loss on drying determinations (Mettler, Hightstown, USA) and allowing the molten wax to cool over the area of the pan to form a uniform film. Films so obtained had a mean thickness of $6.73 \mathrm{X}$ $10^{-4} \mathrm{~m}\left(\mathrm{n}=10\right.$ and $\left.\mathrm{SD}=2.54 \times 10^{-5} \mathrm{~m}\right)$. For the PVA films, a $20 \% \mathrm{w} / \mathrm{w}$ dispersion of the polymer in deionized water was first prepared. This dispersion was then poured on the aluminum pan to deliver $5 \mathrm{~g}$ of solids and dried in an oven at $333 \mathrm{~K}$ for 12 hours. PVA films had a mean thickness of $8.94 \times 10^{-4} \mathrm{~m}\left(\mathrm{n}=10\right.$ and $\left.\mathrm{SD}=2.03 \times 10^{-4} \mathrm{~m}\right)$. To obtain films of greater thickness, the above procedure was repeated with twice the amount (i.e. ten grams) of solid contents for both excipients. The thicker films had a mean thickness of $1.42 \times 10^{-3} \mathrm{~m}\left(\mathrm{n}=10\right.$ and $\left.\mathrm{SD}=3.39 \times 10^{-5} \mathrm{~m}\right)$ and $1.35 \times 10^{-3} \mathrm{~m}(\mathrm{n}=10$ and $\mathrm{SD}=8.13$ 
$\mathrm{X} 10^{-5} \mathrm{~m}$ ) for GB and PVA respectively. No plasticizers were added to maintain purity of excipients in films. A DVST method using DVS-2000 with DVS analysis suite, Version 3.3 Standard (Surface Measurement Systems Limited, N.A., Coopersburg, USA) was defined to establish water activity $\left(a_{w}\right)$ of $0.00,0.17,0.34,0.51,0.68$ and 0.85 . The ultrasensitive balance was calibrated before use and whenever temperature was changed, the humidity probes were calibrated to cover the range of operation as prescribed by the manufacturer. One full cycle facilitated determination of sorption and desorption portions of the isotherm.

\section{Results and discussion}

\subsection{Construction of isotherms}

Films of GB were brittle and hard, whereas PVA films were flexible and soft. Rectangular specimens of the films prepared were cut using a blade for sorption analysis. Usually, DVST uses glass pans to hold the sample. However, to achieve exposure of the entire surface area of the film, the film specimen was inserted in a metallic paper clip and suspended from the balance instead of using glass pans. The method exposed the film sample to each programmed water activity for a minimum of two hours. After the initial two hours, the condition for reaching equilibrium was defined as the percent change in mass per minute $[\mathrm{dm} / \mathrm{dt}(\% / \mathrm{min})$, i.e. slope of sample mass versus time plot] computed over any continuous ten minute duration should fall below a user specified threshold value. The USP suggests that for equilibrium moisture determinations, weighing should be performed every hour until consecutive readings record a mass change of less than $0.25 \%$ (approximately $0.0042 \% / \mathrm{min}$ ). Threshold values of $0.002 \% / \mathrm{min}$ and $0.004 \% / \mathrm{min}$ 
were used for GB and PVA films respectively. GB film samples weighed approximately 0.150 grams and that of PVA weighed about 0.050 grams. The film sample weight and threshold values for equilibration were determined based on preliminary experiments to optimize run time. The isotherms so constructed by plotting equilibrium moisture content (EMC or $\mathrm{V}$ in $\mathrm{g}$ of water/g of film) against water activity for GB and PVA films at $\mathrm{T}=$ 293, 303 and $313 \mathrm{~K}$ are shown in figures 2 and 3 respectively. The shape of isotherms suggests that they are type III isotherms as per Martin (7). Martin stated that type III isotherms are relatively uncommon and result when heat of adsorption in the first layer is less than the latent heat of condensation in the successive layers and the value of BET constant $\left(\mathrm{C}_{\mathrm{BET}}\right)$ is less than 2 .

\subsection{Effect of temperature}

From figures 2 and 3 it is evident that for GB films, increasing temperature leads to increasing area due to hysteresis and higher EMC. Contrarily, PVA films displayed decreasing area due to hysteresis and lower EMC with increasing temperature. Plots of logarithm of EMC against reciprocal temperature at various levels of water activity (shown in figure 4) were found to be linear for GB and PVA films, suggesting an Arrhenius type relationship. A relationship of the type:

$$
\mathrm{V}=\mathrm{A}\left(\exp \left(\mathrm{E}_{\mathrm{sorp}} / \mathrm{RT}\right)\right)
$$

at constant water activity, where $\mathrm{V}$ is the EMC at a specified water activity, $\mathrm{A}$ is a proportionality constant, $\mathrm{R}$ is the universal gas constant and $\mathrm{T}$ is absolute temperature, is valid for $0.17 \leq a_{w} \leq 0.85$. The Arrhenius type relation suggests that the slope should perhaps be construed as a measure of the energy $\left(E_{\text {sorp }}\right)$ associated with the sorption/desorption of moisture in the solid as temperature varies at constant water 
activity. When slopes obtained by linear regression from these plots were graphed against water activity, again a linear relationship was observed for both excipients (shown in figure 5). Hence, a relationship of the form:

$$
\mathrm{E}_{\text {sorp,aw }}=\mathrm{M}_{\mathrm{E}}\left(\mathrm{a}_{\mathrm{w}}\right)+\mathrm{E}_{\text {sorp }, 0}
$$

may be defined for $0.17 \leq \mathrm{a}_{\mathrm{w}} \leq 0.85$ and $293 \leq \mathrm{T}$ (in $\mathrm{K}$ ) $\leq 313$. Here, $\mathrm{E}_{\text {sorpaw }}$ is energy of sorption/desorption at a water activity $\mathrm{a}_{\mathrm{w}}, \mathrm{E}_{\mathrm{sorp}, 0}$ is the same at $\mathrm{a}_{\mathrm{w}}=0$ and $\mathrm{M}_{\mathrm{E}}$ is the change in $\mathrm{E}_{\text {sorpaw }}$ from $\mathrm{E}_{\text {sorp }, 0}$ computed per unit change in $\mathrm{a}_{\mathrm{w}}$. It is possible that there may be binding of water molecules to the electronegative oxygen atom in the terminal carboxylic group of GB via hydrogen bonding. Further, as temperature increases and is closer to the melting temperature of the wax, the intermolecular distances increase leading to greater number of carboxylic groups becoming available for bonding the water molecules. This hypothesis is consistent with the observation of increasing EMC with increasing temperature for GB film. Also, as more water molecules complete bonding with increasing water activity, the $\mathrm{E}_{\text {sorp }}$ decreases steadily in a linear fashion as observed in figure 5 .

\subsection{Estimation of microrate constants}

Langmuir described $\mathrm{k}_{1}$ and $\mathrm{k}_{2}$ as the microrate constants governing the sorption and desorption processes respectively in studying sorption over solids (7). Using the film sample mass data recorded every minute by DVST, we estimated the microrate constants for sorption and desorption for both excipient films. The method of estimation was to calculate the slope of the tangent at the very initial portion of the mass versus time plot at constant water activity. It was assumed that the very initial data during wetting or drying phases results due only to sorption and desorption respectively. The estimated values of 
$k_{1}$ and $k_{2}$ for GB and PVA films at $T=293,303$ and $313 \mathrm{~K}$ have been tabulated in tables 1 and 2.

From the tables it can be inferred that the estimated values of $k_{1}$ and $k_{2}$ for PVA relative to GB are greater by an order of 10 approximately. This is a natural implication of their chemical nature, as GB is very hydrophobic (stemming from the long aliphatic chains attached to the glyceryl backbone) relative to PVA. The data for PVA film follows an orderly pattern and is more precise compared to the GB film. This may be due to the wide variation in GB data resulting from very small changes in weight during sorption or desorption potentially due to its high hydrophobicity. The estimates for both microrate constants increase with increasing water activity and temperature for the PVA film. The same cannot be stated with certainty for GB film due to the wide spread of data. For the isotherms shown in figures 2 and 3, the Langmuir model could not be used to explain the data for both excipients at any temperature. The reasons are obvious as the Langmuir model is based on a simple set of assumptions that are rarely valid in real experimentation. Further, it is incorrect to calculate desorption microrate constants as described above when the recorded data demonstrates hysteresis. The purpose of these computations was to perform a cursory examination of the nature of microrate constants. Hence, it is important that the estimated microrate constants reported here be understood only within a limited scope.

\subsection{BET and GAB analysis}

The BET model was used to analyze the isotherms in figures 2 and 3. BET model could be satisfactorily used to fit sorption data for GB film at T $=293$ and $303 \mathrm{~K}$ and PVA film at $\mathrm{T}=293$ and $313 \mathrm{~K}$, where $0.17 \leq \mathrm{a}_{\mathrm{w}} \leq 0.51$ only. Data for PVÄ and GB 
films at other temperatures did not follow the BET model. The values of BET constant $\left(\mathrm{C}_{\mathrm{BET}}\right)$, monolayer value $\left(\mathrm{V}_{\mathrm{m}}\right)$ and the constant heat due to site interaction $\left(\mathrm{H}_{s}\right)$ so computed for the GB and PVA films have been tabulated in table 3. As stated by Martin, the BET constants in most cases were found to be less than 2. The BET model, although more effective than Langmuir model, also makes assumptions such as the heat of sorption for first layer being constant and equal to the total heat of vaporization plus a constant heat due to site interaction that are not entirely true and hence its applicability is limited (3).

The GAB model is an extended BET model as per the modifications developed by Guggenheim, Anderson and De Boer (8). The GAB equation is:

$$
\mathrm{V}=\left[\mathrm{C}_{\mathrm{GAB}} \cdot \mathrm{K} \cdot \mathrm{V}_{\mathrm{m}} \cdot \mathrm{a}_{\mathrm{w}}\right]\left[\left(1-\mathrm{K} \cdot \mathrm{a}_{\mathrm{w}}\right) /\left(1-\mathrm{K} \cdot \mathrm{a}_{\mathrm{w}}+\mathrm{C}_{\mathrm{GAB}} \cdot \mathrm{K} \cdot \mathrm{a}_{\mathrm{w}}\right)\right]
$$

where $\mathrm{C}_{\mathrm{GAB}}$ and $\mathrm{K}$ are parameters related to the heat of sorption and other variables were defined earlier. In contrast to $\mathrm{BET}$ model, the $\mathrm{GAB}$ model involves the additional parameter $\mathrm{K}$ and takes into account a layer or layers of sorbed vapor, which may be taken up with a degree of binding intermediate to those of the monolayer and the bulk water taken up in a non-specific manner. The parameters $\mathrm{K}$ and $\mathrm{C}_{\mathrm{GAB}}$ may be determined as:

$$
\mathrm{K}=\mathrm{B}_{1} \cdot \exp \left[\left(\mathrm{H}_{\mathrm{L}}-\mathrm{H}_{\mathrm{m}}\right) / \mathrm{RT}\right] \text { and } \mathrm{C}_{\mathrm{GAB}}=\mathrm{D} \cdot \exp \left[\left(\mathrm{H}_{1}-\mathrm{H}_{\mathrm{m}}\right) / \mathrm{RT}\right]
$$

where $B_{1}$ and $D$ are constants, $H_{L}$ is the heat of condensation, $H_{m}$ is the heat of sorption of water sorbed in the intermediate layer and $\mathrm{H}_{1}$ is the heat of sorption of water in the first sorbed monolayer. The GAB model was successfully used to describe the sorption data for both excipient films at all temperatures and over the entire range of water activity. As per the GAB equation, reciprocal of EMC was plotted against water activity and the parameters $\mathrm{K}, \mathrm{C}_{\mathrm{GAB}}$ and $\mathrm{V}_{\mathrm{m}}$ were estimated using nonlinear regression analysis 
(SigmaPlot 4.0 for Windows, SPSS, Inc., Chicago, USA). A typical example showing the ability of GAB model to fit data over the entire range of water activity is shown in figure 6. The resulting parameters from nonlinear regression have been tabulated in table 3 .

There seems to be reasonable agreement between the monolayer values $\left(V_{m}\right)$ estimated from the GAB and BET models for GB and PVA thin films, with the GAB values being greater. A similar observation was made while studying the interaction of water with celluloses, but that report stated that the BET monolayer values as being greater (9). The monolayer values for PVA film relative to the GB film are significantly greater. This may be due to the polymeric nature of PVA, wherein water acts as a plasticizer to open up the long chains that make up the structural matrix and hence exposes all the interior sites for sorption. The monolayer values for GB film increase with increasing temperature whereas for PVA film the same decrease with increasing temperature. Assuming, $B_{1}$ and $D$ to be unity, the values for $\left(\mathrm{H}_{L}-\mathrm{H}_{m}\right)$ and $\left(\mathrm{H}_{1}-\mathrm{H}_{m}\right)$ were computed and are included in table 3. From that table, the heat of sorption of water in the first sorbed monolayer $\left(\mathrm{H}_{1}\right)$ is less than the heat of sorption of water sorbed in the intermediate layers $\left(\mathrm{H}_{\mathrm{m}}\right)$ in most cases leading to the observation of type III isotherms (7).

\subsection{Analysis of hysteresis}

Although, numerous theories have been proposed to clarify the phenomenon of hysteresis, none has offered a comprehensive explanation $(3,10,11,12)$. One popular model extensively used to analyze hysteresis is the Young and Nelson model (YNM) $(13,14)$. The YNM was developed to describe the equilibrium sorption and desorption behavior of biological materials such as starch. They distinguish three forms of moisture: 
a bound or adsorbed monolayer on the surface, normally condensed or external water and absorbed or internal moisture. The mathematical equations describing the YNM are:

$$
\begin{aligned}
& \theta=a_{w} /\left(a_{w}+\left(1-a_{w}\right) E\right) \\
& \varphi=a_{w}(\theta) \\
& \beta=-\left(a_{w} \cdot E\right) /\left(E-\left((E-1) \cdot a_{w}\right)\right)+\left(E^{2} /(E-1)\right) \ln \left(E-\left((E-1) \cdot a_{w}\right) / E\right)-(E+1) \ln \left(1-a_{w}\right) \\
& M_{s}=A(\theta+\beta)+B \varphi \\
& M_{d}=A(\theta+\beta)+B \theta a_{w \max }
\end{aligned}
$$

where $\theta$ is the fraction of surface covered by a monomolecular layer, $\varphi$ is the fraction of surface covered by a layer of water two or more molecules thick and $\beta$ is the total amount of adsorbed moisture in a multilayer, $\mathrm{M}_{\mathrm{s}}$ and $\mathrm{M}_{\mathrm{d}}$ are the moisture contents of the material during sorption and desorption conditions and $\mathrm{a}_{\mathrm{wmax}}$ is the maximum water activity condition. A, B and $\mathrm{E}$ are parameters unique to each material.

$$
\begin{gathered}
E=\exp \left[-\left(\mathrm{q}_{1}-\mathrm{q}_{\mathrm{L}}\right) / \mathrm{kT}\right] \\
\mathrm{A}=\left(\rho_{\mathrm{w}} \mathrm{V}_{\mathrm{m}}\right) / \mathrm{W}_{\mathrm{m}^{\prime}} \\
\mathrm{B}=\left(\rho_{\mathrm{w}} \mathrm{V}_{\mathrm{a}}\right) / \mathrm{W}_{\mathrm{m}}{ }^{\prime}
\end{gathered}
$$

where $\mathrm{q}_{1}$ is the heat of adsorption of water bound to the surface, $\mathrm{q}_{\mathrm{L}}$ is the normal heat of condensation of water, $\mathrm{k}$ is the Boltzmann's constant, $\mathrm{T}$ is absolute temperature, $\mathrm{V}_{\mathrm{m}}$ and $\mathrm{V}_{\mathrm{a}}$ are volumes of adsorbed and absorbed moisture respectively, $\rho_{\mathrm{w}}$ is the density of water and $\mathrm{W}_{\mathrm{m}}$ ' is the mass of the dry material. Finally, A. $\theta$ is the amount of monolayer moisture, A. $(\theta+\beta)$ is the externally adsorbed moisture and B. $\varphi$ is the amount of internally absorbed moisture during the sorption cycle.

Equations 1-5 were used to test fit the sorption/desorption results obtained in this study for both excipient films under various conditions. A segmented nonlinear 
regression procedure was developed to simultaneously fit the sorption and desorption data to YNM equations using SAS statistical software (Version 6.12, SAS Institute Inc., Cary, USA) and obtain best estimates of the parameters A, B and E. In all cases, excellent fit to actual data was observed and a typical example comparing actual and YNM predicted data is shown in figure 7. The estimated parameters for both excipient films at various temperatures have been tabulated in table 4 .

The parameter A for GB film at all conditions was practically zero, signifying that all the moisture adsorbed exists as absorbed moisture in the internal structure of the material. As YNM was developed for biological materials, moisture absorbed in the internal structure would mean that the moisture has crossed the exterior cell wall and entered the interior of the cell. Such an explanation would not fit the present situation due to the non-biological nature of the excipients. Hence, the absorbed moisture should perhaps be understood, as the water molecules that have formed some form of a chemical bond with the adsorbate molecules (chemisorption). Examining the molecular structure of GB it is very likely that such bonding occurs as an irreversible hydrogen bond as discussed earlier. Similarly, the hydroxyl groups in PVA can also form hydrogen bonds with water molecules (15). For the PVA film, the parameter A remains fairly constant with temperature indicating a constant monolayer value. However, the parameter B for both GB and PVA films was found to be varying with temperature, a relationship similar to that discussed earlier between $\ln (\mathrm{V})$ and $1 / \mathrm{T}$ was also seen between $\ln (\mathrm{B})$ and $1 / \mathrm{T}$ for both excipient films. This could be a result of the forming or breaking of hydrogen bonds between water and the adsorbate in an Arrhenius type manner with varying temperature. 
It must be emphasized that although YNM offers a reasonable analytical solution to the hysteresis phenomenon, it does not provide a mechanistic solution due to the assumptions that form its basis. Further, the interpretation of "internally absorbed" moisture for non-biological materials is unclear. It should be applied cautiously and the physical significance of the parameters (A, B and E) must be carefully considered.

\subsection{Effect of film thickness}

Comparative sorption isotherms for thick and thin films of GB and PVA at $\mathrm{T}=303 \mathrm{~K}$ have been presented in figures 8 and 9 respectively. For the thick GB film, the EMC during the sorption portion are lower relative to the thin film. But, at the end of desorption, the amount of moisture being retained remains roughly the same. The GAB model could again be used to describe the entire data for thick films of both excipients and results are shown in table 3. The PVA thick film demonstrated very different behavior compared to the thin one. The PVA thick film takes up moisture only at very high water activities and retains considerably greater moisture upon end of drying. Interestingly, for the thick films of both excipients the parameter A from YNM analysis is zero (results tabulated in table 4), indicating that the retained moisture exists only in the absorbed state. This could result either due to chemisorption as discussed earlier or from the different nature of internal microporous structure of the thick film leading to larger amounts of moisture condensing in the pores in an irreversible manner. In a typical coating process, the particle size of the substrates is heterogeneous and so is the coating film thickness on each substrate. If films of varying thickness retain different amounts of moisture, the process variables should be closely controlled to achieve as uniform a coating thickness as possible for satisfactory product performance. This is of vital 
importance for sustained release and moisture protective coating applications as the residual moisture in the coating film may migrate into the core and interact with the active ingredient in an adverse manner upon storage.

\section{Conclusions}

DVST is an extremely useful tool to develop simple, fast and convenient methods for investigation of sorption and desorption behavior of excipient films. It was found that a model assuming the existence of water in three different states: one tightly bound layer, additional less tightly bound layers and bulk water in a non specific manner is most successful in describing the sorption isotherms for PVA and GB films under all conditions of study. The hysteresis demonstrated by both excipients could be accurately modeled using the YNM, although physical interpretation of model parameters was not definite. It is hypothesized that water molecules may form an irreversible hydrogen bond with the carboxylic and hydroxyl groups in GB and PVA films respectively leading to water retention by the films.

Although the models described here were successful in analytically fitting experimental data, it is necessary to perform a complete thermodynamic analysis of the water-film interaction to clarify the sorption process at a molecular level $(15,16)$. The results pertaining to fits of theoretical models along with the underlying thermodynamics of serption/desorption processes will better facilitate comprehension of interaction of water with excipient films. A relationship similar to Clausius-Clayperon equation was observed between the EMC of films and temperature at constant water activity (3). Also, 
it was found that amount of moisture retained by the film is influenced by the film thickness for the PVA film.

\section{Acknowledgements}

The generous financial support of, access to laboratory and library facilities of SmithKline Beecham Corporation is most gratefully acknowledged. The assistance of Ms. Sara Luke in developing regression routines in SAS software is greatly appreciated.

\section{$\underline{\text { References }}$}

1. A.S. Achanta, P.S. Adusumilli, K.W. James and C.T. Rhodes. Drug Dev. Ind. Pharm., 23, 441-449 (1997).

2. W.A. Strickland, J. Pharm. Sci., 51, 310-314 (1962).

3. T.P. Labuza, Food Tech., 22, 263-272 (1968).

4. J.C. Callahan, G.W. Cleary, M. Elefant, G. Kaplan, T. Kensler and R.A. Nash, Drug Dev. Ind. Pharm., 8, 355-369 (1982).

5. D.E. Wurster, G.E. Peck and D.O. Kildsig, Drug Dev. Ind. Pharm., 8, 343-354 (1982).

6. P. York, Int. J. Pharm., 14, 1-28 (1983).

7. A. Martin and P. Bustamante, Physical Pharmacy, $4^{\text {th }}$ Ed., Lea \& Febiger, Philadelphia (1993).

8. C. Van der berg, Ph.D. Thesis, Agricultural University of Wageningen, 1981. 
9. G.R. Sadeghnejad, P. York and N.G. Stanley-Wood, Drug Dev. Ind. Pharm., 12, 2171-2192(1986).

10. S.Y. Chan and N. Pilpel, J. Pharm. Pharmacol., 35, 477-481 (1983).

11. S. Malamataris and A. Dimitriou, J. Pharm. Pharmacol., 42, 158-163 (1990).

12. S. Malamataris, P. Goidas and A. Dimitriou, Int. J. Pharm., 68, 51-60 (1991).

13. J.H. Young and G.L. Nelson, Transactions of the ASAE, 10, 260-263 (1967).

14. J.H. Young and G.L. Nelson, Transactions of the ASAE, 10, 756-761 (1967).

15. F. Khan and N. Pilpel, Powder Tech., 50, 237-241 (1987).

16. S.E. Tabibi and R.G. Hollenbeck, Int. J. Pharm., 18, 169-183 (1984). 
Table 1: Estimates of microrate constants for sorption $\left(\mathrm{k}_{1}\right)$ and desorption $\left(\mathrm{k}_{2}\right)$ processes assuming Langmuir behavior for glyceryl behenate film at $\mathrm{T}=293,303$ and $313 \mathrm{~K}$

\begin{tabular}{|c|c|c|c|c|c|c|}
\hline \multicolumn{7}{|c|}{ Sorption microrate constant $\left(\mathrm{k}_{1} \times 10^{6}\right.$ in $\left.\mathrm{g} / \mathrm{min}\right)$} \\
\hline & $\mathrm{T}=293 \mathrm{~K}$ & & $\mathrm{~T}=303 \mathrm{~K}$ & & $\mathrm{~T}=313 \mathrm{~K}$ & \\
\hline $\begin{array}{c}\text { Water } \\
\text { activity }\end{array}$ & $\begin{array}{c}\text { Mean } \\
(\mathrm{n}=3)\end{array}$ & $\mathrm{SD}$ & Mean $(\mathrm{n}=3)$ & $\mathrm{SD}$ & Mean $(\mathrm{n}=3)$ & $\mathrm{SD}$ \\
\hline 0.17 & 1.33 & 0.58 & 2.67 & 1.15 & 2.00 & 1.00 \\
\hline 0.34 & 2.67 & 1.15 & 1.67 & 0.58 & 5.67 & 4.51 \\
\hline 0.51 & 2.33 & 0.58 & 3.00 & 1.00 & 4.00 & 1.00 \\
\hline 0.68 & 3.33 & 1.15 & 3.33 & 1.53 & 5.67 & 4.04 \\
\hline 0.85 & 4.00 & 2.65 & 5.00 & 1.00 & 5.67 & 1.53 \\
\hline \multicolumn{7}{|c|}{ Desorption microrate constant $\left(\mathrm{k}_{2} \times 10^{6}\right.$ in $\mathrm{g} /$ min) } \\
\hline Water & $\begin{array}{l}\text { Mean } \\
\text { activity }\end{array}$ & $\mathrm{SD}$ & Mean $(\mathrm{n}=3)$ & $\mathrm{SD}$ & Mean $(\mathrm{n}=3)$ & $\mathrm{SD}$ \\
\hline 0.17 & 4.33 & 3.21 & 2.67 & 1.53 & 4.00 & 1.00 \\
\hline 0.34 & 2.33 & 1.53 & 2.67 & 0.58 & 6.67 & 4.93 \\
\hline 0.51 & 1.67 & 0.58 & 4.33 & 1.15 & 5.00 & 4.58 \\
\hline 0.68 & 2.33 & 0.58 & 7.00 & 0.00 & 7.67 & 4.04 \\
\hline
\end{tabular}


Table 2: Estimates of microrate constants for sorption $\left(\mathrm{k}_{1}\right)$ and desorption $\left(\mathrm{k}_{2}\right)$ processes assuming Langmuir behavior for polyvinyl alcohol film at $\mathrm{T}=293,303$ and $313 \mathrm{~K}$

\begin{tabular}{|c|c|c|c|c|c|c|}
\hline \multicolumn{7}{|c|}{ Sorption microrate constant $\left(\mathrm{k}_{1} \times 10^{6}\right.$ in $\left.\mathrm{g} / \mathrm{min}\right)$} \\
\hline & $\mathrm{T}=293 \mathrm{~K}$ & & $\mathrm{~T}=303 \mathrm{~K}$ & & $\mathrm{~T}=313 \mathrm{~K}$ & \\
\hline $\begin{array}{c}\text { Water } \\
\text { activity }\end{array}$ & $\begin{array}{c}\text { Mean } \\
(\mathrm{n}=3)\end{array}$ & $\mathrm{SD}$ & Mean $(\mathrm{n}=3)$ & $\mathrm{SD}$ & Mean $(\mathrm{n}=3)$ & $\mathrm{SD}$ \\
\hline 0.17 & 13.3 & 5.77 & 20.0 & 0.00 & 26.7 & 5.77 \\
\hline 0.34 & 16.7 & 5.77 & 26.7 & 5.77 & 33.3 & 5.77 \\
\hline 0.51 & 26.7 & 5.77 & 40.0 & 0.00 & 50.0 & 0.00 \\
\hline 0.68 & 46.7 & 5.77 & 66.7 & 5.77 & 86.7 & 5.77 \\
\hline 0.85 & 66.7 & 5.77 & 100 & 0.00 & 100 & 0.00 \\
\hline \multicolumn{7}{|c|}{ Desorption microrate constant $\left(\mathrm{k}_{2} \times 10^{6}\right.$ in g/min) } \\
\hline Water & $\begin{array}{c}\text { Mean } \\
(\mathrm{n}=3)\end{array}$ & $\mathrm{SD}$ & Mean (n=3) & $\mathrm{SD}$ & $\mathrm{Mean}(\mathrm{n}=3)$ & $\mathrm{SD}$ \\
\hline activity & 20.0 & 0.00 & 30.0 & 0.00 & 40.0 & 0.00 \\
\hline 0.17 & 26.7 & 5.77 & 46.7 & 5.77 & 60.0 & 0.00 \\
\hline 0.34 & 63.3 & 11.5 & 83.3 & 5.77 & 100.0 & 0.00 \\
\hline 0.51 & 6.0 & 10.0 & 100.0 & 0.00 & 200.0 & 0.00 \\
\hline 0.68 & 80.0 &
\end{tabular}


Table 3: Results of BET and GAB model fits for glyceryl behenate and polyvinyl alcohol films at varying temperatures. (th) indicates films of greater thickness and BET results are valid for $0.17 \leq \mathrm{a}_{\mathrm{w}} \leq 0.51$

\begin{tabular}{|c|c|c|c|c|c|c|}
\hline \multicolumn{7}{|c|}{ BET data for glyceryl behenate films } \\
\hline$T(K)$ & Slope & Intercept & $C_{B E T}$ & \multicolumn{2}{|c|}{$V_{m}$ (g of water/g of film) } & $H_{s}(J /$ mole $)$ \\
\hline & & & & \multirow{2}{*}{\multicolumn{2}{|c|}{$4.546 \times 10^{-4}$}} & \\
\hline 293 & 1244.2 & 955.63 & 2.302 & & & 2031.05 \\
\hline 303 & 491.15 & 752.93 & 1.652 & \multicolumn{2}{|c|}{$8.038 \times 10^{-4}$} & 1264.62 \\
\hline \multicolumn{7}{|c|}{ BET data for PVA films } \\
\hline 293 & -19.14 & 36.94 & 0.482 & \multicolumn{2}{|c|}{$5.618 \times 10^{-2}$} & -1778.52 \\
\hline 313 & 11.24 & 21.11 & 1.532 & \multicolumn{2}{|c|}{$3.092 \times 10^{-2}$} & 1110.07 \\
\hline 303 (th) & -764.35 & 846.61 & 0.099 & \multicolumn{2}{|c|}{$1.187 \times 10^{-2}$} & -5818.44 \\
\hline \multicolumn{7}{|c|}{ GAB data for GB films } \\
\hline$T(K)$ & $K$ & $C_{G A B}$ & \multicolumn{2}{|c|}{$\begin{array}{c}V_{m}(g \text { of water } / g \text { of } \\
\text { film) }\end{array}$} & $H_{1}-H_{m}(J /$ mole $)$ & $\begin{array}{c}H_{L}-H_{m} \\
(\mathrm{~J} / \text { mole })\end{array}$ \\
\hline 293 & 0.8361 & 1.948 & \multicolumn{2}{|c|}{$6 \times 10^{-4}$} & 1624.39 & -436.08 \\
\hline 303 & 0.7655 & 1.087 & \multicolumn{2}{|c|}{$15 \times 10^{-4}$} & 210.16 & -673.20 \\
\hline 313 & 0.8974 & 0.767 & \multicolumn{2}{|c|}{$30 \times 10^{-4}$} & -691.35 & -281.72 \\
\hline 303 (th) & 0.9834 & 0.535 & \multicolumn{2}{|c|}{$10 \times 10^{-4}$} & -1575.75 & -42.17 \\
\hline \multicolumn{7}{|c|}{ GAB data for PVA films } \\
\hline 293 & 0.9291 & 0.365 & \multicolumn{2}{|c|}{0.080} & -2455.23 & -179.15 \\
\hline 303 & 0.8567 & 0.501 & \multicolumn{2}{|c|}{0.080} & -1741.17 & -389.64 \\
\hline 313 & 0.9570 & 1.430 & \multirow{2}{*}{\multicolumn{2}{|c|}{0.034}} & 930.26 & -114.38 \\
\hline 303 (th) & 1.0850 & 0.238 & & & -3612.09 & 205.52 \\
\hline
\end{tabular}


Table 4: Estimates of Young and Nelson model parameters A, B and E used to describe hysteresis in sorption data at various temperatures for glyceryl behenate and polyvinyl alcohol films.

\begin{tabular}{|c|c|c|c|c|c|}
\hline Excipient film & $T(K)$ & $A$ & $B$ & $E$ & $\mathrm{q}_{\mathrm{L}}-\mathrm{q}_{1}(\mathrm{~J} / \mathrm{mole})$ \\
\hline GB & 293 & $<10^{-11}$ & $1.58 \times 10^{-3}$ & 0.0341 & -8230.23 \\
\hline GB & 303 & $<10^{-11}$ & $2.94 \times 10^{-3}$ & 0.1685 & -4486.30 \\
\hline GB & 313 & $<10^{-11}$ & $6.65 \times 10^{-3}$ & 0.3749 & -2553.18 \\
\hline GB (thick) & 303 & 0.00 & $2.184 \times 10^{-3}$ & 0.0294 & -8884.41 \\
\hline PVA & 293 & $\begin{array}{c}49.59 \times \\
10^{-3}\end{array}$ & $98.17 \times 10^{-3}$ & 2.696 & 2416.04 \\
\hline PVA & 303 & $\begin{array}{c}53.04 \times \\
10^{-3}\end{array}$ & $26.96 \times 10^{-3}$ & 1.908 & 1627.56 \\
\hline PVA & 313 & $\begin{array}{c}54.03 \times \\
10^{-3}\end{array}$ & $5.84 \times 10^{-3}$ & 1.696 & 1374.76 \\
\hline \multicolumn{7}{|l|}{} \\
\hline PVA (thick) & 303 & 0.00 & $110.1 \times 10^{-3}$ & 4.049 & 3522.94 \\
\hline
\end{tabular}


Figure 1: Schematic representation of the dynamic vapor sorption technique apparatus

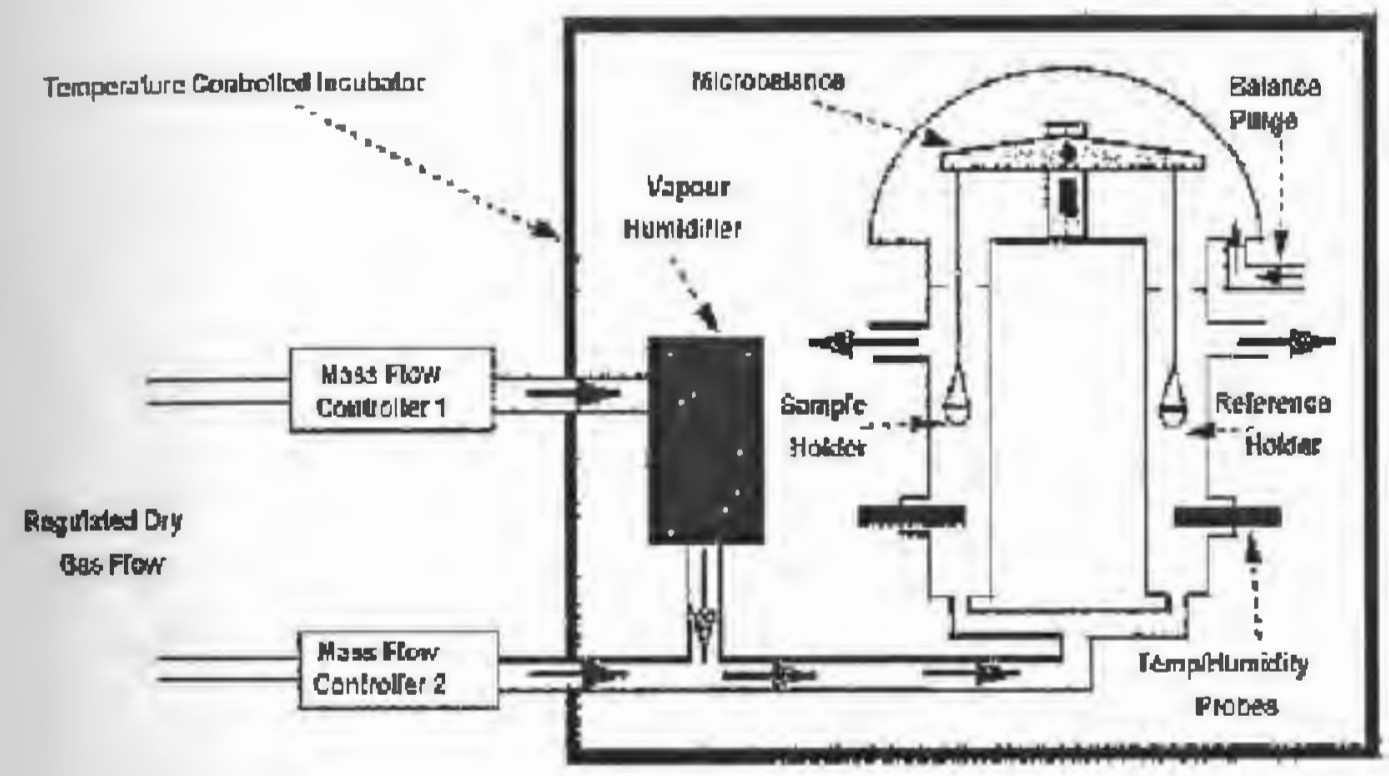


Figure 2: Sorption isotherms for glyceryl behenate film at various temperatures. Values of equilibrium moisture content (V) are mean of $n=3$

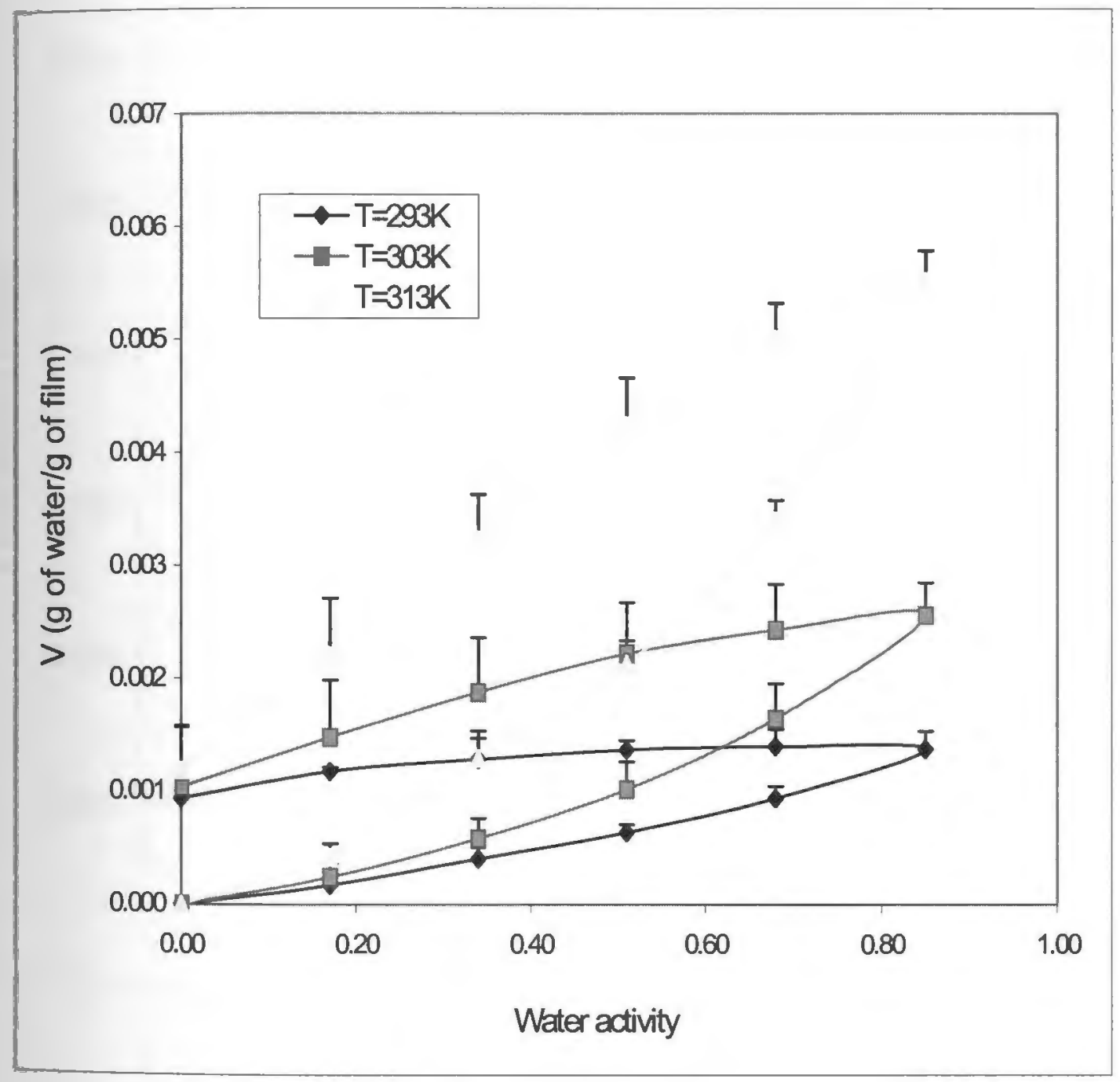


Figure 3: Sorption isotherms for polyvinyl alcohol film at various temperatures. Values of equilibrium moisture content (V) are mean of $n=3$

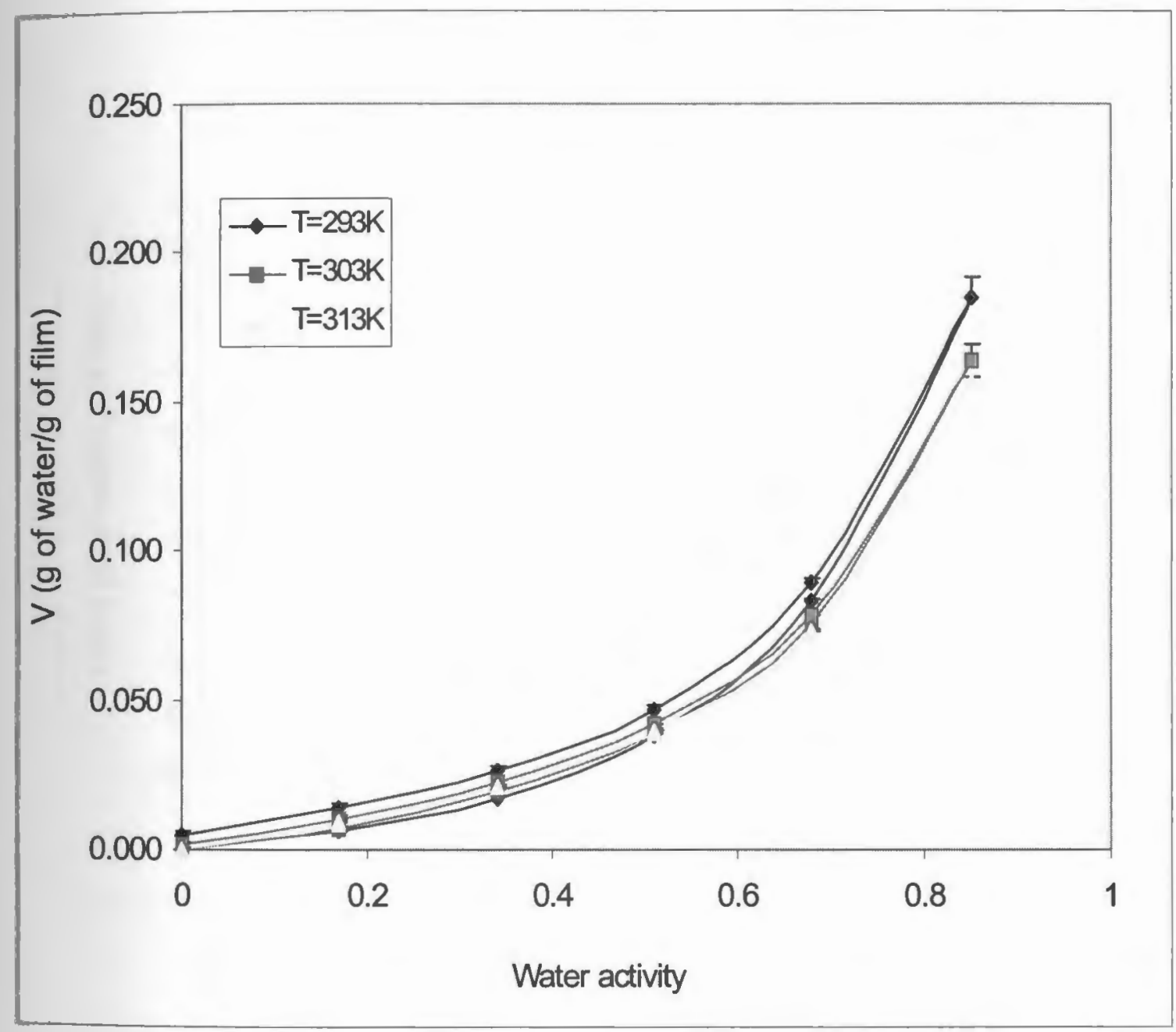


Figure 4: Arrhenius plots of mean equilibrium moisture content $(V$ and $n=3)$ at constant water activity for glyceryl behenate film (solid lines are best fit lines)

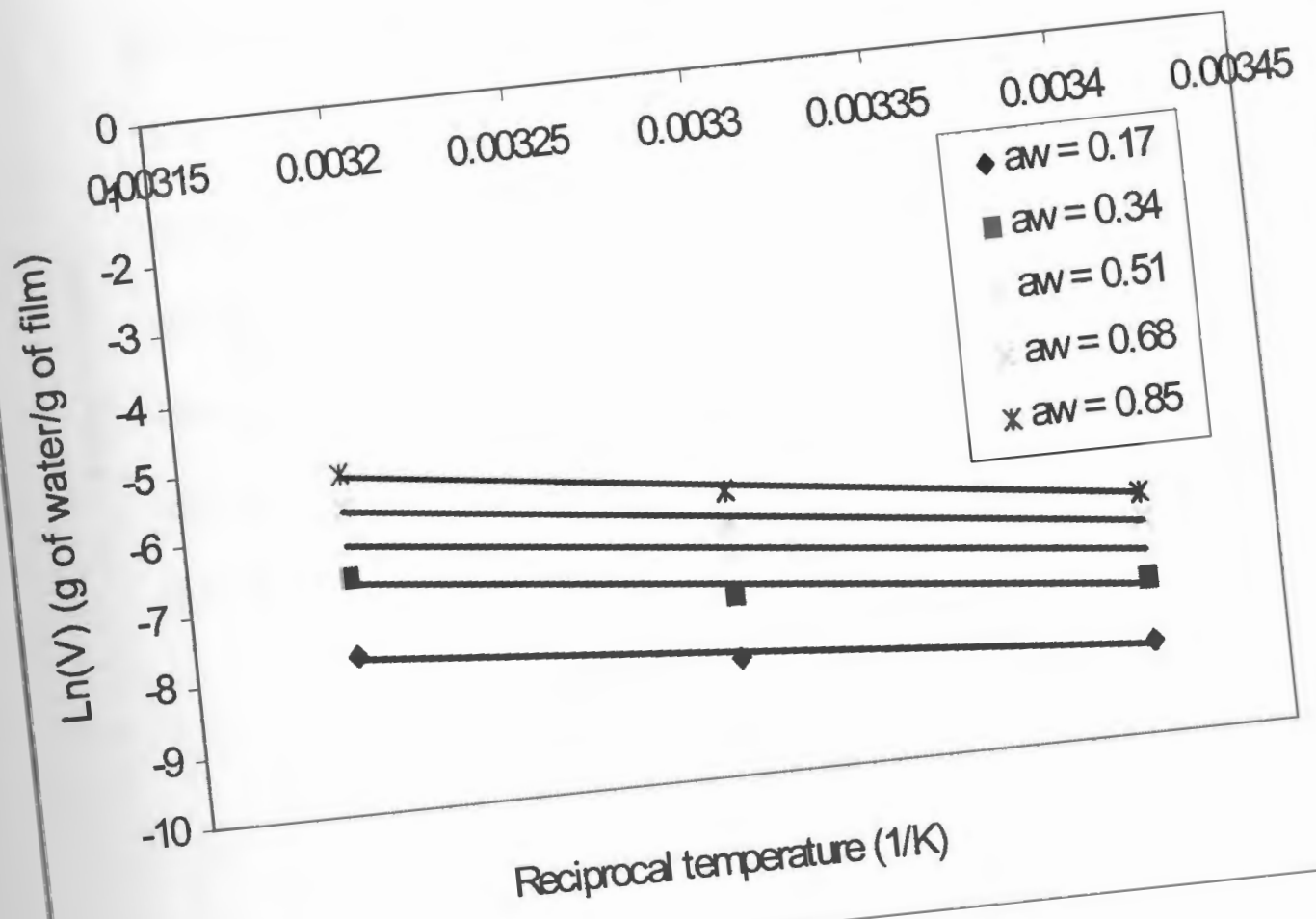


Figure 5: Variation in energy of sorption $\left(\mathrm{E}_{\text {sorp }}\right)$ for glyceryl behenate and polyvinyl alcohol films (solid lines are best fit lines)

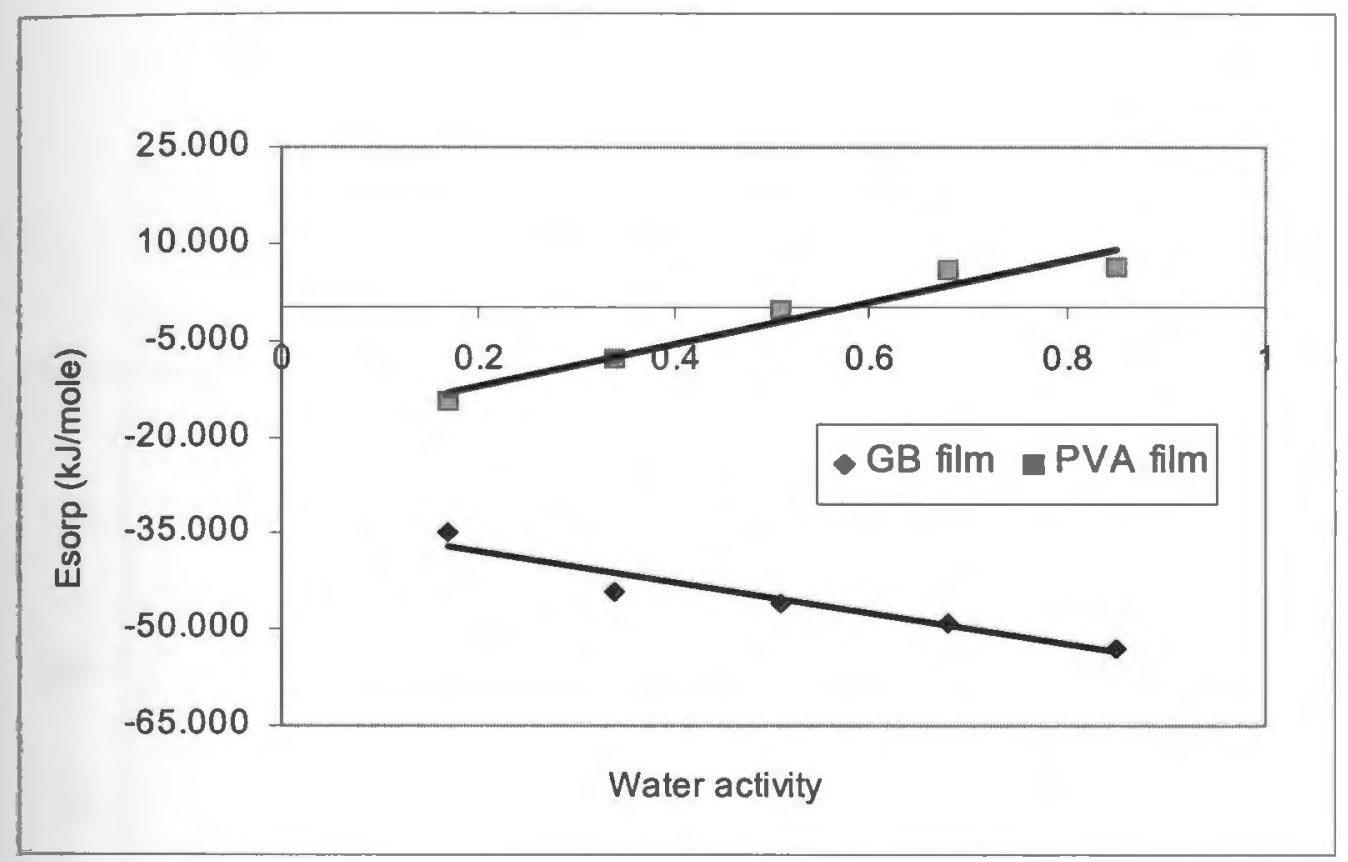


Figure 6: Fit of sorption data using GAB model for polyvinyl alcohol film at $\mathrm{T}=293 \mathrm{~K}$, • indicates actual data and — represents the fitted data obtained by nonlinear regression. $1 / V$ is the reciprocal of mean equilibrium moisture $(n=3)$.

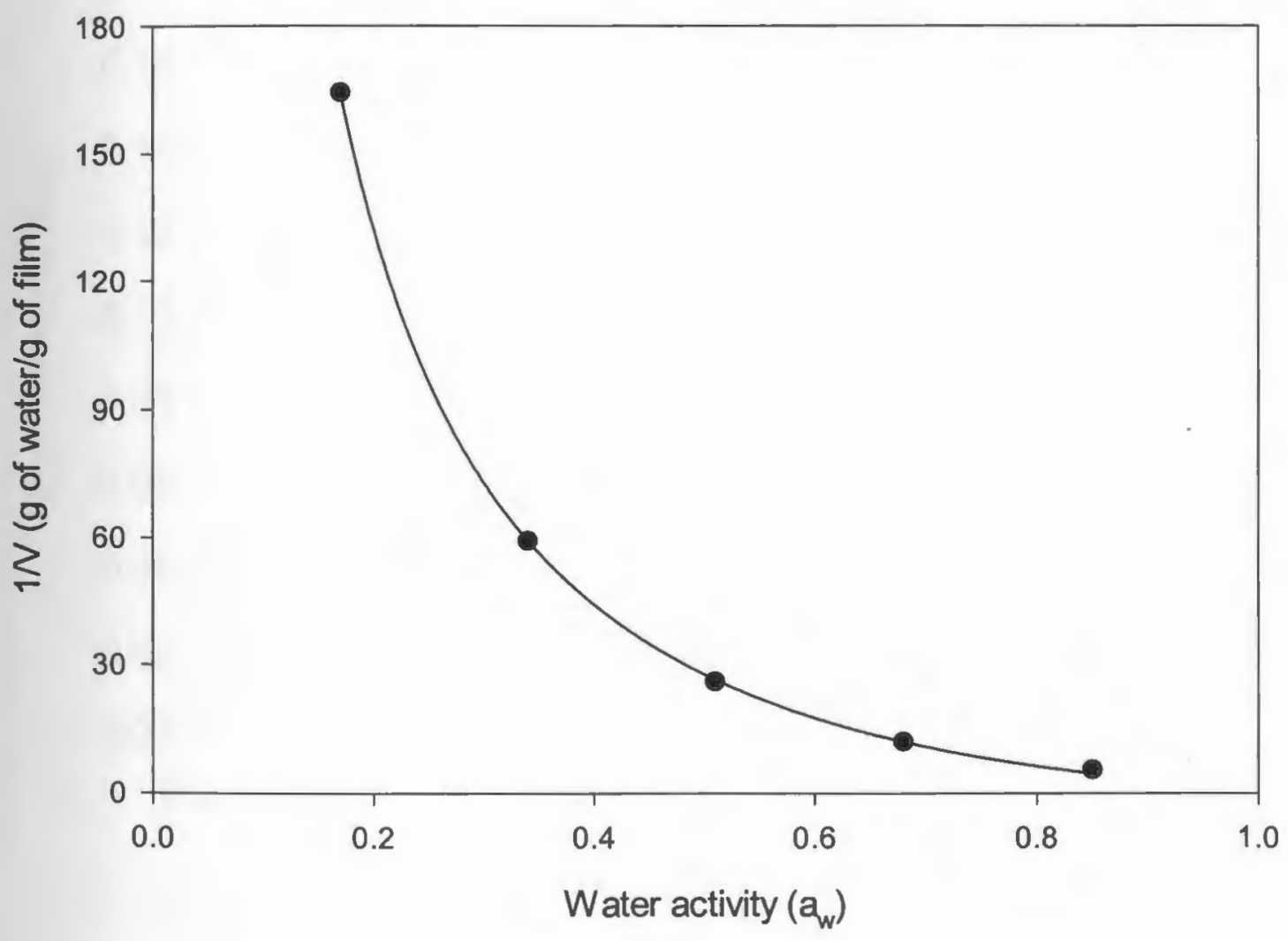


Figure 7: Comparative sorption isotherms of actual and predicted data obtained using

Young and Nelson model for polyvinyl alcohol film at $\mathrm{T}=303 \mathrm{~K}$. V is mean equilibrium moisture content $(n=3)$.

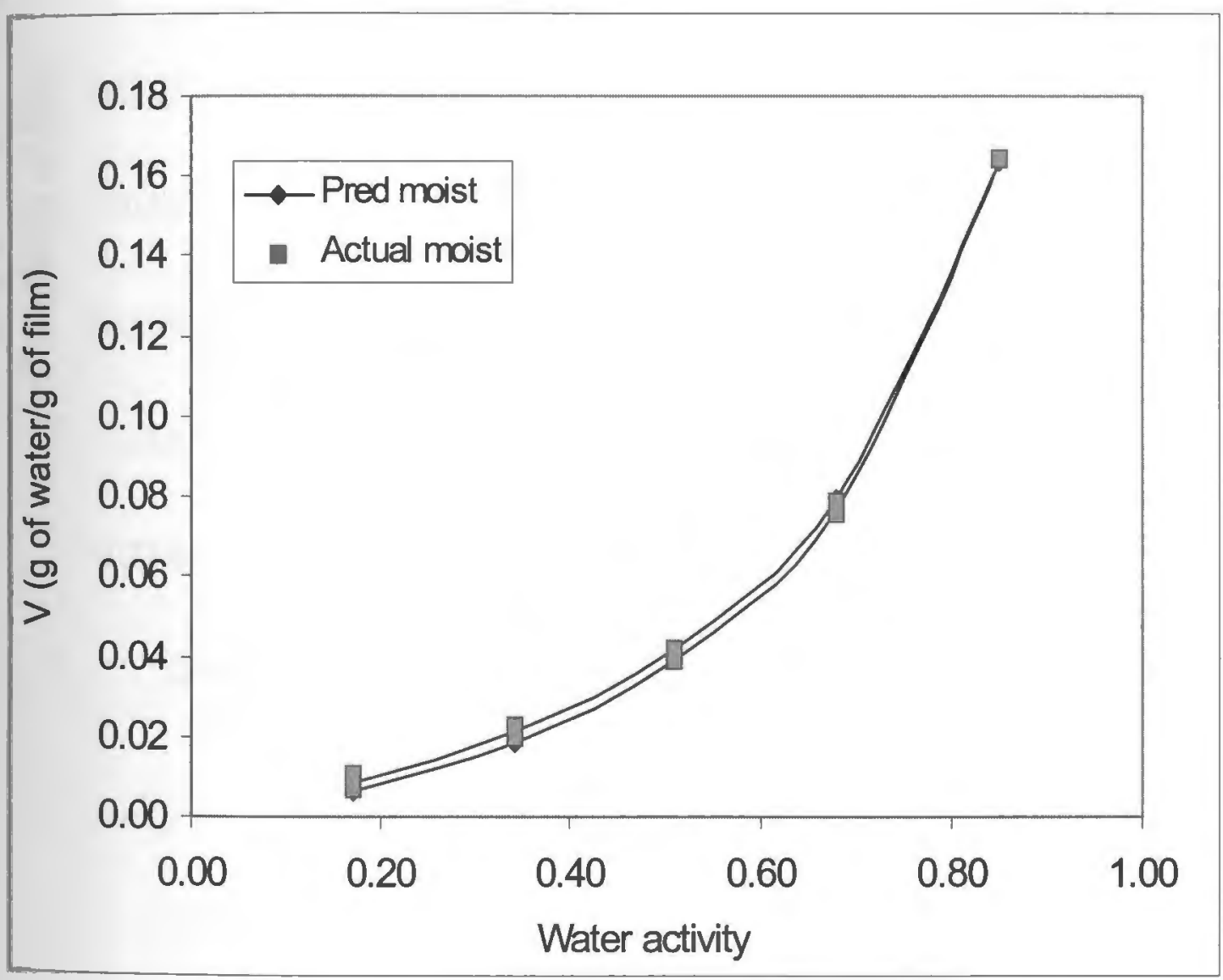


Figure 8: Comparative sorption isotherms for glyceryl behenate films of varying thickness at $T=303 \mathrm{~K} . \mathrm{V}$ is mean equilibrium moisture content $(\mathrm{n}=3)$.

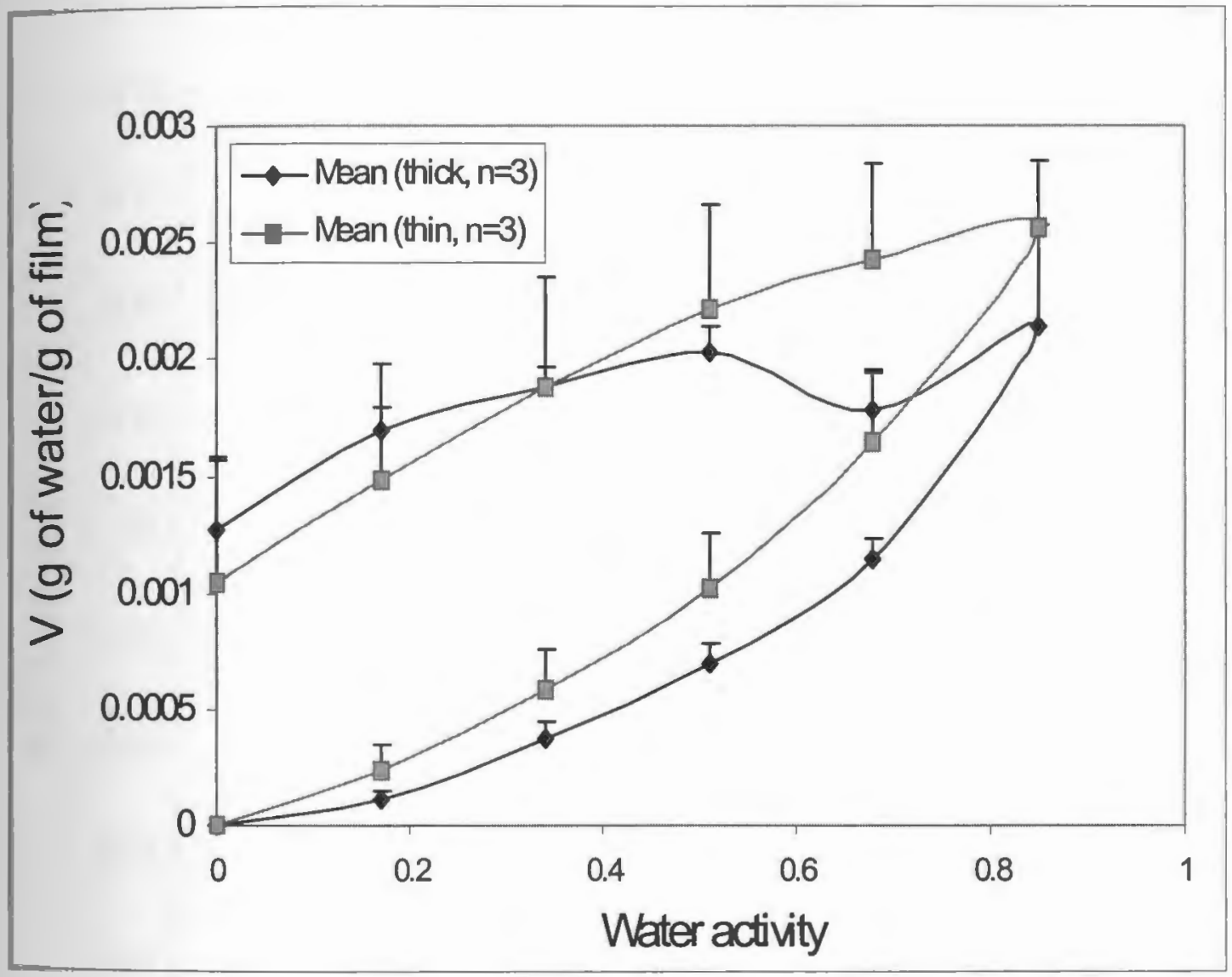


Figure 9: Comparative sorption isotherms for polyvinyl alcohol films of varying thickness at $T=303 \mathrm{~K} . \mathrm{V}$ is mean equilibrium moisture content $(\mathrm{n}=3)$.

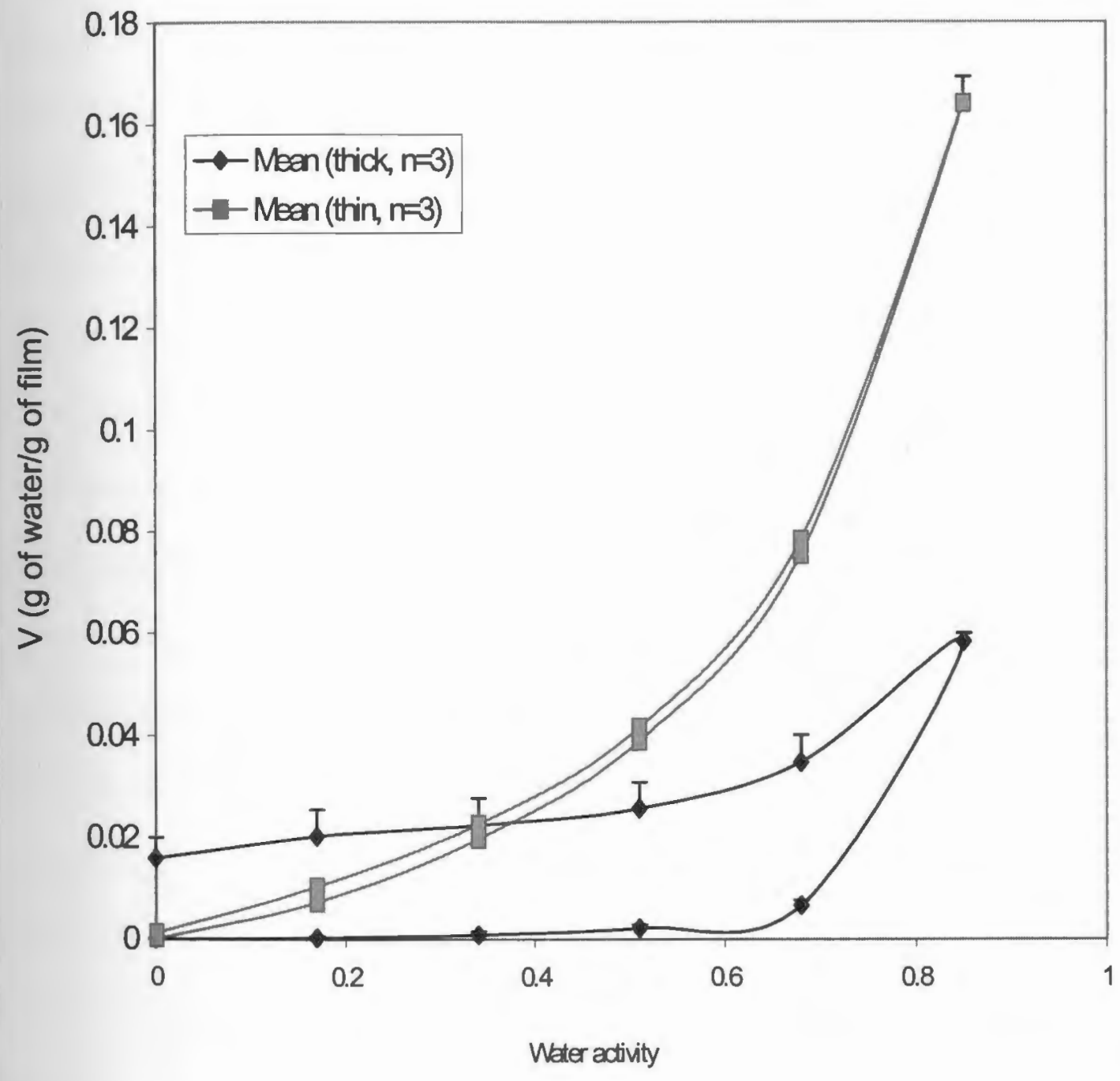




\section{MANUSCRIPT III}

Thermodynamic analysis of water interaction with excipient films 
Abstract

The interaction of water with excipients that can form moisture protective coatings was examined earlier by the application of theoretical models. In this study, thermodynamic analysis of water-excipient film systems has been performed to elucidate the mechanistic details of the water-excipient interaction. Partial molal free energies, enthalpies and entropies were computed for films of lipidic (glyceryl behenate) and polymeric (polyvinyl alcohol) coating excipients using the temperature dependence of the adsorption process. The analysis of free energy changes showed that excipient films were not inert participants in the water sorption process. The isoteric heats of adsorption confirmed that water formed hydrogen bonds with the excipient films and allowed estimation of number of hydrogen bonds per water molecule. This result also provided the reason for hysteresis during drying. A comparative evaluation of the application of theoretical models and thermodynamic analysis revealed that results obtained from both approaches were not always complementary in nature. An exponential relationship was found to exist between sorption microrate constants and water activity for the polyvinyl alcohol films at all temperatures. 


\section{Introduction}

The quantity and state of moisture present in a pharmaceutical excipient can profoundly influence the performance of the final dosage form of which it is a component. This is particularly important for excipients that can encapsulate solid dosage forms to offer protection from the adverse effects of moisture. Hence, it is important to study the interaction of water with excipient films that are applied to form a moisture protective coating over the drug laden substrate. In an earlier report, water sorption behavior of films of glyceryl behenate (GB), a hydrophobic waxy excipient and a formulation of polyvinyl alcohol (PVA), a novel polymeric aqueous film coating excipient for moisture protective applications was described using the powerful new technique of dynamic vapor sorption (DVST) (1).

Previously, established theoretical models of sorption and desorption were employed to understand the water-excipient film interaction as a function of temperature and film thickness. Although application of theoretical models is analytically useful, it does not facilitate comprehensive characterization due to the limited validity of assumptions upon which the model was developed. Hence, an investigation of the thermodynamics of water-excipient film systems is necessary to clarify the process of water sorption/desorption. It is the objective of this report to perform a complete thermodynamic analysis of the process by which water interacts with GB and PVA films as temperature varies. Further, the results of this analysis will elucidate the mechanism by which water interacts with these excipient films. A second objective was to perform a comparative evaluation of the results obtained through the application of theoretical models and thermodynamic analysis. 
2. Materials and methods

Glyceryl behenate (Compritol 888 ATO, Lot \# A17008) and polyvinyl alcohol (Opadry AMB OY-B-28920, Lot \# 5066503) were obtained from Gattefossé, Saint Priest, France and Colorcon, West Point, USA respectively. Films of GB and PVA of varying thickness (thin and thick) were cast. The sorption/desorption isotherms for GB and PVA thin films at $\mathrm{T}=293,303$ and $313 \mathrm{~K}$ are presented in figures 1 and 2 respectively. The thick films were studied for comparison at $\mathrm{T}=303 \mathrm{~K}$ only. The smoothed adsorption and desorption data was obtained from the isotherms by extrapolating the water activity values corresponding to amount of water ( $\mathrm{n}_{2}$ in $\mathrm{mmol}$ of water $/ 100 \mathrm{~g}$ of film) by manual graphing. An example of the smoothed adsorption data is shown in table 1. All details of the experimental methods have been described in an earlier report and have not been repeated here (1).

\section{Theoretical}

The method of Tabibi and Hollenbeck based on the thermodynamic theory developed by Copeland and Young has been used to study the thermodynamics of water-excipient film systems $(2,3)$. Standard free energy relations were used to calculate the following thermodynamic properties:

$$
\begin{aligned}
& \Delta G_{2}=R T(\ln a) \\
& n_{1} \Delta G_{1}=-R T \int_{0}^{a} n_{2} d(\ln a) \\
& \Delta G=n_{1} \Delta G_{1}+n_{2} \Delta G_{2} \\
& \Delta G_{2 h}=R T \ln \left(\frac{a_{d}}{a_{s}}\right)
\end{aligned}
$$


The subscripts 1 and 2 have been used to represent the excipient film (adsorbent) and water (adsorbate) respectively. $\Delta \mathrm{G}_{1}$ and $\Delta \mathrm{G}_{2}$ are the relative partial molal free energy changes of the excipient and water respectively, $n_{1}$ and $n_{2}$ are the number of moles of excipient and water involved in the sorption process respectively, $\Delta \mathrm{G}$ is the integral free energy change associated with the adsorption process, $a$ is water activity, $R$ is the universal gas constant and T is absolute temperature. $\Delta \mathrm{G}_{2 \mathrm{~h}}$ is the free energy change of water associated with the hysteresis phenomenon, and $a_{d}$ and $a_{s}$ denote the water activity during desorption and sorption phases respectively. The quantity $n_{1} \Delta G_{1}$ was determined graphically by plotting $\left(\mathrm{n}_{2} / \mathrm{a}\right)$ versus a, and the area under the curve was computed using the trapezoidal rule (4). The temperature dependence of the sorption process was used to compute the isoteric (equal coverage) heats of adsorption in the following manner:

$$
\Delta H=\left[\frac{\partial\left(\frac{\Delta G}{T}\right)}{\partial\left(\frac{1}{T}\right)}\right]
$$

The appropriate free energy changes were used to compute the corresponding $\Delta H$ values for water, excipient film and total process. The general definition of entropy:

$$
\Delta S=\left(\frac{(\Delta H-\Delta G)}{T}\right)
$$

was used to compute the entropy changes using the appropriate enthalpy and free energy changes for the water-excipient film systems at various temperatures.

\section{Results and discussion}

4.1. Free energy changes 
Relative partial molal free energy change of water $\left(\Delta \mathrm{G}_{2}\right)$, weighted relative partial molal free energy of water $\left(\mathrm{n}_{2} \Delta \mathrm{G}_{2}\right)$ and excipient film $\left(\mathrm{n}_{1} \Delta \mathrm{G}_{1}\right)$ along with the integral free energy of adsorption $(\Delta \mathrm{G})$ were computed. Figures 3 and 4 respectively present $\Delta \mathrm{G}_{2}$ as a function of water sorbed for GB and PVA thin films at different temperatures. The relative partial molal free energy change of water reflects the difference between adsorption of one mole of water on the excipient film and water, i.e., pure water is used as the standard state. As expected, the greater the dryness of the excipient film the larger is this quantity $\left(\Delta \mathrm{G}_{2}\right)$, with the negative sign indicating the spontaneous nature of the adsorption process. From figure 3, for the GB thin film, two points of inflection may be noted at all temperatures in the otherwise monotonous curves. At $\mathrm{T}=313 \mathrm{~K}$, the inflection points occur at about $3 \mathrm{mmol}$ and $8 \mathrm{mmol}$ of water $/ 100 \mathrm{~g}$ of film. These inflections possibly reflect the completion of monolayer formation and subsequent additional layers of water sorption. For PVA thin film, the inflection points were recorded at about 100 mmol and $250 \mathrm{mmol}$ of water $/ 100 \mathrm{~g}$ of film. Examination of similar plots for thin and thick films of GB and PVA revealed a dramatic difference only in case of PVA. The thick PVA film displayed a very low $\Delta \mathrm{G}_{2}$ value suggesting that the drying of the thin film prior to conducting the sorption experiment was more successful.

The contribution of water to the overall free energy change associated with the adsorption process is given by the product, $\mathrm{n}_{2} \Delta \mathrm{G}_{2}$. While the thermodynamic quantities of water are important, they do not fully characterize the adsorption process unless the adsorbent (excipient film) is inert. Hence, it is desirable to examine the relative partial molal free energy change of the adsorbent, $\Delta \mathrm{G}_{1}$, but unfortunately the term $\mathrm{n}_{1} \Delta \mathrm{G}_{1}$ cannot be separated. The quantity $n_{1}$ denotes the number of moles of the excipient in the film 
surface that actually participate in the adsorption process. As it is impossible to determine the number of layers of the excipient film involved in the sorption process, $\mathrm{n}_{1}$ cannot be determined. Also, $\mathrm{n}_{1}$ is not constant and varies with $\mathrm{n}_{2}$. Hence, the effect of adsorption on the adsorbent and adsorbate has been studied by comparing the quantities $n_{1} \Delta G_{1}, n_{2} \Delta G_{2}$ and $\Delta \mathrm{G}$. These quantities for GB and PVA thin films at $\mathrm{T}=303 \mathrm{~K}$ have been presented in figures 5 and 6 respectively.

For both films, the quantity $n_{2} \Delta G_{2}$, decreases initially to attain a minima (about 4 mmol of water/100g of GB film and $200 \mathrm{mmol}$ of water/100g of PVA film). Following additional water sorption there is a plateau region that is followed by an increasing trend in the quantity. It seems useful to divide the $\mathrm{n}_{2} \Delta \mathrm{G}_{2}$ curve into three distinct regions: region $\mathrm{A}$, representing the decreasing part up to attainment of minima, region $\mathrm{B}$, indicating the plateau region and region $\mathrm{C}$, indicating the increasing trend in $\mathrm{n}_{2} \Delta \mathrm{G}_{2}$. It is believed that these three regions signify completion of monolayer, formation of intermediate layers and finally bulk water respectively. Also, in region A the most dramatic changes occur for water as the film is dry initially and the magnitude of $n_{2} \Delta G_{2}$ at the minima is suggested to be an indicator of the affinity of water to the solid. Comparison of $\mathrm{n}_{2} \Delta \mathrm{G}_{2}$ minima at $\mathrm{T}=303 \mathrm{~K}$ for GB and PVA thin films (about $10 \mathrm{~J} / \mathrm{mol}$ for GB film and $400 \mathrm{~J} / \mathrm{mol}$ for PVA film) shows that water has greater affinity for PVA film. Interestingly, the quantity, $\mathrm{n}_{1} \Delta \mathrm{G}_{1}$, for both excipient films displayed a monotonous decrease with increasing water sorption. Although, minor inflections were observed, the decrease was almost linear. Consequently, the assumption of inertness of the excipient during the sorption process is certainly not valid. It has been suggested that this perturbation of the film surface becomes very significant after specific sites of adsorption 
have been saturated (5). It is also believed that in region A, the film surface is actually restructured due to the interaction with water and this altered surface serves as the substrate for subsequent adsorption. Surprisingly, the integral free energy function $(\Delta \mathrm{G})$ is deceptively smooth and follows a monotonic decline. This observation emphasizes the need to examine the relative contributions of water and the excipient film and proves them to be more informative. The behavior described here was consistently observed for GB and PVA films under all conditions of study.

It is evident from figures 1 and 2 that both GB and PVA films exhibit hysteresis during desorption. Assuming that the adsorbed and desorbed states reflect different equilibrium positions, the partial molal free energy of water (adsorbate) in the adsorbed and desorbed states may be examined. As stated earlier, $\Delta \mathrm{G}_{2 \mathrm{~h}}$ is the excess partial molal free energy of water due to hysteresis phenomena. Actually, $\Delta \mathrm{G}_{2 \mathrm{~h}}$ is the partial molal free energy of water using the sorption part of the isotherm as the standard state. Figures 7 and 8 show the $\Delta G_{2 h}$ values computed for $G B$ and PVA thin films at varying temperatures respectively. $\Delta \mathrm{G}_{2 \mathrm{~h}}$ values for GB film increase rapidly upto $8 \mathrm{mmol}$ of water $/ 100 \mathrm{~g}$ of film. Afterwards, the rate of approach to $\Delta \mathrm{G}_{2 \mathrm{~h}}=0$ slows down significantly. Similar behavior was noticed for PVA thin film with the inflection point being approximately at $150 \mathrm{mmol}$ of water $/ 100 \mathrm{~g}$ of film. At $\mathrm{T}=313 \mathrm{~K}$, there was practically no hysteresis observed for the PVA film. When $\Delta G_{2 h}$ values for GB and PVA films were plotted at $\mathrm{T}=303 \mathrm{~K}$ to examine the effect of film thickness, substantial differences were observed although the general behavior remained same as described above.

\subsection{Isoteric heats of adsorption}


Figures 9 and 10 respectively show $\Delta \mathrm{H}_{2}$ for GB and PVA thin films at different temperatures. At $\mathrm{T}=303 \mathrm{~K}$ for the GB film, five exothermic maxima (at $\mathrm{n}_{2} \cong 0.75,1.25$, $1.75,2.25$ and $3.25 \mathrm{mmol} / 100 \mathrm{~g}$ of film) were observed. But at $\mathrm{T}=313 \mathrm{~K}$, only three exothermic maxima (at $\mathrm{n}_{2} \cong 0.25,5.50$ and $7.25 \mathrm{mmol} / 100 \mathrm{~g}$ of film) were noticed highlighting the differences in $\Delta \mathrm{H}_{2}$ profiles at different temperatures. The $\Delta \mathrm{H}_{2}$ function flattens out after $\mathrm{n}_{2} \cong 4 \mathrm{mmol} / 100 \mathrm{~g}$ of film at $\mathrm{T}=303 \mathrm{~K}$, whereas the same shows an increasing trend at amount of water above $\mathrm{n}_{2} \cong 8 \mathrm{mmol} / 100 \mathrm{~g}$ of film at $\mathrm{T}=313 \mathrm{~K}$. These exothermic maxima denote the completion of tightly bounded monolayer, followed by additional intermediate layers. In the region where $\Delta \mathrm{H}_{2}$ shows an increasing trend after the last exothermic maxima, water molecules progressively assume a more liquid like structure (i.e. bulk water).

From the studies of Texter et al., the energy values at exothermic maxima can provide further details of the nature of water interaction (6). The first exothermic maxima of about $20 \mathrm{~kJ} / \mathrm{mol}(64 \mathrm{~kJ} / \mathrm{mol}$ when water vapor is the reference) indicates that each water molecule is involved in two hydrogen bonds. Similarly at $\mathrm{T}=313 \mathrm{~K}$, an energy value of $90 \mathrm{~kJ} / \mathrm{mol}$ suggests the formation of three hydrogen bonds per water molecule. Examination of $\Delta \mathrm{H}_{2}$ profiles for PVA thin films showed similar behavior except for the differences in energy values at exothermic maxima. At $\mathrm{T}=303 \mathrm{~K}$, a maxima of $60 \mathrm{~kJ} / \mathrm{mol}$ suggests formation of two hydrogen bonds per water molecule and at $\mathrm{T}=313 \mathrm{~K}, 90 \mathrm{~kJ} / \mathrm{mol}$ denotes three hydrogen bonds per water molecule. It must be noted that the values of the exothermic maxima are in agreement with the reported range of $60-90 \mathrm{~kJ} / \mathrm{mol}$ believed to indicate chemisorption. This observation corroborates our earlier hypothesis of chemisorption through formation of irreversible hydrogen bonds with the excipient films. 
In addition to the enthalpy changes of water it is also useful to investigate the functions $\Delta H, n_{1} \Delta H_{1}$ and $n_{2} \Delta H_{2}$. Figure 11 presents these functions for the GB thin film at $\mathrm{T}=303 \mathrm{~K}$. As in case of free energy changes, the $\Delta \mathrm{H}$ function is smooth and shows a linear increase, whereas $n_{1} \Delta H_{1}$ and $n_{2} \Delta H_{2}$ functions are more informative due to the inflection points (although minor). The enthalpy function of water progressively decreases, whereas the same for the excipient film steadily increases. Similar behavior was observed at $\mathrm{T}=313 \mathrm{~K}$ also. Similar plots of $\Delta \mathrm{H}, \mathrm{n}_{1} \Delta \mathrm{H}_{1}$ and $\mathrm{n}_{2} \Delta \mathrm{H}_{2}$ for PVA thin film at $\mathrm{T}=303 \mathrm{~K}$ shown in figure 12 are quite different. The $\Delta \mathrm{H}$ function increases upto $\mathrm{n}_{2}=250 \mathrm{mmol} / 100 \mathrm{~g}$ of film and then decreases slowly. The $\mathrm{n}_{2} \Delta \mathrm{H}_{2}$ function rapidly attains a minima followed by a progressive increase, whereas $n_{1} \Delta H_{1}$ curve reaches a maxima wherefrom a rapid decline is observed. These functions behaved in the same manner at $\mathrm{T}=313 \mathrm{~K}$ also.

\subsection{Entropy changes}

Figures 13 and 14 respectively show the entropy variation for water $\left(\Delta S_{2}\right)$ for GB and PVA thin films. Interestingly, the entropy profiles are very similar to the enthalpy profiles discussed earlier. This similarity arises from the fact that $\Delta \mathrm{G}_{2}$ as discussed earlier shows dramatic changes only in the lower coverage regions and then flattens out. Combining this observation with the formula used for $\Delta S_{2}$ computation, differences are evident only in the lower coverage areas with the shapes of the curves remaining similar. The initial rapid decrease in entropy indicates the lack of mobility as water molecules adsorb on to the film surface in a tightly bound manner. As additional water is sorbed the disorder and mobility increases due to the formation of clusters of water molecules around the sorbed water. At greater water content, the formation of two or three- 
dimensional condensed surface phases is observed requiring that water molecules lose part of their translational entropy due to lateral hydrogen bonding (5).

Examination of $n_{1} \Delta S_{1}, n_{2} \Delta S_{2}$ and $\Delta S$ was also performed. As discussed these functions were entirely consistent with the profiles of $n_{1} \Delta H_{1}, n_{2} \Delta H_{2}$ and $\Delta H$ described earlier. For the GB film, the $n_{2} \Delta S_{2}$ function showed a monotonic decline whereas $n_{1} \Delta S_{1}$ and $\triangle S$ showed a monotonic increase at both temperatures. In case of PVA thin film, $n_{1} \Delta S_{1}$ and $\Delta S$ showed initial increase and then remained constant whereas $n_{2} \Delta S_{2}$ decreased initially followed by a progressive increase at both temperatures.

\subsection{Behavior of microrate constants}

In an earlier report, sorption and desorption microrate constants for both excipient films at various temperatures were estimated. From the results of this analysis the desorption microrate constants are not true estimates as the excipient films undergo a change due to hydrogen bonding with the water molecules and upon completion of drying, equilibrium state is not achieved. Hence, the variation of sorption microrate constants with temperature has only been examined here. Only PVA thin film data was used as the GB film data showed wide variation. Figure 15 shows the plots of $\ln \left(\mathrm{k}_{1}\right)$ versus water activity at three different temperatures. It is interesting to note that these plots are linear suggesting an exponential type relationship between sorption microrate constants and water activity. Upon linear regression analysis, the fits were excellent $\left(R^{2}>0.97\right.$ in all cases) and the estimated slopes were very similar $(2.12$ at $T=313 \mathrm{~K}, 2.43$ at $\mathrm{T}=303 \mathrm{~K}$ and 2.49 at $\mathrm{T}=293 \mathrm{~K}$ ). These results suggest the utility of these relationships in predicting sorption microrate constants at varying water activity and temperature.

\subsection{Comparative evaluation}


A comparative evaluation of the results obtained by application of theoretical models and thermodynamic analysis was performed to understand the nature of information elicited from each method of analysis. The successful fit of GAB model to sorption data suggested the existence of water in three different states and this observation has been corroborated by the results of the thermodynamic study. However, there was very poor agreement between the monolayer values $\left(V_{m}\right)$ computed through the use of GAB model and thermodynamic analysis. The observation of type III isotherms suggesting the heat of sorption of water in the first layer to be less than the same in intermediate layers has been verified through the computation of isoteric heats of adsorption for both excipients.

Whereas the theoretical models assumed inertness of the excipient films in the sorption process, the results from the thermodynamic study have proven this assumption to be invalid. The postulate of hydrogen bonding between water molecules and excipient films to explain hysteresis upon drying has been confirmed. Further, the energy values corresponding to the exothermic maxima (in $\Delta \mathrm{H}_{2}$ curves) facilitated the determination of number of hydrogen bonds formed per water molecule. Theoretical models are useful from an analytical and predictive/modeling perspective (quantitative aspects) and thermodynamic analysis allows clarification of mechanistic details (qualitative aspects) in studying water interaction with excipient film systems.

\section{Conclusions}

The results from both studies clearly show that for comprehensive elucidation of water interaction phenomena with excipient films it is necessary to employ both, 
application of theoretical models and thermodynamic analysis. It can be inferred that application of theoretical models facilitates comprehension of quantitative aspects and thermodynamic analysis provides qualitative aspects of water sorption phenomena. Results from both studies confirm that sorbed water exists in three different states: one tightly bound layer, additional less tightly bound layers and bulk water. This study has confirmed that due to irreversible hydrogen bonding between water and the excipient films, hysteresis is observed upon isothermal drying. Relative partial molal free energies of the adsorbent (excipient films) have shown the assumption of inertness of adsorbent in the adsorption process to be incorrect. It has also been found that sorption microrate constants increased exponentially with water activity for the PVA thin film at all temperatures studied.

\section{Acknowledgements}

The generous financial support of, access to laboratory and library facilities of SmithKline Beecham Corporation is most gratefully acknowledged.

\section{$\underline{\text { References }}$}

1. A.S. Achanta, P.S. Adusumilli, K.W. James and C.T. Rhodes, Hot melt coating: water sorption behavior of excipient films (to be submitted for publication in Drug Dev. \& Ind. Pharm.)

2. L.E. Copeland and T.F. Young, Adv. Chem. Series, 33, 348-355 (1961).

3. S.E. Tabibi and R.G. Hollenbeck, Int. J. Pharm., 18, 169-183 (1984). 
4. R.G. Hollenbeck, G.E. Peck and D.O. Kildsig, J. Pharm. Sci., 67, 1599-1606 (1978).

5. S.E. Tabibi, Ph.D. Thesis, University of Maryland (1982).

6. J. Texter, K. Klier and A.C. Zettlemoyer, Water at surfaces, in Progress in surface and membrane science, Vol. 12 (P.A. Cadenhead and J.K. Danielli, Eds.), Academic Press, New York, 1978, pp. 327-403. 
Table 1: An illustrative example of smoothed adsorption data shown for water-GB thin film system at $T=293 \mathrm{~K}$

\begin{tabular}{|c|c|c|c|}
\hline $\begin{array}{c}\mathrm{n}_{2}(\mathrm{mmol} / 100 \mathrm{~g} \text { of } \\
\text { film) }\end{array}$ & Water activity & $\begin{array}{c}\mathrm{n}_{2}(\mathrm{mmol} / 100 \mathrm{~g} \text { of } \\
\text { film })\end{array}$ & Water activity \\
\hline 0.00 & 0.000 & 4.00 & 0.560 \\
\hline 0.25 & 0.040 & 4.25 & 0.595 \\
\hline 0.50 & 0.085 & 4.50 & 0.620 \\
\hline 0.75 & 0.135 & 4.75 & 0.640 \\
\hline 1.00 & 0.165 & 5.00 & 0.665 \\
\hline 1.25 & 0.210 & 5.25 & 0.685 \\
\hline 1.50 & 0.240 & 5.50 & 0.710 \\
\hline 1.75 & 0.275 & 5.75 & 0.740 \\
\hline 2.00 & 0.305 & 6.00 & 0.760 \\
\hline 2.25 & 0.345 & 6.25 & 0.770 \\
\hline 2.50 & 0.375 & 6.50 & 0.785 \\
\hline 2.75 & 0.405 & 6.75 & 0.805 \\
\hline 3.00 & 0.450 & 7.00 & 0.825 \\
\hline 3.25 & 0.485 & 7.25 & 0.840 \\
\hline 3.50 & 0.500 & 7.50 & 0.850 \\
\hline 3.75 & 0.535 & & \\
\hline
\end{tabular}


Figure 1: Sorption isotherms for glyceryl behenate thin film at various temperatures.

Values of equilibrium moisture are mean of $n=3$

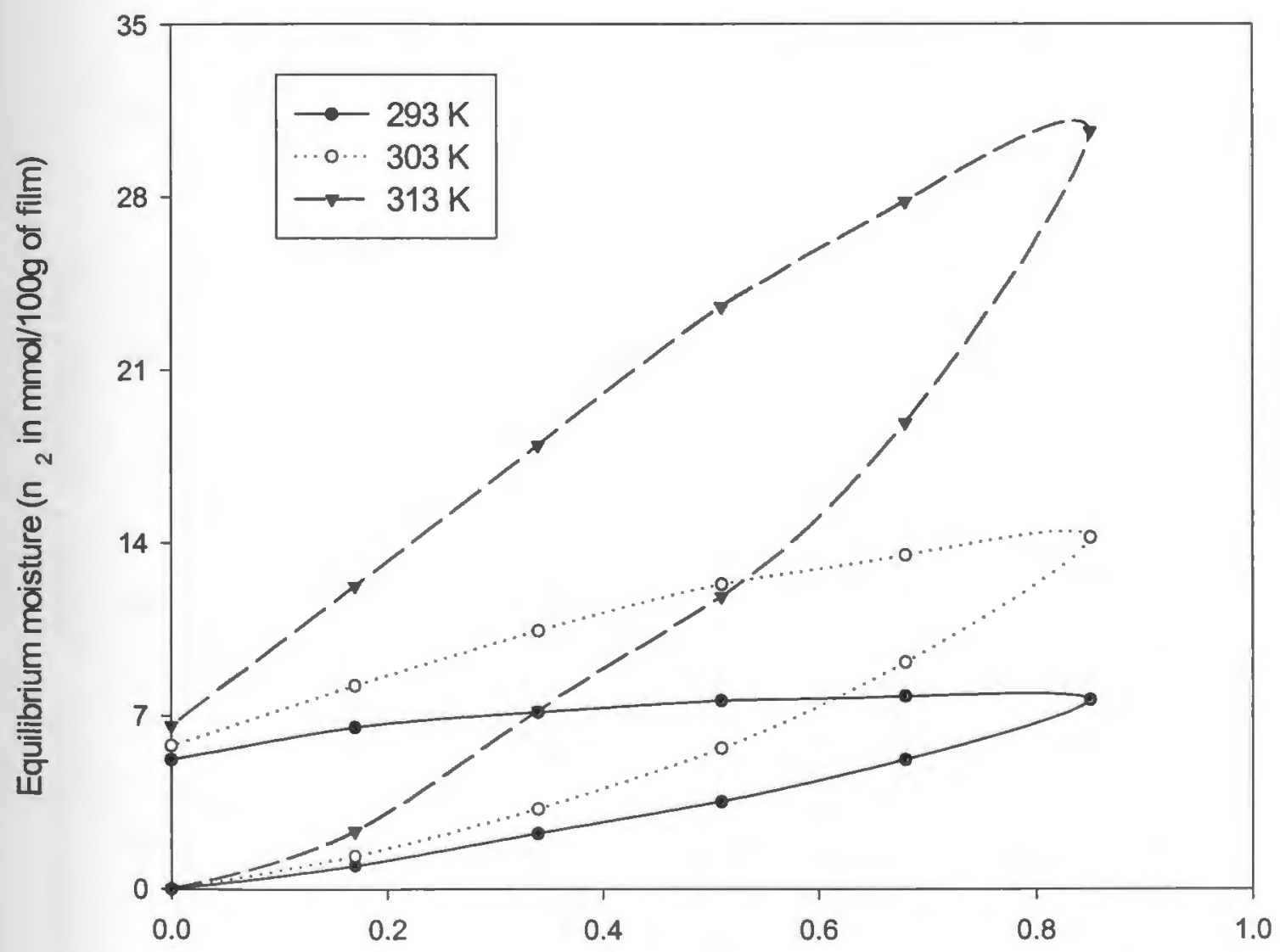

Water activity (a) 
Figure 2: Sorption isotherms for polyvinyl alcohol thin film at various temperatures.

Values of equilibrium moisture are mean of $n=3$

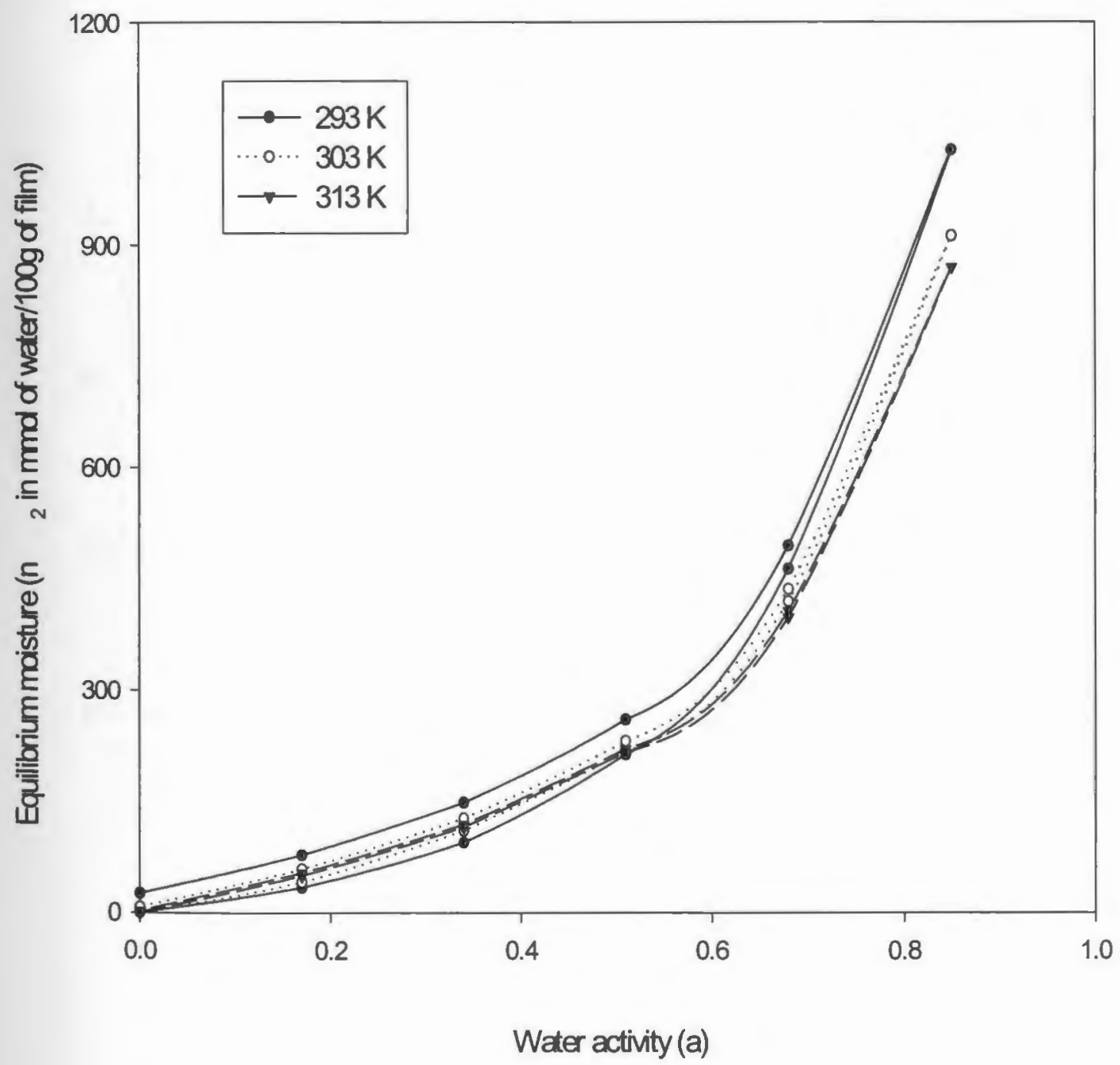


Figure 3: Relative partial molal free energy of adsorbed water on GB thin film at various temperatures

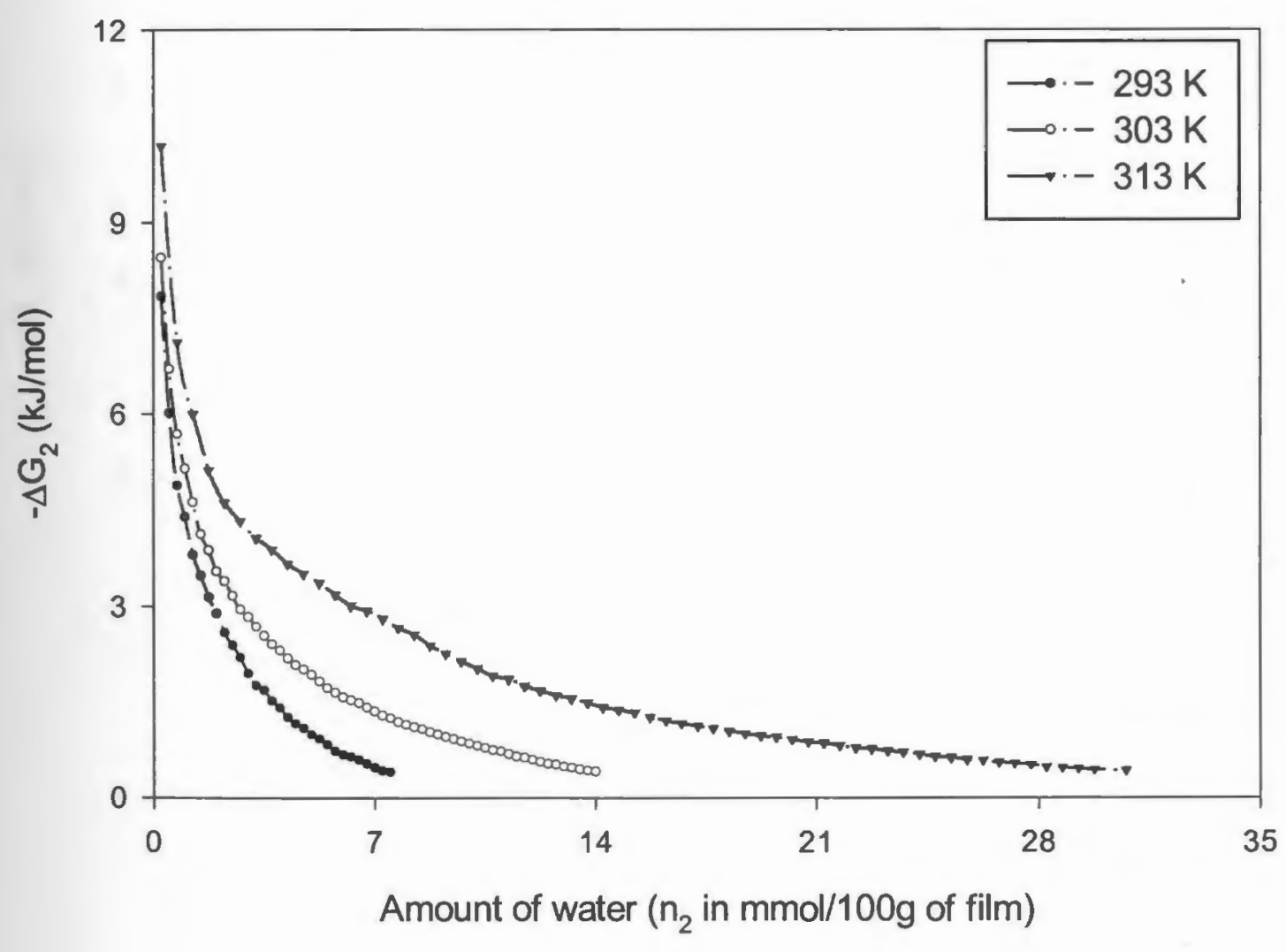


Figure 4: Relative partial molal free energy of adsorbed water on PVA thin film at various temperatures

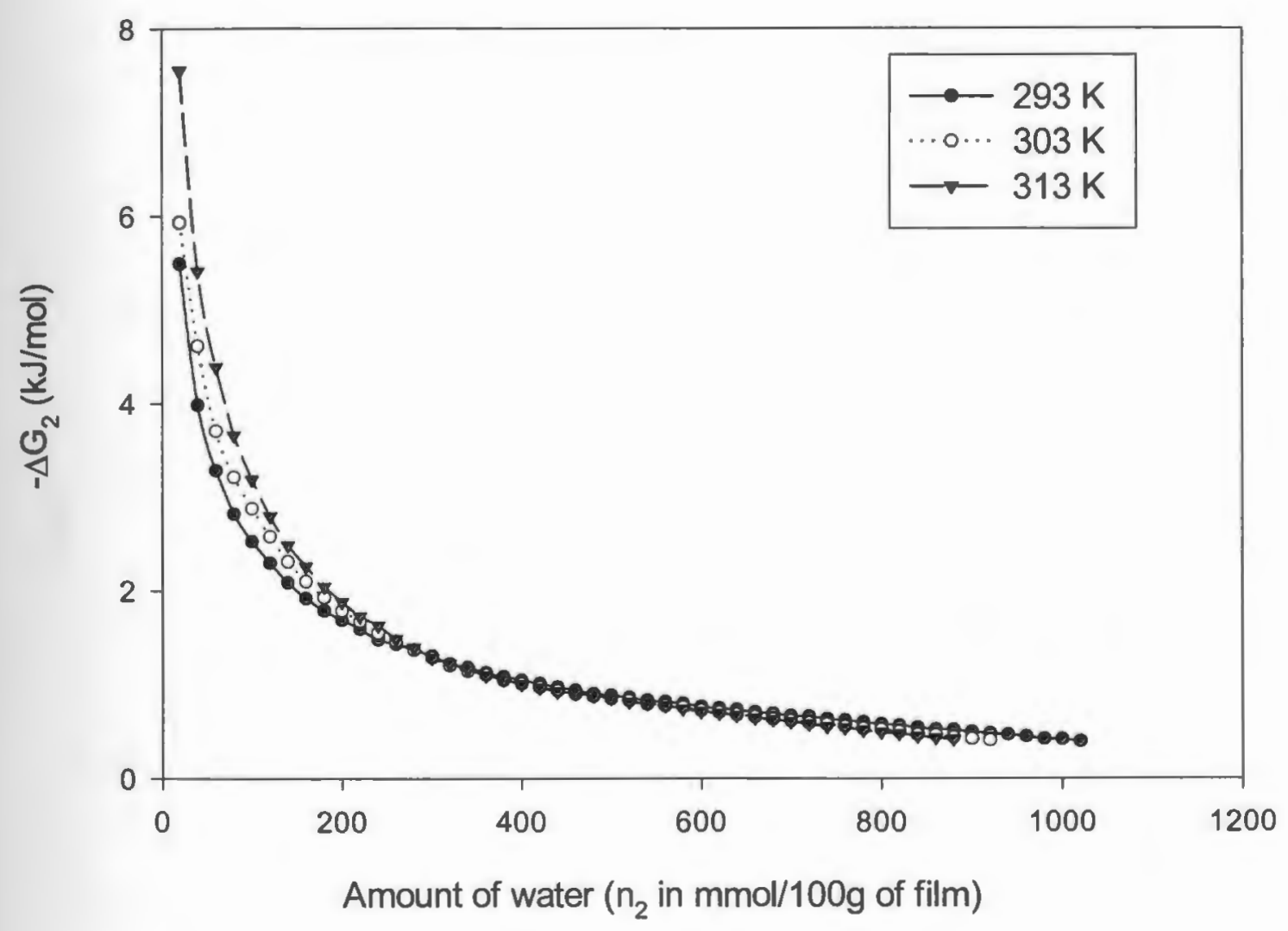


Figure 5: Integral free energy of adsorption $(\Delta G)$ and weighted relative partial molal free energies of excipient film $\left(n_{1} \Delta G_{1}\right)$ and water $\left(n_{2} \Delta G_{2}\right)$ for water-GB thin film system at

$$
\mathrm{T}=303 \mathrm{~K}
$$

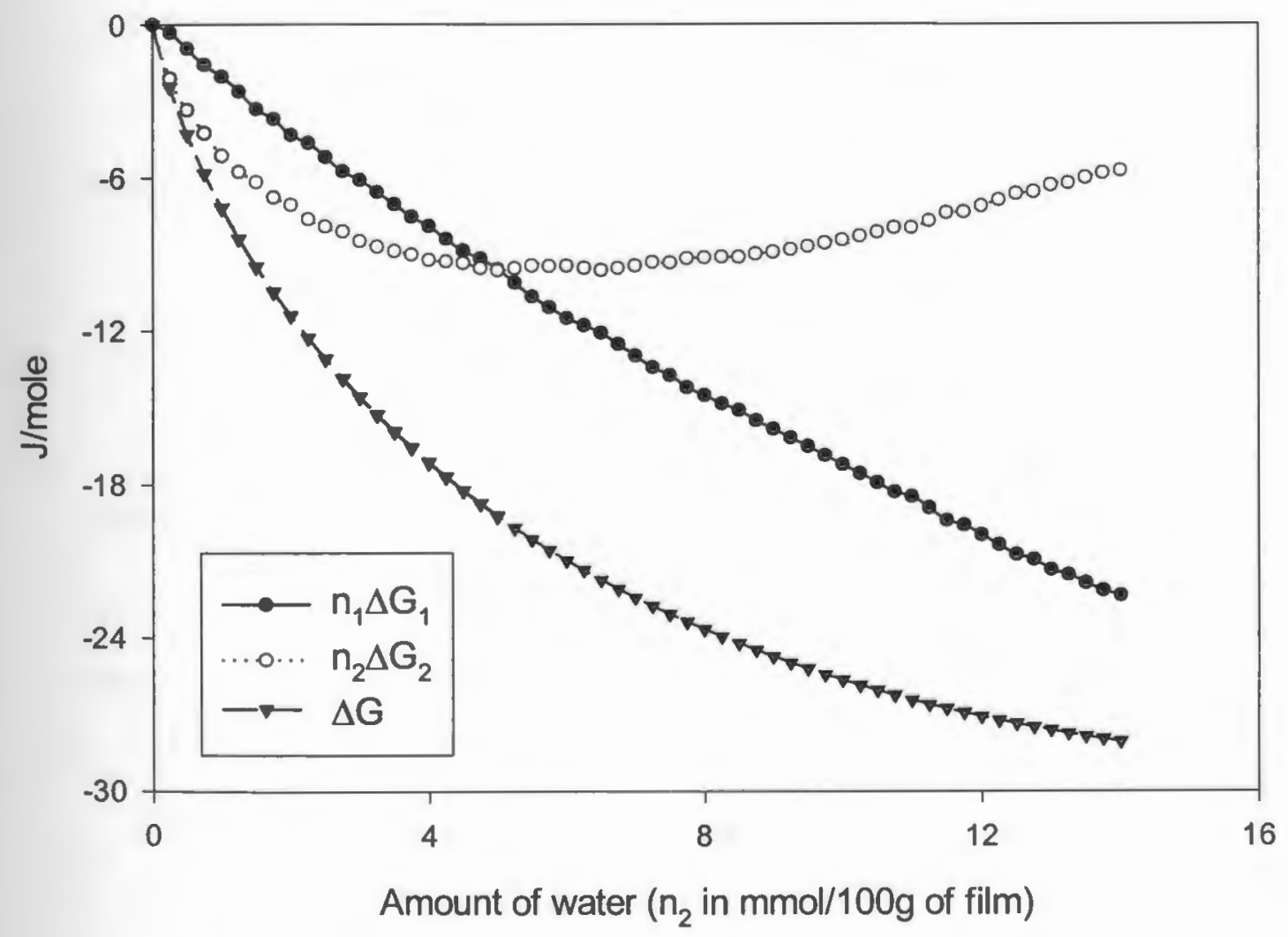


Figure 6: Integral free energy of adsorption $(\Delta G)$ and weighted relative partial molal free energies of excipient film $\left(n_{1} \Delta G_{1}\right)$ and water $\left(n_{2} \Delta G_{2}\right)$ for water-PVA thin film system at $\mathrm{T}=303 \mathrm{~K}$

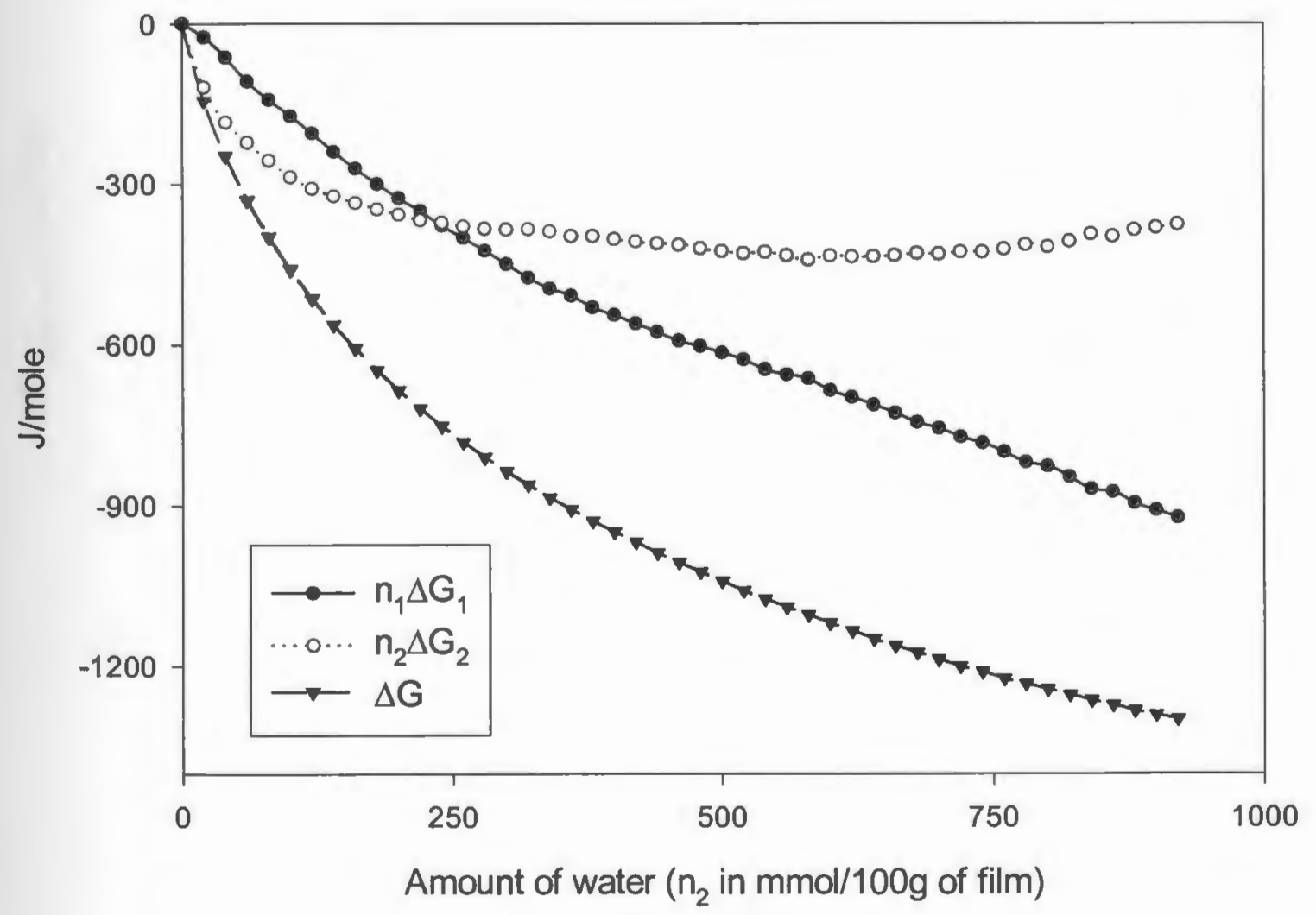


Figure 7: Relative partial molal free energy of hysteresis for adsorbed water on GB thin film at various temperatures

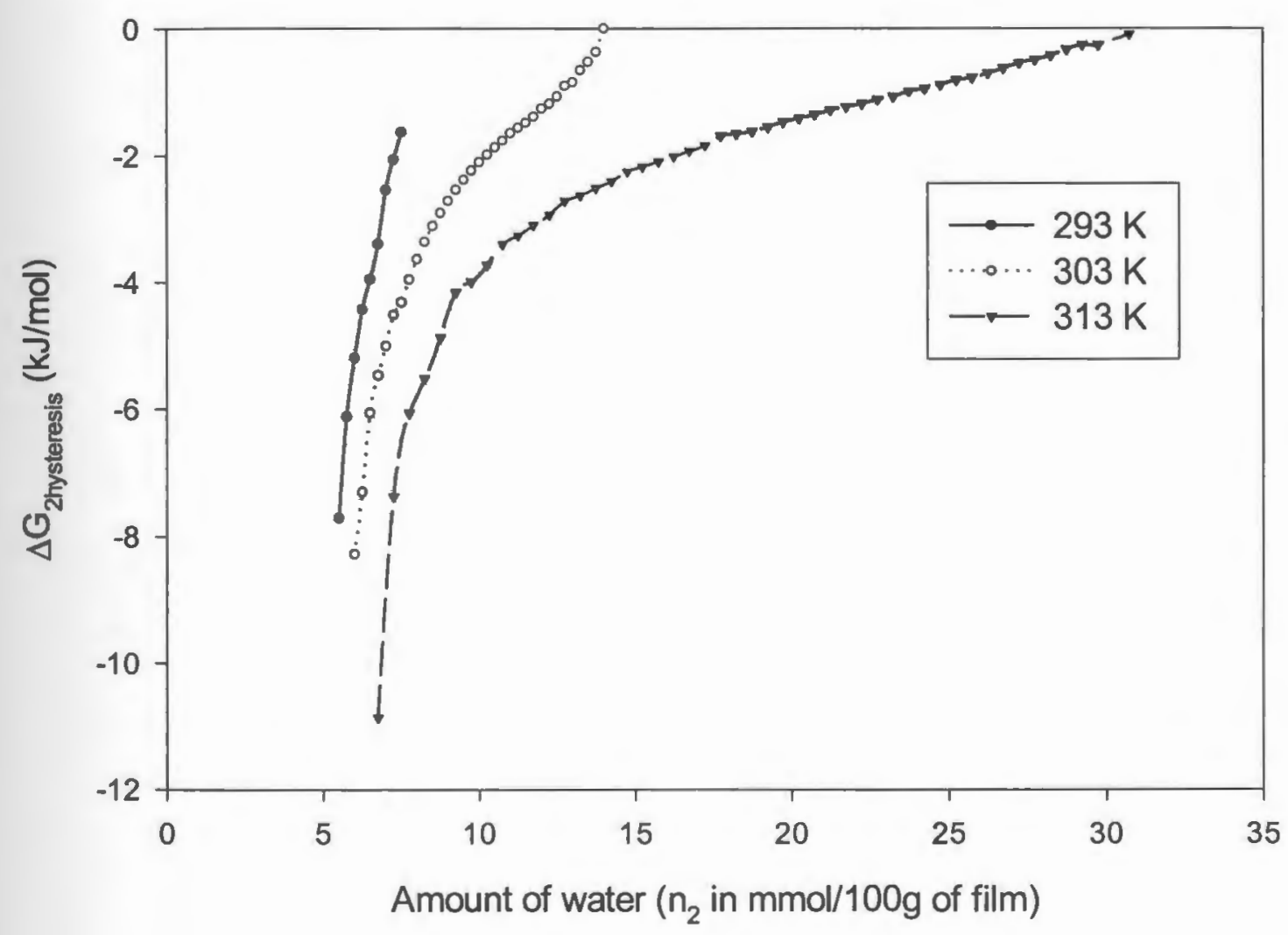


Figure 8: Relative partial molal free energy of hysteresis for adsorbed water on PVA thin film at various temperatures

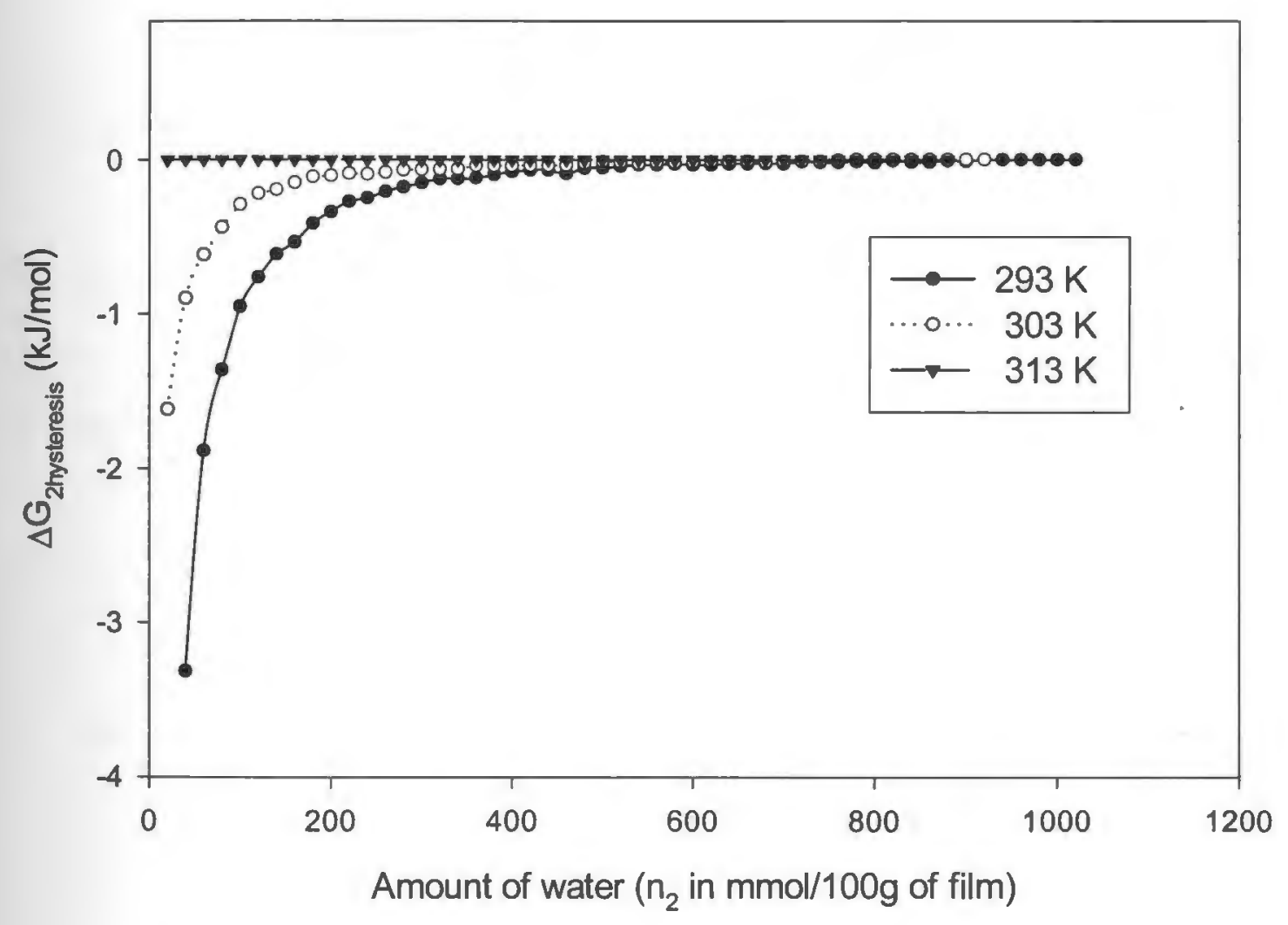


Figure 9: Relative partial molal enthalpy of adsorbed water on GB thin film at various temperatures

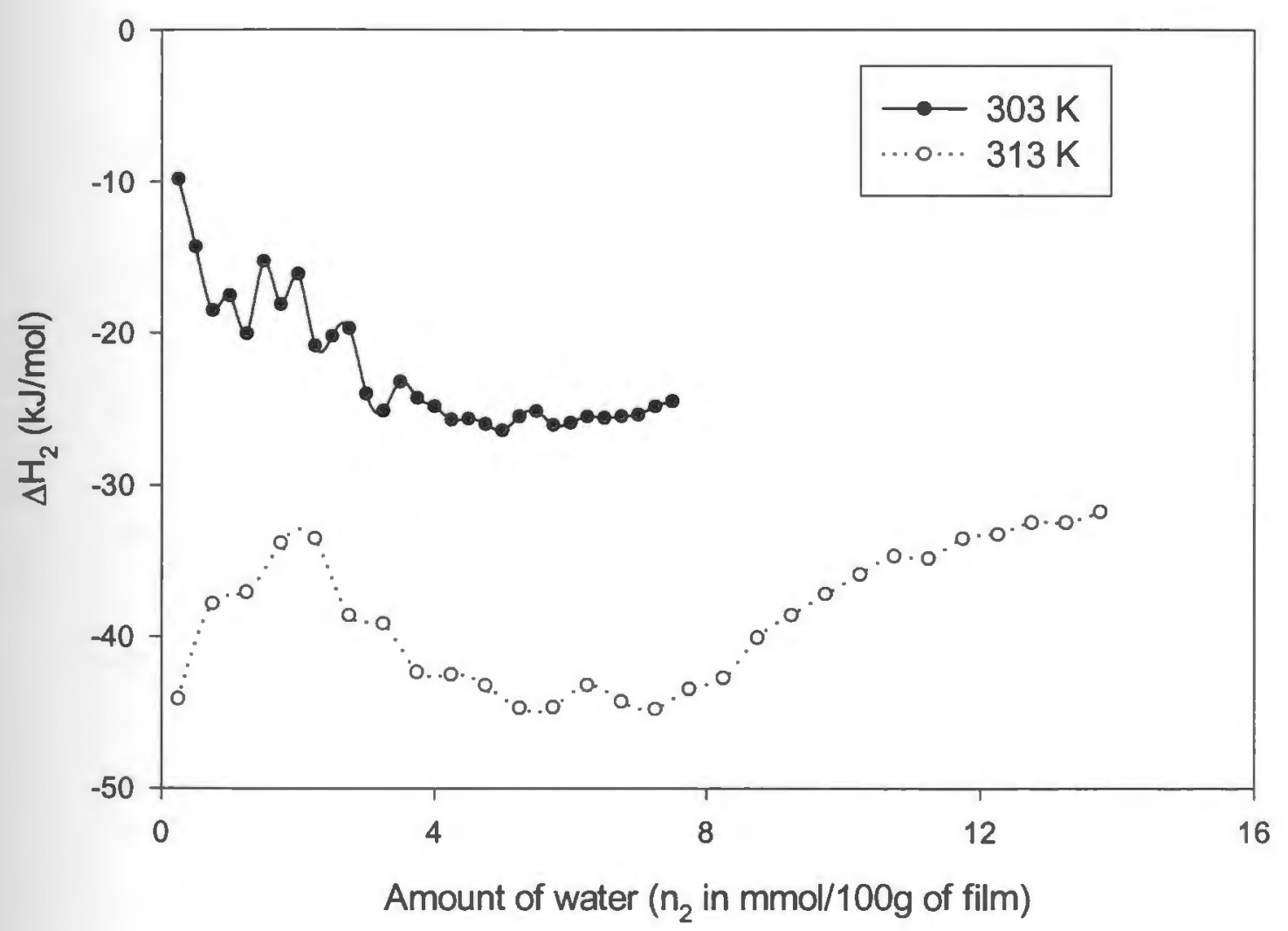


Figure 10: Relative partial molal enthalpy of adsorbed water on PVA thin film at various temperatures

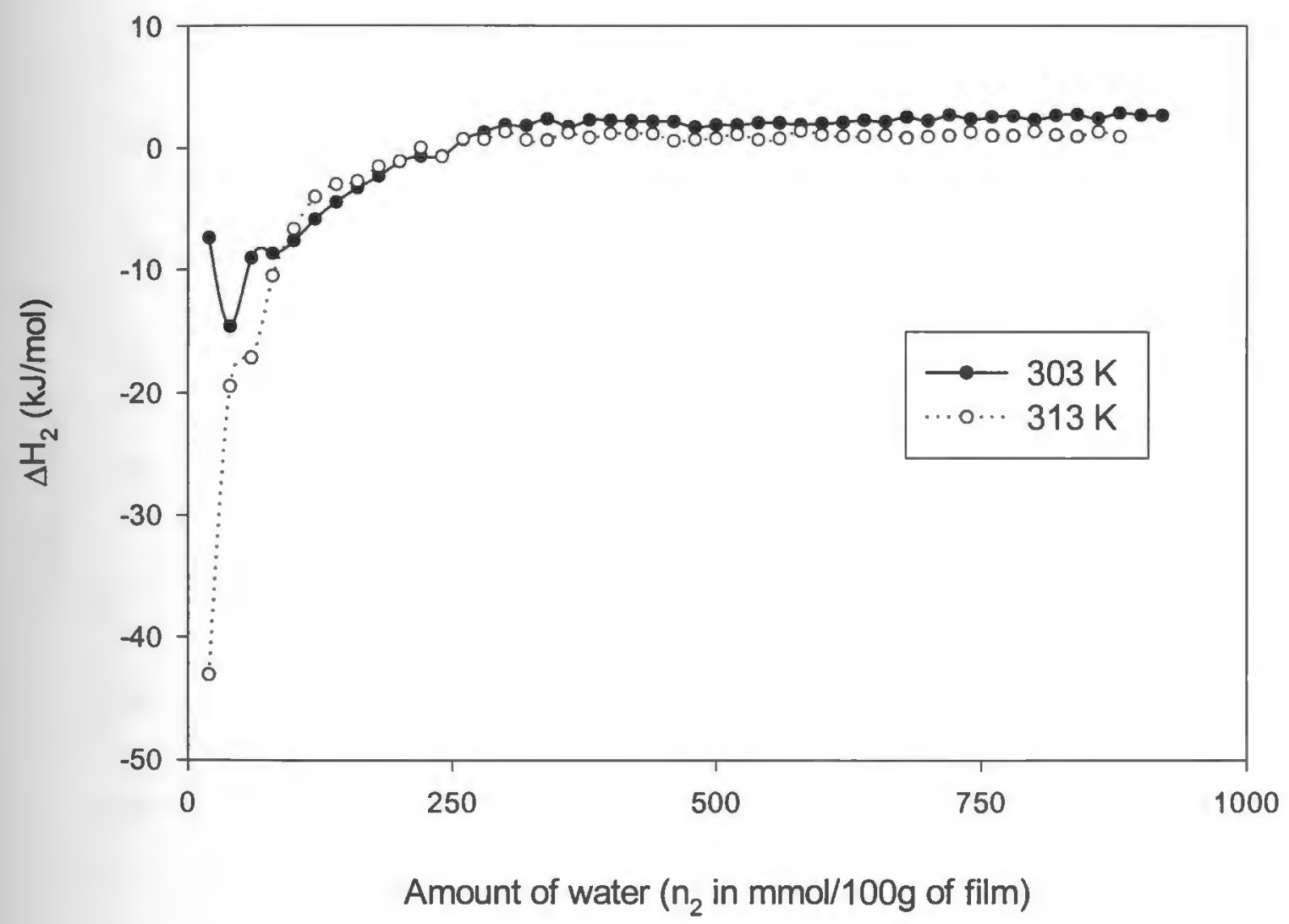


Figure 11: Integral enthalpy of adsorption $(\Delta \mathrm{H})$ and weighted relative partial molal enthalpies of excipient film $\left(n_{1} \Delta H_{1}\right)$ and water $\left(n_{2} \Delta H_{2}\right)$ for water-GB thin film system at

$$
\mathrm{T}=303 \mathrm{~K}
$$

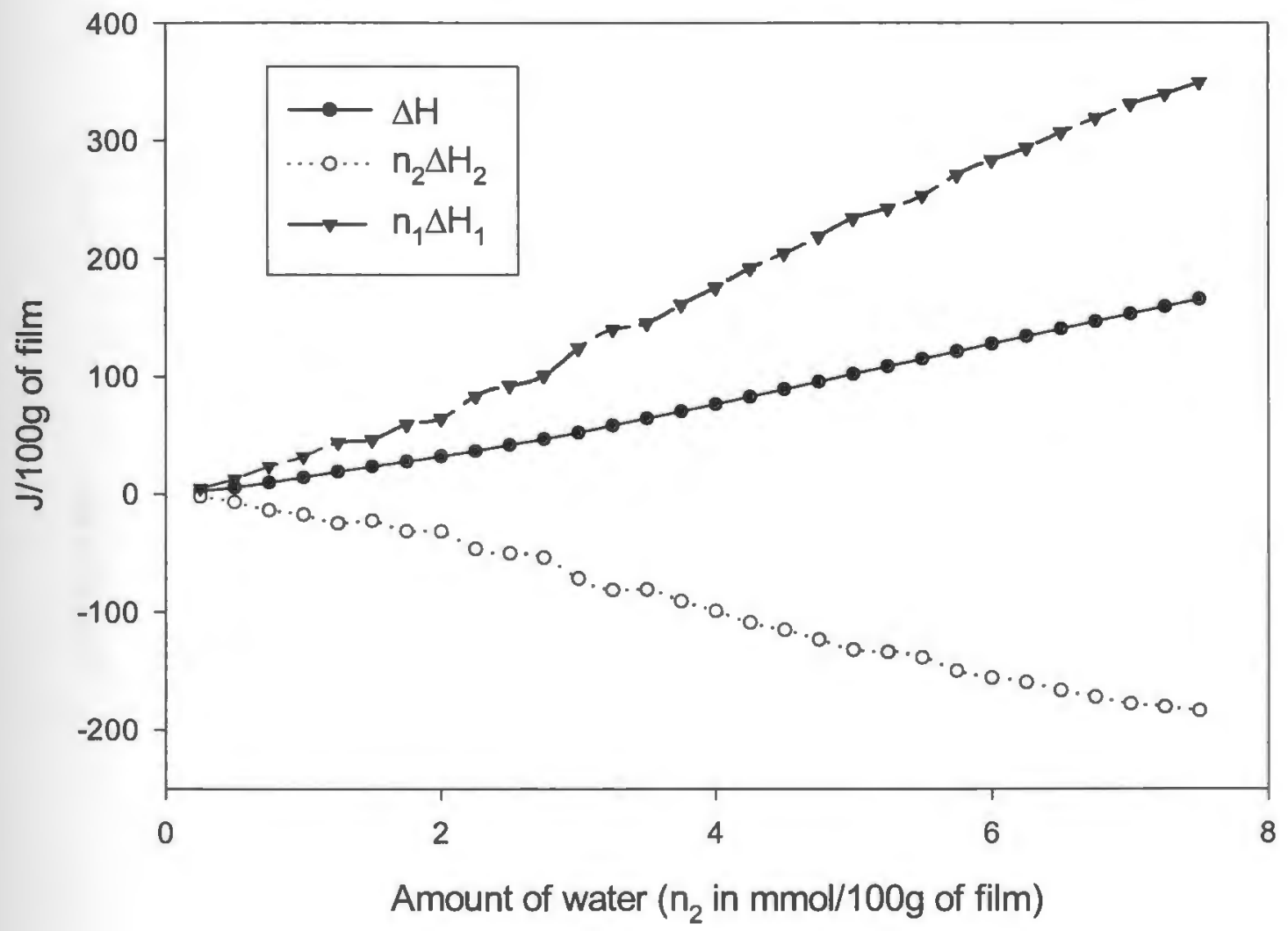


Figure 12: Integral enthalpy of adsorption $(\Delta \mathrm{H})$ and weighted relative partial molal enthalpies of excipient film $\left(\mathrm{n}_{1} \Delta \mathrm{H}_{1}\right)$ and water $\left(\mathrm{n}_{2} \Delta \mathrm{H}_{2}\right)$ for water-PVA thin film system at

$$
\mathrm{T}=303 \mathrm{~K}
$$

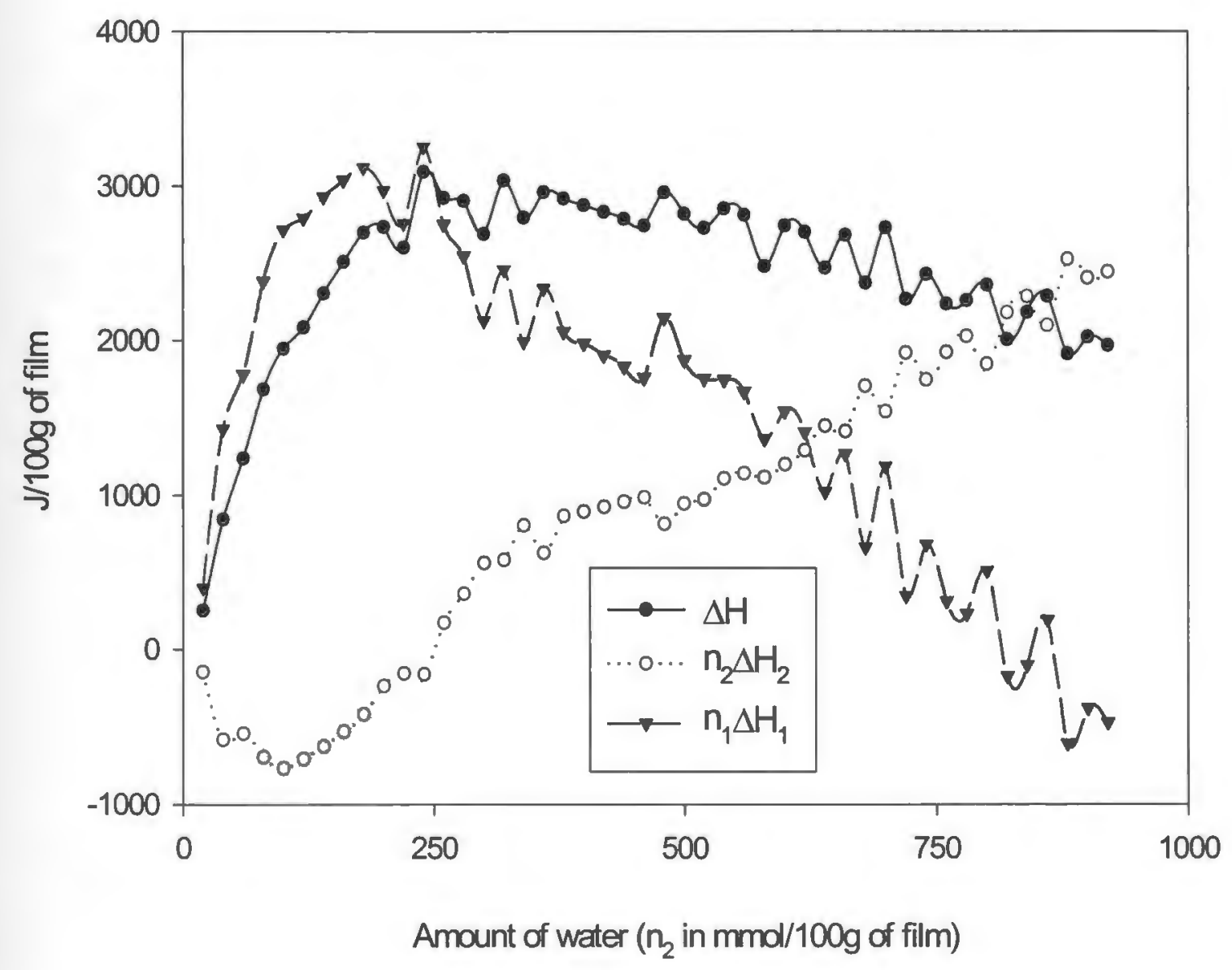


Figure 13: Relative partial molal entropy of adsorbed water on GB thin film at various temperatures

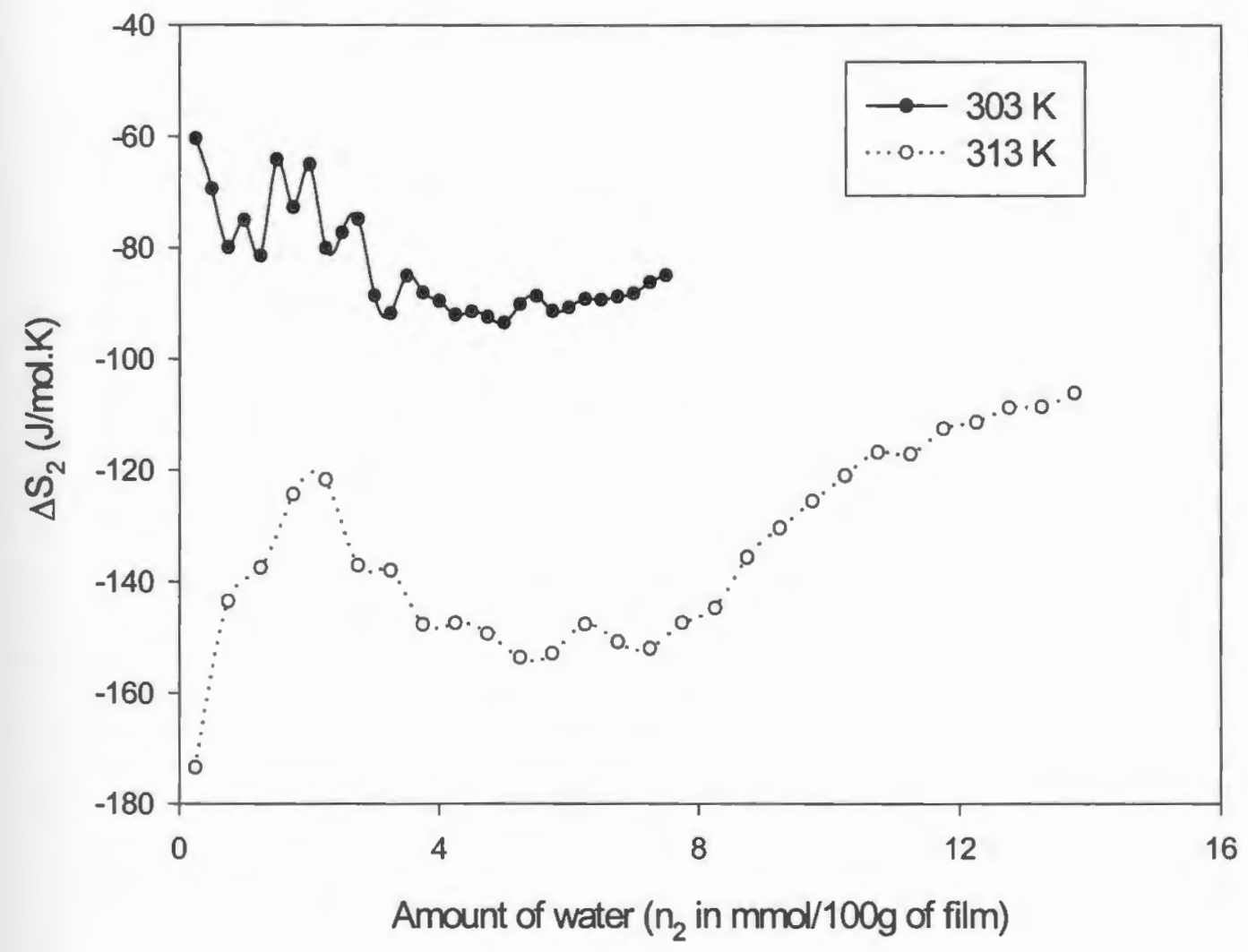


Figure 14: Relative partial molal entropy of adsorbed water on PVA thin film at various temperatures

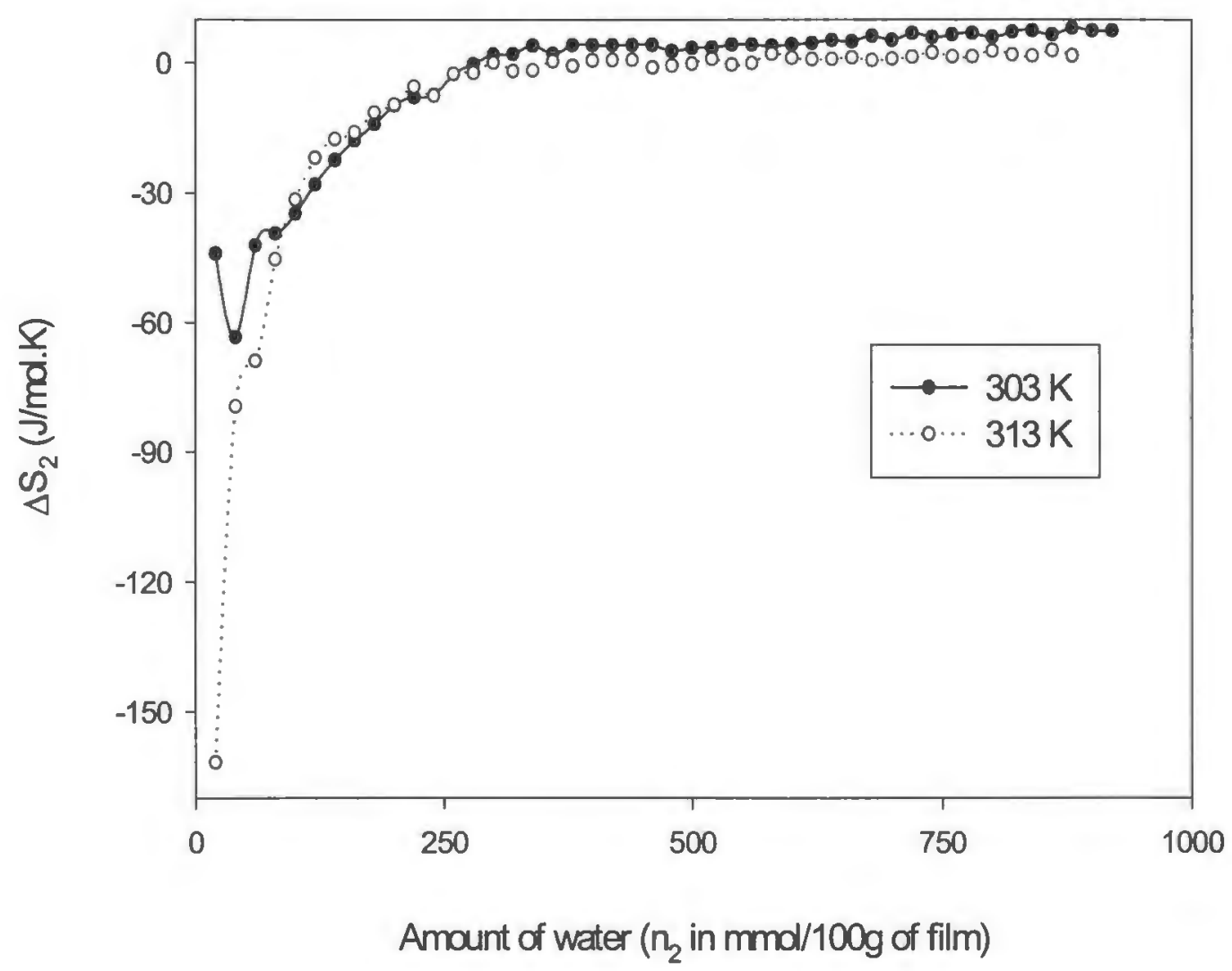


Figure 15: Variation of sorption microrate constants $\left(\mathrm{k}_{1}\right)$ with water activity for waterPVA thin film system at different temperatures (solid lines are best fit lines)

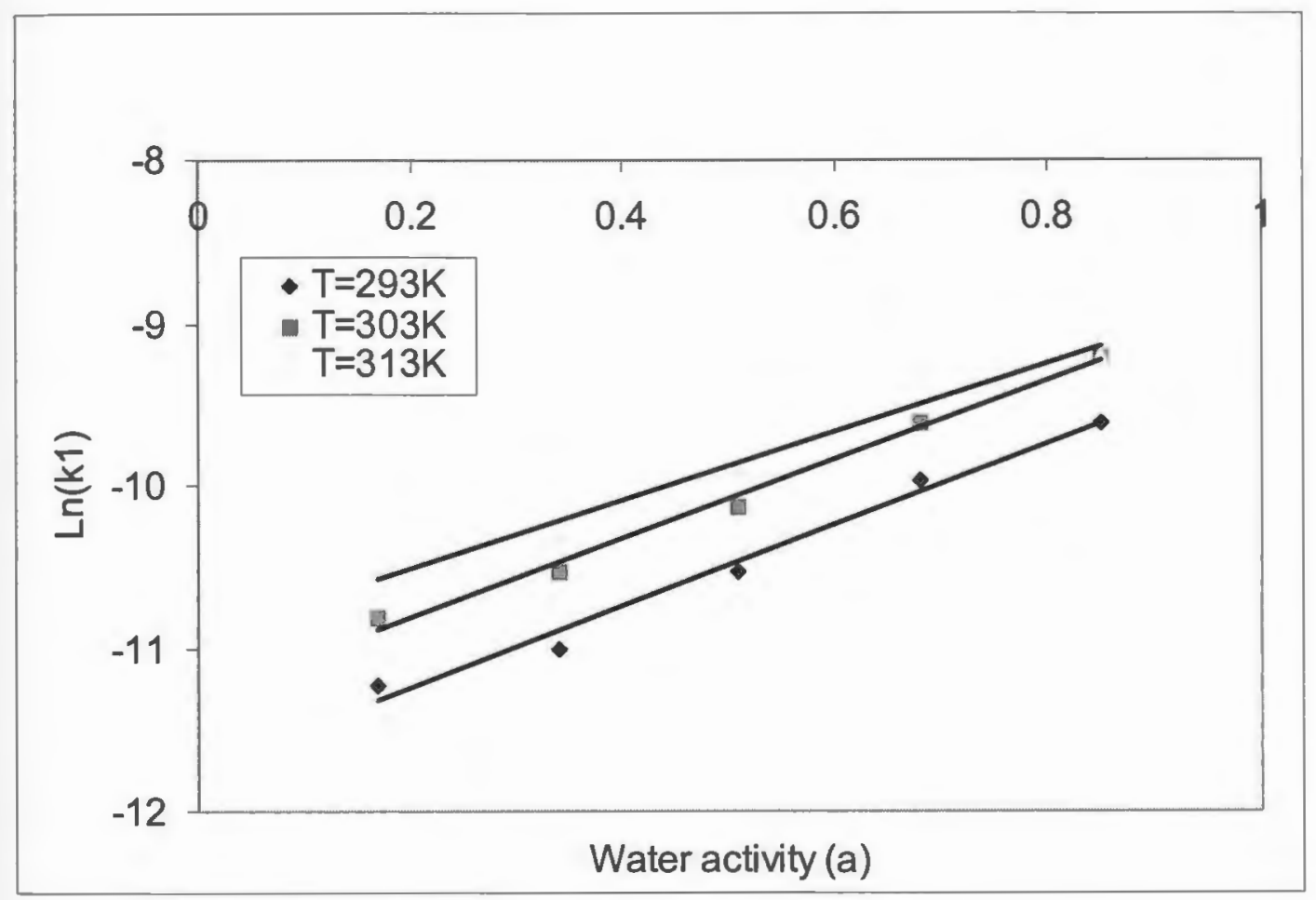


SECTION III 


\section{APPENDIX A}

\section{LIST OF PUBLICATIONS}

The following is a list of the journals in which the manuscripts have been or will be submitted for publication:

Manuscript I: Development of Hot Melt Coating Methods

Published in Drug Development and Industrial Pharmacy, 23(5): 441-449 (1997)

Manuscript II: Hot melt coating: Water sorption behavior of excipient films

To be submitted for publication in Drug Development and Industrial Pharmacy

Manuscript III: Thermodynamic analysis of water interaction with excipient films To be submitted for publication in Drug Development and Industrial Pharmacy 


\section{APPENDIX B}

\section{DETAILS OF REGRESSION FOR GAB MODEL FITTING}

The following illustrates the nonlinear regression routine used along with the regression report generated by SigmaPlot using adsorption data for glyceryl behenate thin film at $\mathrm{T}=303 \mathrm{~K}$.

Nonlinear Regression

[Variables]

$\mathrm{a}=\operatorname{col}(1)$

$\mathrm{y}=\operatorname{col}(2)$

[Parameters]

$\mathrm{K}=0.5$

$\mathrm{C}=0.5$

$\mathrm{W}=0.0003$

[Equations]

$f=\left(\left(1-\left(K^{*} a\right)\right) *\left(\left(1-\left(K^{*} a\right)\right)+\left(C * K^{*} a\right)\right)\right) /\left(C * K^{*} a * W\right)$

fit $f$ to $y$

[Constraints]

$\mathrm{W}<0.0015$

[Options]

tolerance $=0.000100$

stepsize $=100$

iterations $=100$

$\mathrm{R}=0.99963743 \quad$ Rsqr $=0.99927500 \quad$ Adj Rsqr $=0.99855000$

Standard Error of Estimate $=58.6181$

\begin{tabular}{lllll} 
& \multicolumn{2}{l}{ Coefficient } & Std. Error & $\mathbf{t}$ \\
$\mathrm{K}$ & 0.7655 & 0.1663 & 4.6034 & 0.0441 \\
$\mathrm{C}$ & 1.0869 & 0.5046 & 2.1540 & 0.1641 \\
$\mathrm{~W}$ & 0.0015 & 0.0010 & 1.5714 & 0.2567
\end{tabular}

Analysis of Variance:

$\begin{array}{llllll} & \text { DF } & \text { SS } & \text { MS } & \text { F } & \text { P } \\ \text { Regression2 } & 9471950.4059 & 4735975.2030 & 1378.3090 & 0.0007 \\ \text { Residual } & 2 & 6872.1532 & 3436.0766 & & \\ \text { Total } & 4 & 9478822.5591 & 2369705.6398 & \end{array}$


PRESS $=1568480.3004$

Durbin-Watson Statistic $=1.7242$

Normality Test: $\quad$ Passed $(P=0.3492)$

Constant Variance Test: $\quad$ Passed $(P=0.0500)$

Power of performed test with alpha $=0.0500: 1.0000$

Regression Diagnostics:

\begin{tabular}{|c|c|c|c|c|}
\hline Row & Predicted Residual & Std. Res. & Stud. Res. & Stud. Del. Res. \\
\hline 1 & 4146.352222 .0778 & 0.3766 & 2.8117 & $>1 \mathrm{e} 20$ \\
\hline 2 & $1782.7167-64.3267$ & -1.0974 & -1.6454 & $>1 \mathrm{e} 20$ \\
\hline 3 & $990.2163 \quad-9.4763$ & -0.1617 & -0.2076 & -0.1484 \\
\hline 4 & 590.4996 & 0.3030 & 0.3637 & 0.2661 \\
\hline 5 & 347.8965 & 0.7321 & 1.5049 & $>1 \mathrm{e} 20$ \\
\hline
\end{tabular}

Influence Diagnostics:

\begin{tabular}{lllll} 
Row & \multicolumn{2}{l}{ Cook's Dist. } & Leverage & DFFITS \\
1 & 144.2171 & 0.9821 & $>1 \mathrm{e} 20$ & \\
2 & 1.1265 & 0.5552 & $>1 \mathrm{e} 20$ & \\
3 & 0.0093 & 0.3934 & -0.1195 & \\
4 & 0.0194 & 0.3060 & 0.1767 & \\
5 & 2.4347 & 0.7633 & $>1 \mathrm{e} 20$
\end{tabular}

95\% Confidence

Row Predicted Regression 5\% Population 5\% Population 95\%

$\begin{array}{llllll}1 & 4146.3522 & 3896.4122 & 4396.2922 & 3791.2726 & 4501.4317 \\ 2 & 1782.7167 & 1594.7865 & 1970.6468 & 1468.1865 & 2097.2468 \\ 3 & 990.2163 & 832.0181 & 1148.4144 & 692.4947 & 1287.9378 \\ 4 & 590.4996 & 450.9891 & 730.0101 & 302.2729 & 878.7263 \\ 5 & 347.8965 & 127.5403 & 568.2526 & 12.9811 & 682.8118\end{array}$




\section{DETAILS OF REGRESSION FOR Y\&N MODEL FITTING}

The following three pages describe the segmented nonlinear regression routine used along with the regression report generated by SAS using adsorption data for polyvinyl alcohol thick film at $\mathrm{T}=303 \mathrm{~K}$ as an illustrative example. 
Protocol: Water activity

* program: water0520.sas

* Programmer: Sara Luke

* Date: May 20, 1999

$\star$

* Segmented Non-Linear Model

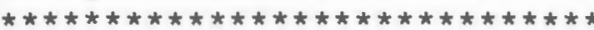

options pageno $=1$ number date;

data test;

input col water moist1 moist2; cards ;

$\begin{array}{llll}1 & 0 & 0 & 0 \\ 2 & .17 & 0.000283528 & 0.000114711 \\ 3 & .34 & 0.00088622 & 0.0003714 \\ 4 & .51 & 0.002250343 & 0.000691956 \\ 5 & .68 & 0.006701884 & 0.001149585 \\ 6 & .85 & 0.058387043 & 0.00214398 \\ 7 & .68 & 0.034779452 & 0.001775862 \\ 8 & .51 & 0.025706853 & 0.002027346 \\ 9 & .34 & 0.022455514 & 0.00188124 \\ 10 & .17 & 0.020329746 & 0.00169517 \\ 11 & 0 & 0.015969167 & 0.001265792\end{array}$

;

run;

omacro donlin(var, title);

title1 "\&title";

proc nlin data=test;

parm $\mathrm{a}=.1 \mathrm{~b}=.1 \mathrm{E}=.1$;

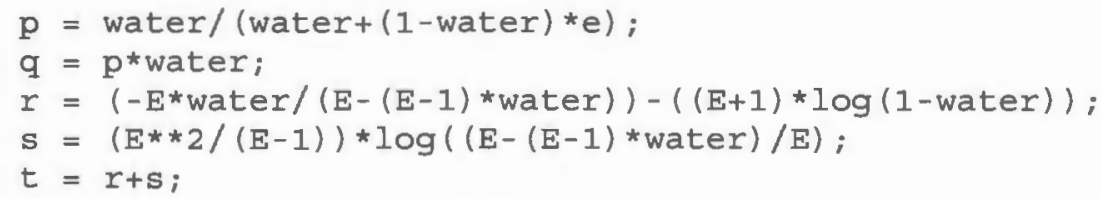

if col le 6 then do;

model \&var $=a *(p+t)+(b * q)$;

bounds $a>0$;

bounds $b>0$;

bounds $\mathrm{E}>0$;

end;

if col ge 6 then do;

model \&var $=a^{*}(p+t)+\left(b * p^{*}(.85)\right)$;

bounds $a>0$;

bounds $b>0$;

bounds $E>0$;

run;

end $i$ 
omend donlin;

\&donlin (moist1, Opamb Thick - $\mathrm{T}=303 \mathrm{~K}$ );

odonlin(moist2, Compritol Thick - T=303K);

Opamb Thick - T=303K

16:27 Wednesday. September 22, $1999 \quad 1$

Non-Linear Least Squares Iterative Phase Dependent Variable MOIST1 Method: Gauss-Newton

$\begin{array}{crccc}\text { Iter } & A & B & E & \text { Sum of Squares } \\ 0 & 0.100000 & 0.100000 & 0.100000 & 0.396701 \\ 1 & 5.475221 \mathrm{E}-18 & 0.049695 & 0.134640 & 0.002074 \\ 2 & 0 & 0.049695 & 0.134640 & 0.002074 \\ 3 & 0 & 0.045003 & 0.290534 & 0.001525 \\ 4 & 0 & 0.050896 & 0.560208 & 0.001403 \\ 5 & 0 & 0.059584 & 0.966863 & 0.001309 \\ 6 & 0 & 0.070249 & 1.529771 & 0.001240 \\ 7 & 0 & 0.081819 & 2.205633 & 0.001199 \\ 8 & 0 & 0.092465 & 2.873943 & 0.001180 \\ 9 & 0 & 0.100520 & 3.402236 & 0.001174 \\ 10 & 0 & 0.105497 & 3.735900 & 0.001172 \\ 11 & 0 & 0.108079 & 3.910545 & 0.001171 \\ 12 & 0 & 0.109268 & 3.991124 & 0.001171 \\ 13 & 0 & 0.109779 & 4.025830 & 0.001171 \\ 14 & 0 & 0.109993 & 4.040300 & 0.001171 \\ 15 & 0 & 0.110080 & 4.046248 & 0.001171 \\ 16 & 0 & 0.110116 & 4.048679 & 0.001171 \\ 17 & 0 & 0.110131 & 4.049670 & 0.001171\end{array}$

NOTE: Convergence criterion met.

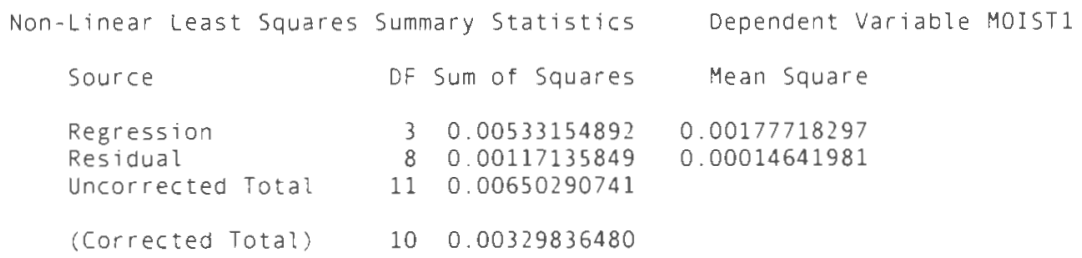

\begin{tabular}{|c|c|c|c|c|}
\hline \multirow[t]{2}{*}{ Parameter } & \multirow[t]{3}{*}{ Estimate } & Asymptotic & \multicolumn{2}{|c|}{ Asymptotic $95 \%$} \\
\hline & & Std. Error & & \\
\hline & & & Lower & Upper \\
\hline A & 0.000000000 & 0.056717914 & -0.130793005 & 0.1307930 \\
\hline 8 & 0.110130927 & 0.406320299 & -0.826854402 & 1.0471162 \\
\hline E & 4.049670083 & 12.944983127 & -25.801802530 & 33.9011426 \\
\hline
\end{tabular}


Asymptotic Correlation Matrix

\begin{tabular}{lccr} 
Corr & \multicolumn{1}{c}{ A } & B & $E$ \\
ffffffffffffffffffffffffffffffffffffffffffffffffffffffffffffffffff \\
A & 1 & -0.985697063 & -0.938283438 \\
B & -0.985697063 & 1 & 0.9810426978 \\
E & -0.938283438 & 0.9810426978 & 1
\end{tabular}




\section{SUMMARY OF CONCLUSIONS}

1. Hot melt coating methods offer an interesting alternative to commonly employed aqueous polymeric coating technologies. They are environment-friendly, cost effective and may be used for a variety of applications such as sustained drug delivery, protection from environmental degradation and taste masking of unpalatable drugs.

2. A simple and rapid method employing an automated gravimetric apparatus, dynamic vapor sorption technique (DVST) has been described to study the interaction of water with excipient films of pharmaceutical significance. Films of glyceryl behenate and polyvinyl alcohol were used as model excipients to examine the effect of temperature and film thickness on moisture sorption/desorption in this study.

3. Both excipient films studied displayed type III sorption isotherms and demonstrated hysteresis during desorption. The sorption data for both excipient films did not follow the Langmuir model and the BET model could only be used restrictively.

4. The GAB model assuming the existence of water in three different states: one tightly bound layer, additional less tightly bound layers and bulk water in a non specific manner was most successful in describing the sorption data for both excipient films.

5. The hysteresis displayed by both excipient films could be modeled accurately using the Young and Nelson model, but meaningful physical interpretation of the model's parameters was not possible.

6. For the glyceryl behenate film, increasing temperature led to increased area under hysteresis and higher equilibrium moisture contents whereas the contrary was true for 
polyvinyl alcohol film. An Arrhenius type relationship was established between equilibrium moisture content and temperature for both excipient films at constant water activity. The energy of sorption determined from such Arrhenius plots was found to vary linearly with water activity for both excipient films.

7. Using the real time sorption/desorption data recorded by DVST apparatus, estimates of sorption and desorption microrate constants were obtained assuming Langmuir behavior at varying water activity and temperature. It was found that the sorption microrate constants for polyvinyl alcohol thin film varied exponentially with water activity at constant temperature.

8. The effect of film thickness on the sorption/desorption behavior of polyvinyl alcohol films was found to be significant, but the same was not true for the glyceryl behenate films.

9. A complete thermodynamic analysis of water-excipient film interaction was performed using the temperature dependence of the sorption process. Partial molal free energies, enthalpies and entropies were computed for water-excipient film systems.

10. A comparative evaluation of the results obtained via application of theoretical models and thermodynamic analysis, showed they were not always consistent, emphasizing the need to perform both analyses for complete characterization of water-excipient film systems.

11. It was hypothesized that desorption hysteresis resulted due to the irreversible bonding of water with the excipients via hydrogen bonding. Examination of the behavior of isoteric heat of adsorption with sorbed moisture confirmed that hydrogen bonding 
was occurring and allowed estimation of number of hydrogen bonds per water molecule. 


\section{BIBLIOGRAPHY}

Achanta A.S., Adusumilli P.S., James K.W. and Rhodes C.T., "Development of hot melt coating methods", Drug Development \& Industrial Pharmacy, 23: $441-449$ (1997).

Arroyo R., Cuesta C., Garrido-Polonio C., Lopez-Varela S. and Sanchez-Muniz F.J., "High-performance size exclusion chromatographic studies on polar components formed in sunflower oil used for frying", Journal of American Oil Chemists Society, 69(6): 557563 (1992).

Banker G.S. and Rhodes C.T., Modern Pharmaceutics, Third Edition, Published by Marcel Dekker, New York (1996).

Barth H.G., Boyes B.E. and Jackson C., "Size exclusion chromatography", Analytical Chemistry, 66(12): 595R-620R (1994).

Bourret E., Ratsimbazafy V., Maury L. and Brossard C., "Rheological behavior of saturated polyglycolysed glycerides" Journal of Pharmacy and Pharmacology, 46: 538541 (1994).

Brittain H.G., Physical Characterization of Pharmaceutical Solids, Published by Marcel Dekker, New York (1995).

Busfield W.K. and Proschogo P.N., "Thermal analysis of palm stearine by DSC", Journal of American Oil Chemists Society, 67(3): 171-175 (1990).

Busfield W.K. and Proschogo P.N., "Hydrogenation of palm stearine: Changes in chemical composition and thermal properties", Journal of American Oil Chemists Society, 67(3): 176-181 (1990). 
Callahan J.C., Cleary G.W., Elefant M., Kaplan G., Kensler T. and Nash R.A., "Equilibrium moisture content of pharmaceutical excipients", Drug Development \& Industrial Pharmacy, 8: 355-369 (1982).

Carstensen J.T., Drug Stability, Principles and Practices, Published by Marcel Dekker, New York (1995).

Chan S.Y. and Pilpel N., "Absorption of moisture by sodium cromoglycate and mixtures of sodium cromoglycate and lactose", Journal of Pharmacy and Pharmacology, 35: 477481 (1983).

Coben L.J. and Lordi N.G., "Physical stability of semisynthetic suppository bases", Journal of Pharmaceutical Sciences, 69(8): 955-960 (1980).

Copeland L.E. and Young T.F., "A thermodynamic theory of adsorption", Advances in Chemistry Series, 33: 348-355 (1961).

Craig D.Q.M. and Newton J.M., "Characterisation of polyethylene glycols using differential scanning calorimetry", International Journal of Pharmaceutics, 74: 33-41 (1991).

Craig D.Q.M., "A review of thermal methods used for the analysis of the crystal form, solution thermodynamics and glass transition behaviour of polyethylene glycols", Thermochimica Acta, 248: 189-203 (1995).

DeMan L., deMan J.M. and Blackman B., "Polymorphic behavior of some fully hydrogenated oils and their mixtures with liquid oil", Journal of American Oil Chemists Society, 66(12): 1777-1780 (1989).

Duddu S.P. and Grant D.J.W., "The use of thermal analysis in the assessment of crystal disruption", Thermochimica Acta, 248: 131-145 (1995). 
Flaherty B., " Characterisation of waxes by differential scanning calorimetry", Journal of Applied Chemistry and Biotechnology, 21: 144-148 (1971).

Ghebre-Sellassie I., Multiparticulate Oral Drug Delivery, Published by Marcel Dekker, New York (1994).

Gines J.M., Veiga M.D., Arias M.J. and Rabasco A.M., "Elaboration and thermal study of interactions between cinnarizine and gelucire ${ }^{\circledR} 53 / 10$ physical mixtures and solid dispersions" International Journal of Pharmaceutics, 126: 287-291 (1995).

Hagemann J.W., Tallent W.H. and Kolb K.E., "Differential scanning calorimetry of single acid triglycerides: Effect of chain length and unsaturation", Journal of American Oil Chemists Society, 49: 118-123 (1972).

Hollenbeck R.G., Peck G.E. and Kildsig D.O., "Application of immersional calorimetry to investigation of solid-liquid interactions: microcrystalline cellulose-water system", Journal of Pharmaceutical Sciences, 67: 1599-1606 (1978).

Husain S., Sastry G.S.R. and Raju N.P., "Molecular weight averages as criteria for quality assessment of heated oils and fats", Journal of American Oil Chemists Society, 68(11): 822-826 (1991).

Khan F. and Pilpel N., "An investigation of moisture sorption in microcrystalline cellulose using sorption isotherms and dielectric response", Powder Technology, 50: 237 241 (1987).

Kotsiomiti E. and McCabe J.F., "Stability of dental waxes following repeated heatings", Journal of Oral Rehabilitation, 22: 135-143 (1995).

Labuza T.P., "Sorption phenomena in foods", Food Technology, 22: 263-272 (1968). 
Lachman L., Lieberman H.A. and Kanig J.L, The Theory and Practice of Industrial Pharmacy, Third Edition, Published by Lea \& Febiger, Philadelphia (1986).

Letoffe J.M., Claudy P., Kok M.V., Garcin M. and Volle J.L., "Crude oils: characterization of waxes precipitated on cooling by DSC and thermomicroscopy", Fuel, 74(6): 810-817 (1995).

Liversidge G.G., Grant D.J.W. and Padfield J.M., "Drug-excipient interactions and polymorphism in triglyceride suppository formulations", Analytical Proceedings, 549553 (1982).

Malamataris S. and Dimitriou A., "Moisture sorption profiles and tensile strength of tableted phenobarbitone formulations", Journal of Pharmacy and Pharmacology, 42: $158-163(1990)$.

Malamataris S., Goidas P. and Dimitriou A., "Moisture sorption and tensile strength of some tableted direct compression excipients", International Journal of Pharmaceutics, 68: 51-60 (1991).

Martin A. and Bustamante P., Physical Pharmacy, Fourth Edition, Published by Lea \& Febiger, Philadelphia (1993).

McGinity J.W., Aqueous Polymeric Coatings for Pharmaceutical Dosage Forms, Second Edition, Published by Marcel Dekker, New York (1997).

Sadeghnejad G.R., York P. and Stanley-Wood N.G., "Water vapor interaction with cellulose powders", Drug Development \& Industrial Pharmacy, 12: 2171-2192 (1996).

Sanchez-Muniz F.J., Cuesta C. and Garrido-Polonio C., "Sunflower oil used for frying: Combination of column, gas and high-performance size-exclusion chromatography for its evaluation", Journal of American Oil Chemists Society, 70(3): 235-240 (1993). 
Simon K. and Suverkrup R., "Comparison of recent techniques to characterize the crystallization behaviour of fatty suppository bases", Thermochimica Acta, 248: 271-287 (1995).

Strickland W.A., "Study of water vapor sorption by pharmaceutical powders", Journal of Pharmaceutical Sciences, 51: 310-314 (1962).

Sutananta W., Craig D.Q.M. and Newton J.M., "An investigation into the structure and stability of gelucire $43 / 01$ using differential scanning calorimetry and optical microscopy", Journal of Pharmacy and Pharmacology', 45(S2): 1099 (1993).

Sutananta W., Craig D.Q.M. and Newton J.M., "The effects of ageing on the thermal behaviour and mechanical properties of pharmaceutical glycerides", International Joumal of Pharmaceutics, 111: 51-62 (1994).

Tabibi S.E., "Water vapor adsorption by compressible sugar and its effect on powder compressibility", Ph.D. Thesis, University of Maryland, USA (1982).

Tabibi S.E. and Hollenbeck R.G., "Interaction of water vapor and compressible sugar", International Joumal of Pharmaceutics, 18: 169-183 (1984).

United States Pharmacopeia 23/National Formulary 18, The United States Pharmacopeial Convention, Rockville (1995).

Wurster D.E., Peck G.E. and Kildsig D.O., "A comparison of the moisture adsorptiondesorption properties of corn starch, USP and directly compressible starch", Drug Development \& Industrial Pharmacy, 8: 343-354 (1982).

Yap P.H., deMan J.M. and deMan L., "Polymorphism of palm oil and palm oil products", Journal of American Oil Chemists Society, 66(5): 693-697 (1989). 
York P., "Analysis of moisture sorption hysteresis in hard gelatin capsules, maize starch, and maize starch:drug powder mixtures", Journal of Pharmacy and Pharmacology, 33: 269-273 (1981).

York P., "Solid state properties of powders in the formulation and processing of solid dosage forms", International Journal of Pharmaceutics, 14: 1-28 (1983).

Young J.H. and Nelson G.L., "Theory of hysteresis between sorption and desorption isotherms in biological materials", Transactions of the American Society of Agricultural Engineers, 10: 260-263 (1967)

Young J.H. and Nelson G.L., "Research of hysteresis between sorption and desorption isotherms of wheat", Transactions of the American Society of Agricultural Engineers, 10: 756-761 (1967). 